\title{
EFFECTS OF INTENSIVE INTERACTION ON THE SOCIAL AND COMMUNICATION BEHAVIOUR OF THREE STUDENTS WITH PROFOUND/MULTIPLE DISABILITIES
}

\author{
BY
}

HEATHER DRYSDALE

\begin{abstract}
A thesis
Submitted to the Victoria University of Wellington In fulfillment of the requirements for the degree of Master of Education
\end{abstract}

Victoria University of Wellington 2011 


\begin{abstract}
Objective: To evaluate the effects of an intervention, known as Intensive Interaction (II), on the social and communicative behaviour of three students with profound/multiple learning disabilities (PMLD).

Methods: Three secondary school-aged students with PMLD were observed, and their level of social and communicative engagement rated, during an initial baseline and subsequent intervention phase. The intervention was introduced across participants in a multiple-baseline across subjects design. Results: Social and communicative engagement increased during intervention relative to baseline for each of the three students.

Conclusion: II appeared to be effective in increasing social and communicative engagement of the participants and may therefore be viewed as a potentially promising approach for other students with PMLD.
\end{abstract}




\section{ACKNOWLEDGEMENTS}

This research would not have been possible without the support of a number of people. Perhaps most important of all was the generosity of the participants' families for letting me be involved with their daughters in conducting this research. For the young women themselves, it was always a two-way learning relationship where probably I learnt more than they did. Other families too gave their consent for me to video in the classroom to allow for anyone coming within my orbit. Students would greet me by name, smile, and let me spend time alongside them. The head teacher and staff at the special unit where I collected my data were also fantastic. Two staff members in particular gave their time and good will to videotape me over the term and a half. All the staff at the unit made me feel welcome, and like a member of staff. Thank you for the ukulele lessons, the coaching on self care routines, and inviting me to the prize giving and staff Christmas dinner. I cannot name any of you for confidentiality reasons but you know who you are.

Of course, my supervisor, Jeff Sigafoos, had a huge task to do in supporting me. Thank you for being so knowledgeable in this field and so generous with that knowledge. While working on my thesis I was also a research assistant for Vanessa Green. I was lucky enough to be involved with her research, which used the same research design, and this gave me greater understanding and insights for my own research. I was part of a postgraduate group of students who gave me a lot of support including how to create graphs using excel. Thanks especially to Larah and Donna for this. To Donna too, more thanks are needed, for being my inter rater for my 
literature review. I could not have done it either without those special librarians, Meg, Nicola, and Rui. Thank you.

Friends, colleagues and family also gave me great support. An old friend and colleague, Lynn, came out of retirement to provide the interobserver reliability I needed. Thank you to the Ministry of Education who gave me the time off to go on my research journey and to my colleagues who kept in touch with me and were always interested in what I was doing. Thanks to my speech-language therapy special interest group for your interest in my updates and to my WOGL friends for the drinks and lunches. Thank you to my study buddies Ann, Andrew, Colleen, Helen, Bridget, Jackie, and Nan. It's always so good to have people to rave to without eyes glazing over.

My large family has been great particularly over what has been a hard time for us. Special thanks to my sister Kathy, who provided a labour of love in editing many parts of my thesis. And to my immediate family, Steve, Patrick, Joseph, and Hannah. It's a funny feeling being a student when your grown up kids are too. Steve, for all those meals, household tasks that you took over in an uncomplaining manner, and more. Thanks heaps. 


\section{DEDICATION}

For Dad.

You are missed. 


\section{TABLE OF CONTENTS}

CHAPTER 1 INTRODUCTION ............................................................. 1

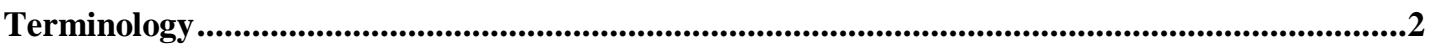

Defining Profound Multiple Learning Disabilities..............................................................................3

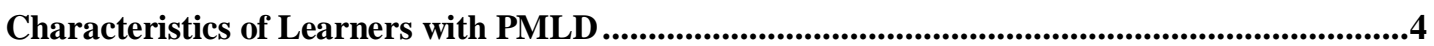

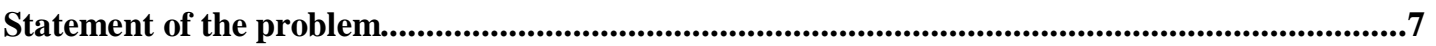

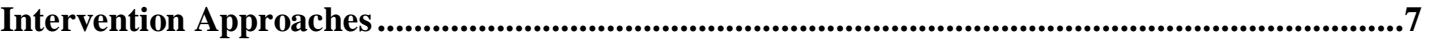

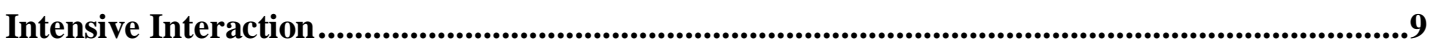

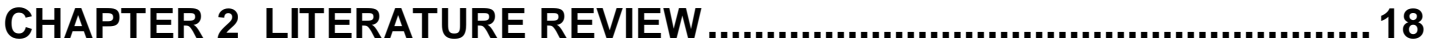

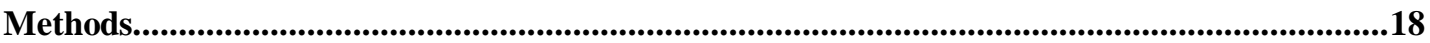

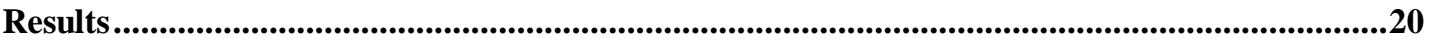

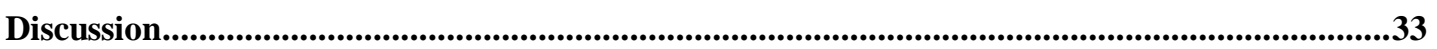

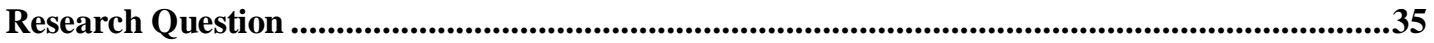

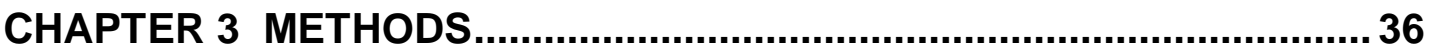

Ethical Approval and Recruitment ............................................................................................36

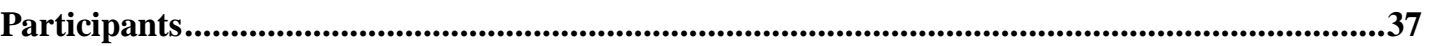

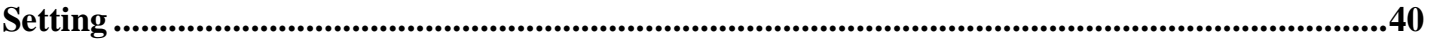

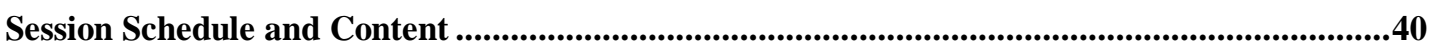

Measurement and Response Definitions.................................................................................41

Experimental Design...........................................................................................................43

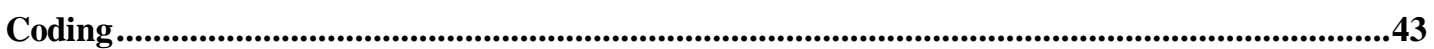

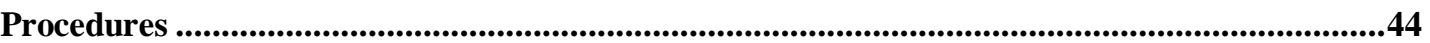

Inter-observer Agreement ...........................................................................................................48

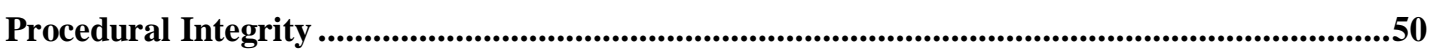

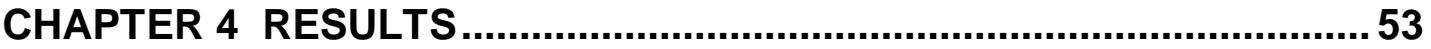

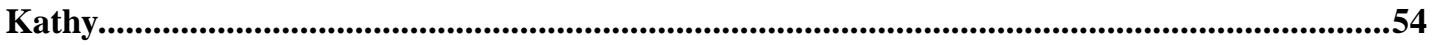

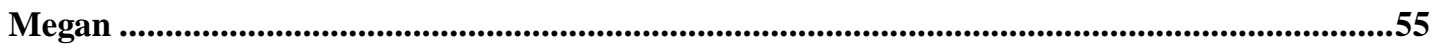

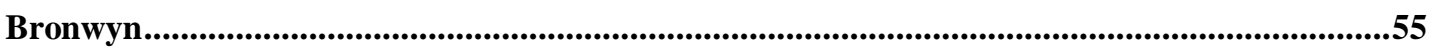

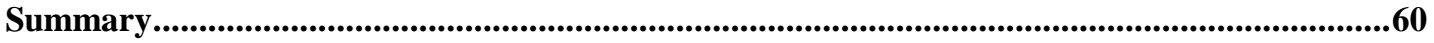

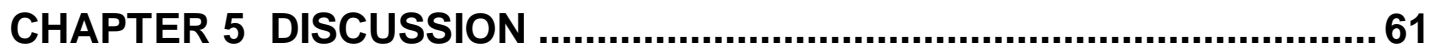

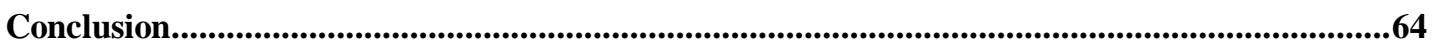

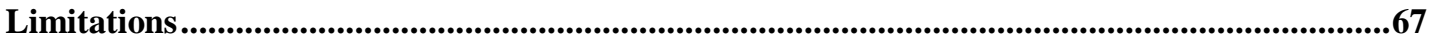

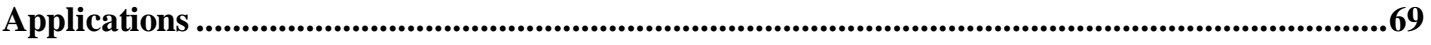

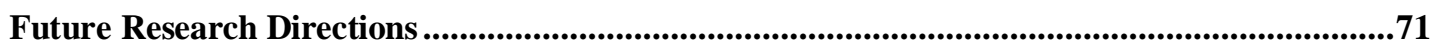


REFERENCES

APPENDIX 1 INTER-RATER AGREEMENT- SYSTEMATIC LITERATURE

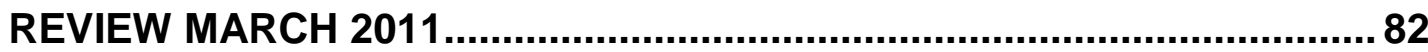

APPENDICES 2-16 INFORMATION LETTERS \& CONSENT FORMS ..... 85

APPENDIX 17 BASELINE/INTERVENTION CODING FORM ................. 134

APPENDIX 18 PROCEDURAL INTEGRITY RATING FORM ................... 136 


\section{LIST OF TABLES}

Table 1: Naturalistic Interventions 10

Table 2: II Summary of Quantitative Research Studies Focused on Adult and

Child Participants.

Table 3: Participant Characteristics.

Table 4: Categories and Definitions for the Levels of Social and Communicative

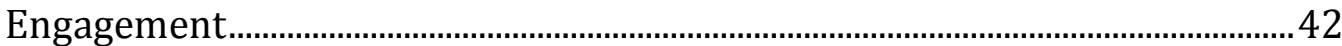

Table 5: Baseline and intervention mean scores.............................................................54

\section{LIST OF FIGURES}

Figure 1: Frequency (ten second segments for five minutes) of target

behaviours (withdrawal and present) for Kathy, Megan, and Bronwyn .......57

Figure 2: Frequency (ten second segments for five minutes) of target

behaviours (responding and increased responding) for Kathy, Megan, and

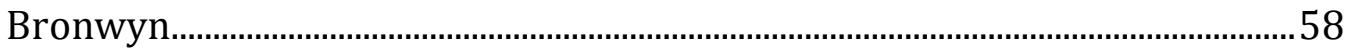

Figure 3: Frequency (ten second segments for five minutes) of target

behaviours (intentional and extension) for Kathy, Megan, and Bronwyn ....59 


\section{CHAPTER 1}

\section{INTRODUCTION}

Students with profound and multiple learning difficulties (PMLD) often present an educational challenge to the people who support them, whether it be their families, the staff at educational and vocational settings, and/or the health and educational professionals who work with staff and families. In the school context, the term challenge can be taken to refer to students, who because of significant disabilities, require a high level of planning and support from staff to meet their educational and related service needs (Arthur-Kelly, Bochner, Center, \& Mok, 2007; Arthur-Kelly, Foreman, Bennet, \& Pascoe, 2008; Byers, 1999; Nind, 2007). The challenges could arise because of mobility issues, self care issues, the need to adapt the curriculum, and/or the severe communication difficulties experienced by these students.

Within New Zealand schools, students with PMLD are most likely to receive additional educational support to meet the above outlined challenges through the Ongoing Resourcing Scheme (ORS) (Ministry of Education, 2011). ORS funding is provided to approximately $1 \%$ of the total school population (Ministry of Education, 2010) . Among students who received ORS funding, some of these receive the highest amount of possible support funding and are thus considered to have very high levels of educational needs. Among all students receiving support through ORS (1\%), approximately $23 \%$ of these students are funded at the very high level (Ministry of Education, 2010). It is this $23 \%$ of ORS students funded at very high levels who are most likely to have PMLD. 
Students with PMLD are likely to present with a number of significant educational and care needs, including the need to learn how to interact socially and communicate with others (Arthur-Kelly, et al., 2008). An important question in relation to these two needs is what intervention procedures can be used to enhance the social and communication behaviours of students with PMLD. This thesis evaluates the effectiveness of an intervention known as Intensive Interaction (II) for the purpose of determining its effects on enhancing the social and communication behaviours of students with PMLD. II requires additional evaluations of the type undertaken in this thesis because, while it has been suggested as a possible approach for increasing social and communicative engagement of students with PMLD (Barber, 2008; Kellet, 2000, 2003, 2004, 2005; Nind \& Hewett, 2005), there are limited experimental data supporting its use in the education of students with PLMD (Kimhi, 2010; Sellers \& Higbee, 2010).

\section{Terminology}

Literature relevant to the education of people with PMLD has presented a variety of terms to refer to people with PMLD and those who support and interact with them. While this thesis involved school-aged students, other studies have involved adults. A term that encapsulates all these people is learner, and this term will be used to refer to people with PMLD except when discussing particular groups or the participants. People supporting and looking after learners can include family members, teachers, teacher assistants, adult care staff, and professionals who visit to support and advise on programmes. The term used to refer to these people will be 
communication partner (CP) except when specific groups of people are being discussed.

\section{Defining Profound Multiple Learning Disabilities}

Learners with PMLD have a disability in more than one area. Their areas of disabilities could include a combination of physical disabilities, cognitive impairment, communication impairment, sensory needs, complex health issues, behavioural issues, mental health needs as well as learning needs (Profound and multiple learning disabilities network, 2009; Ware, 2004). Other terms used to refer to learners with these characteristics include profound/multiple disabilities, developmental and physical disabilities, severe and profound intellectual disability, and significant disability (Lynch \& Adams, 2008; Matson, Cooper, Malone, \& Moskow, 2008; Petry \& Maes, 2006). Learners on the autistic spectrum can also come under the heading of PMLD if they have difficulties in more than one area (e.g., hearing impairment and intellectual disability) and if these difficulties cause severe to profound impairment in adaptive behaviour functioning. For example, it has been estimated that approximately $25 \%$ of children diagnosed with autism will fail to develop sufficient speech to meet their communication needs (Osterling, Dawson, \& McPartland, 2001) and around 60\% will have significant cognitive impairment (Towbin, Mauk, \& Batshaw, 2002 ; Wagner, 1999). Several genetic syndromes are associated with PMLD, including Rett syndrome, Cri-du-chat and Angelman syndromes. Rett syndrome is a neurodevelopmental disorder that affects mainly girls (Batshaw, Pellegrino, \& Roizen, 2007; Towbin, et al., 2002 ). Following a 6 to 18 month period of seemingly typical development, there is a progressive loss of communicative, 
cognitive and physical skills in Rett syndrome and many children with the syndrome develop specific hand-wringing or hand-washing like mannerisms (Woodyatt, Marinac, Darnell, Sigafoos, \& Halle, 2010). Cri-du chat syndrome is characterized by severe intellectual impairment, physical disabilities, health issues, feeding issues, delayed communication and there are also high numbers of students who have self injurious behaviours and display hyperactivity (Batshaw, et al., 2007; Cornish \& Bramble, 2002). Angelman syndrome is characterized by severe motor, communication and intellectual impairment (Batshaw, et al., 2007; Towbin, et al., 2002 ). In each of these syndromes the associated impairments are usually of such severity that the person would be considered to have profound/multiple disability.

\section{Characteristics of Learners with PMLD}

Learners with PMLD have significant impairment in a number of adaptive behaviour domains, including the social, communication, motor, and self-care domains. With respect to self-care needs, a study involving 133 parents of children living at home, aged 1-17 years with PMLD (Tadema \& Vlascamp, 2009), found that parents reported that their children had a high level of dependency across a number of self-care tasks (e.g., feeding, dressing, washing and toileting) and that these needs did not abate over a child's life. A high level of dependency was defined as children requiring greater amounts of time and energy from their parents compared to children with other levels of disability. Parents were involved in all the self-care tasks listed above as well as seeing to children throughout the night. Figures for parent involvement were $100 \%$ parent support for dressing, $97 \%$ parent 
support for eating and changing, and 83\% parent support for drinking (p. 38). This high level of care is also required at school (Arthur-Kelly, et al., 2008).

In terms of providing education, learners with PMLD have also been reported to have significant difficulty in accessing the regular educational curriculum (Lynch \& Adams, 2008). With respect to the New Zealand curriculum, these children are most likely to be operating below Level 1 (Central Regional Special Schools Administration Cluster, 2005, 2008). Level 1 is the entry level for all curriculum areas and typically relates to years 1-3 at school for children aged between 5 and 8 years (Ministry of Education, 2007). Instead, as Arthur-Kelly et al. (2007) discussed, students with PMLD will typically require an individualised educational curriculum focused on developing social, communication and daily living skills. In New Zealand this type of individualized education plan or IEP specifies the needs and priority goals for the student as well as the interventions, treatments, procedures or strategies that will be implemented in an attempt to meet those goals (Ministry of Education, 1999).

In terms of communication development, learners with PMLD often fail to develop any appreciable amount of speech and language and are often considered to function at the pre-intentional stage of communication development (Halle, Brady, \& Drasgow, 2004; Petry \& Maes, 2006). Learners who are considered to be at the pre-intentional stage of communication development must often rely on the CPs around them to anticipate and interpret their needs and actions in order to have their every day functions and activities carried out. This includes relying on CPS to anticipate their needs when they are hungry, require self-care, want to begin 
a new activity, are in pain, and when they do not like something and want to stop an activity. It is therefore important that CPs are able to anticipate the learner's wants and needs and be responsive to any potential communicative initiations on the part of the learner (Porter, Ouvry, Morgan, \& Downs, 2001). However, CPs can have difficulty in interpreting the often idiosyncratic and potentially communicative signals of learners with PMLD (Downing, 2004; Poppes, van der Putten, \& Vlaskamp, 2010; Porter, et al., 2001). When CPs have such difficulties, it often leads to communication breakdowns (Halle, et al., 2004). These communication breakdowns can, in turn, lead learners to stop the original behaviour (extinction) and escalate to problematic forms of behaviours in expressing their wants and needs (Sigafoos, Arthur-Kelly, \& Butterfield, 2006).

In terms of behavior problems, there is a high prevalence of problem behavior, such as self-injurious behaviour and aggression, among learners with PMLD (Cornish \& Bramble, 2002; Duncan, Matson, Bamburg, Cherry, \& Buckley, 1999; Matson, et al., 2008; Porter, et al., 2001). In addition, many such learners engage in frequent stereotyped and repetitive behaviours, such as body rocking, hand flapping, and twirling objects (Kellet, 2004; Nind \& Kellet, 2002a). There appears to be an inverse relationship between the frequency and severity of problem behaviour and the level of communication ability (Downing, 2004; Sigafoos, 2000). Based on this relationship, it has been suggested that some of the problem behaviours of learners with developmental disabilities, including PMLD, could serve a communicative function (Carr, et al., 1994; Durand, 1999; Meyer \& Evans, 2006). Several communicative functions have been suggested for problem behaviours of 
learners with developmental disabilities, including: (a) recruiting attention, (b) gaining access to preferred items and activities, and (c) escape from nonpreferred items and activities (Carr, et al., 1994).

\section{Statement of the problem}

Given the learning and behavioural characteristics associated with PMLD, improving the social and communicative engagement of children with PMLD would seem to be an obvious and an important educational priority (Arthur-Kelly, et al., 2008). Kishida and Kemp (2006) discussed the importance of social and communicative engagement for learning (pp. 102103). Several intervention approaches have been proposed to address this priority area.

\section{Intervention Approaches}

Two approaches that have been suggested are the behavioural approach and the more naturalistic approach (Cowan \& Allen, 2007; Quill, 2000). While these two approaches could be viewed as mutually exclusive (Cohen, 1998; Schopler, 2001), another viewpoint is to see these procedures as lying at different ends of a continuum or overlapping one another (Cowan \& Allen, 2007; Quill, 2000). It is also the case that one could use both approaches for different purposes and at different times (Firth, Berry, \& Irvine, 2010; Nind \& Hewett, 2005). Briefly, for the purposes of this study, the behavioural approach was identified as involving planned and ordered sessions, specific goals and activities, and being based on behavioural learning theories (Quill, 2000; Richard, 2000), whereas naturalistic interventions were identified as involving loosely structured sessions, 
conducted in a range of natural settings, using a variety of stimuli, and where the child initiates and dictates the pace of the sessions (Cowan \& Allen, 2007, p. 702). Both of these approaches have some empirical evidence to support their use in educational programmes for learners with PMLD (Green \& Luce, 1996; Odom, Boyd, Hall, \& Hume, 2010; Quill, 2000; Richard, 2000). However, researchers have long expressed pessimism regarding the extent to which such interventions do in fact lead to increased social and communicative development in children with PLMD (Bailey, 1981; Granlund \& Olsson, 1999; Thurman, Jones, \& Tarleton, 2005). Indeed, Bailey (1981) noted that educational programming for students with profound, multiple disabilities may require a shift in emphasis away from adaptive skill training towards an approach that focuses more on providing them with increased social interaction and increased access to preferred sources of stimulation. Smith, Klevstrand, and Lovaas, (1995) found that behavioural intervention was ineffective for addressing the behavioral deficits and excesses associated with Rett syndrome, a syndrome associated with PLMD. In light of these reservations, and seemingly little success, other approaches would seem to be worthy of consideration. One newer approach that has been recommended for improving the communicative and social engagement of learners with PMLD is known as Intensive Interaction (Firth, et al., 2010; Nind \& Hewett, 2005). 


\section{Intensive Interaction}

Intensive interaction (II) has been presented as an effective approach for increasing social and communicative engagement of learners with PLMD (Barber, 2007b; Firth, et al., 2010; Nind \& Hewett, 2005). Nind and Hewett (2005) described II as combining a developmental model with student or process-centered teaching. II could best be described as a naturalistic intervention (Cowan \& Allen, 2007). It shares similarities with a number of naturalistic interventions, while having some unique features, as will be covered in the following discussion. Table 1 provides a brief overview of similarities and differences between II and some of the other naturalistic interventions, using the strategies of II as a guide. As discussed previously there is overlap between some naturalistic and behavioural approaches (Cowan \& Allen, 2007).

An aspect of II that differentiates it from other naturalistic interventions is that II is intended to be used with both children and adults whereas the other interventions are intended for use with children. The argument is that II is appropriate for all learners who are operating at such early stages of communication. Jeffries (2009) has asked if we can be certain whether adults and children with PMLD are similarly responding to and processing the use of II. Hogg (2002) has also suggested that II as a developmental intervention based on early mother-child interactions, does not necessarily extrapolate to practitioners' use with children and adults with impairments. 
Table 1: Naturalistic Interventions

\begin{tabular}{|c|c|c|c|c|c|c|}
\hline Intervention & Intensive intervention & $\begin{array}{l}\text { Behavioural } \\
\text { indication }\end{array}$ & $\begin{array}{l}\text { Milieu } \\
\text { teaching }\end{array}$ & $\begin{array}{l}\text { Incidental } \\
\text { teaching }\end{array}$ & Floortime & RIT \\
\hline Targeted population & $\begin{array}{l}\text { Adults and children with } \\
\text { PMLD }\end{array}$ & $\begin{array}{l}\text { Children with severe } \\
\text { disabilities }\end{array}$ & $\begin{array}{l}\text { Individuals with disabilities } \\
\text { at early stages of } \\
\text { language development } \\
\text { Early childhood settings } \\
\text { referred to }\end{array}$ & $\begin{array}{l}\text { Originally developed } \\
\text { for children from } \\
\text { disadvantaged } \\
\text { backgrounds and } \\
\text { adapted for children } \\
\text { with ASD. } \\
\text { Context of early } \\
\text { childhood }\end{array}$ & $\begin{array}{l}\text { Children with } \\
\text { developmental } \\
\text { disabilities }\end{array}$ & Children with ASD \\
\hline Setting & Natural setting & Natural setting & Natural setting & Natural setting & Natural setting & Natural setting \\
\hline Person centred/activity & $\begin{array}{l}\text { CP joins in with activity } \\
\text { learner is already engaged } \\
\text { with }\end{array}$ & $\begin{array}{l}\text { CP joins in with activity } \\
\text { learner is already } \\
\text { engaged with }\end{array}$ & $\begin{array}{l}\text { CP follows learner's } \\
\text { attentional lead and } \\
\text { following their interest may } \\
\text { offer choice of activities to } \\
\text { learner }\end{array}$ & $\begin{array}{l}\text { Motivating activities } \\
\text { are arranged so } \\
\text { learner can request } \\
\text { them. Activities based } \\
\text { on learner's interests }\end{array}$ & $\begin{array}{l}\text { CP follows learner's } \\
\text { interests and their lead }\end{array}$ & $\begin{array}{l}\text { Not stated but in } \\
\text { imitating what the } \\
\text { learner is doing, the CP } \\
\text { is following their lead }\end{array}$ \\
\hline Level & $\begin{array}{l}\text { CP will join in at level of } \\
\text { learner whether sitting, } \\
\text { standing, mobile, or lying } \\
\text { down }\end{array}$ & $\begin{array}{l}\text { Not stated but could be } \\
\text { inferred that CP will join } \\
\text { learner at their level }\end{array}$ & $\begin{array}{l}\text { Not stated but could be } \\
\text { inferred that CP will join } \\
\text { learner at their level }\end{array}$ & $\begin{array}{l}\text { No specification for } \\
\text { level }\end{array}$ & $\begin{array}{l}\text { CP joins learner in their } \\
\text { play on the floor or } \\
\text { wherever they are } \\
\text { playing }\end{array}$ & $\begin{array}{l}\text { No specification for } \\
\text { level }\end{array}$ \\
\hline Tasks/Goals & $\begin{array}{l}\text { "taskless", doesn't have } \\
\text { specific goals except } \\
\text { general goal of CP using II } \\
\text { and through that } \\
\text { encouraging more } \\
\text { engagement }\end{array}$ & $\begin{array}{l}\text { To teach signs (or other } \\
\text { symbolic forms) to } \\
\text { replace idiosyncratic } \\
\text { forms. Hand over hand } \\
\text { facilitation may be used. }\end{array}$ & $\begin{array}{l}\text { Agreed on target skills, } \\
\text { usually request behaviours } \\
\text { Noted that useful for } \\
\text { teaching early } \\
\text { communication behaviour, } \\
\text { AAC, and spoken } \\
\text { language }\end{array}$ & $\begin{array}{l}\text { Goal to increase } \\
\text { learner's initiations } \\
\text { either verbal or non- } \\
\text { verbal }\end{array}$ & $\begin{array}{l}\text { Four major goals } \\
\text { First two are } \\
\text { "encouraging intimacy } \\
\text { and attention" and } \\
\text { developing "two way } \\
\text { communication }\end{array}$ & $\begin{array}{l}\text { Goal to teach imitation } \\
\text { skills, particularly with } \\
\text { requesting }\end{array}$ \\
\hline Responding & $\begin{array}{l}\text { Responds to all learner's } \\
\text { behaviours as if they are } \\
\text { intentional by imitation, } \\
\text { passing items, pausing, no } \\
\text { or minimal use of language, } \\
\text { introducing new behaviour }\end{array}$ & $\begin{array}{l}\text { Responds by hand over } \\
\text { hand facilitation of } \\
\text { desired sign, modelling } \\
\text { of sign and reinforcing } \\
\text { with desired item. }\end{array}$ & $\begin{array}{l}\text { CP rewards learner with } \\
\text { item after target behaviour } \\
\text { and uses praise. If learner } \\
\text { doesn't use target } \\
\text { behaviour, CP can prompt } \\
\text { with model or physical } \\
\text { guidance }\end{array}$ & $\begin{array}{l}\text { Learner gets toy or } \\
\text { activity on request. } \\
\text { CP prompts for an } \\
\text { elaborated initiation }\end{array}$ & $\begin{array}{l}\text { CP responds by joining } \\
\text { in learner's activity, by } \\
\text { imitating their actions, } \\
\text { playing alongside and } \\
\text { commenting on their } \\
\text { behaviour. No set } \\
\text { reinforcement }\end{array}$ & $\begin{array}{l}\text { CP praises learner for } \\
\text { imitating request and } \\
\text { access to item. If no } \\
\text { imitation can do hand } \\
\text { over hand physical } \\
\text { guidance and model } \\
\text { behaviour again }\end{array}$ \\
\hline Imitation & $\begin{array}{l}\text { CP will imitate what learner } \\
\text { is doing e.g. body } \\
\text { movement, vocalising, } \\
\text { action on object etc... or CP } \\
\text { will respond to timbre of } \\
\text { behaviour, e.g. tapping the } \\
\text { table in response to learner } \\
\text { hitting themselves. }\end{array}$ & $\begin{array}{l}\text { No specification for } \\
\text { imitation }\end{array}$ & $\begin{array}{l}\text { May use at beginning of } \\
\text { activity to begin } \\
\text { engagement. Imitating } \\
\text { vocalising is discussed }\end{array}$ & $\begin{array}{l}\text { No specification for } \\
\text { imitation }\end{array}$ & $\begin{array}{l}\text { CP can use imitation of } \\
\text { learner's actions } \\
\text { including repetitive } \\
\text { behaviours as initial } \\
\text { means to encourage first } \\
\text { goal }\end{array}$ & $\begin{array}{l}\text { Contingent imitation } \\
\text { used initially to enhance } \\
\text { communication and as a } \\
\text { reinforcer. Can imitate } \\
\text { gestures, vocalisations, } \\
\text { etc... }\end{array}$ \\
\hline
\end{tabular}




\begin{tabular}{|c|c|c|c|c|c|c|}
\hline Intervention & Intensive intervention & $\begin{array}{l}\text { Behavioural } \\
\text { indication }\end{array}$ & $\begin{array}{l}\text { Milieu } \\
\text { teaching }\end{array}$ & $\begin{array}{l}\text { Incidental } \\
\text { teaching }\end{array}$ & Floortime & RIT \\
\hline Pausing & $\begin{array}{l}\text { CP pauses when learner } \\
\text { turns or moves away as } \\
\text { requesting a break or end } \\
\text { to activity. Restarts when } \\
\text { learner restarts. CP pauses } \\
\text { when allowing time for } \\
\text { learner to respond in turn } \\
\text { taking activity }\end{array}$ & $\begin{array}{l}\text { No specification for } \\
\text { pausing }\end{array}$ & $\begin{array}{l}\text { CP uses strategy of } \\
\text { looking expectant and } \\
\text { pauses to encourage } \\
\text { request behaviour }\end{array}$ & $\begin{array}{l}\text { CP uses pausing to } \\
\text { mark the end of each } \\
\text { communication } \\
\text { episode (trial) }\end{array}$ & $\begin{array}{l}\text { Being responsive to } \\
\text { learner's need for a } \\
\text { break by pausing, } \\
\text { making learner aware of } \\
\text { conversational turns, } \\
\text { and using pausing as a } \\
\text { gap between different } \\
\text { circles of communication }\end{array}$ & $\begin{array}{l}\text { No specification for } \\
\text { pausing }\end{array}$ \\
\hline Use of Language & $\begin{array}{l}\text { No or minimal language } \\
\text { used }\end{array}$ & $\begin{array}{l}\text { No specification for } \\
\text { language }\end{array}$ & $\begin{array}{l}\text { CP uses linguistic } \\
\text { mapping, full sentences as } \\
\text { examples }\end{array}$ & $\begin{array}{l}\text { CP uses language to } \\
\text { prompt, as a model, } \\
\text { and to expand } \\
\text { learner's request }\end{array}$ & $\begin{array}{l}\text { CP uses language to } \\
\text { describe learner's } \\
\text { feelings, what they are } \\
\text { doing, and expand on } \\
\text { what they are saying }\end{array}$ & $\begin{array}{l}\text { CP uses language to } \\
\text { describe what learner is } \\
\text { doing "linguistic } \\
\text { mapping" }\end{array}$ \\
\hline $\begin{array}{l}\text { Using learner's own } \\
\text { behaviour }\end{array}$ & $\begin{array}{l}\text { CP introduces behaviours } \\
\text { previously used by learner } \\
\text { into shared activity }\end{array}$ & $\begin{array}{l}\text { No specification for } \\
\text { learner's behaviour }\end{array}$ & $\begin{array}{l}\text { No specification for } \\
\text { learner's behaviour }\end{array}$ & $\begin{array}{l}\text { No specification for } \\
\text { learner's behaviour }\end{array}$ & $\begin{array}{l}\text { Used in initial stages to } \\
\text { join in with them and } \\
\text { imitate, then added to }\end{array}$ & $\begin{array}{l}\text { CP chooses behaviours } \\
\text { already in learner's } \\
\text { repertoire to first teach } \\
\text { imitation }\end{array}$ \\
\hline Using novel behaviour & $\begin{array}{l}\text { CP introduces novel } \\
\text { behaviour into a repetitive } \\
\text { sequence such as placing } \\
\text { item in a different place }\end{array}$ & $\begin{array}{l}\text { No specification for } \\
\text { novel behaviour }\end{array}$ & $\begin{array}{l}\text { No specification for novel } \\
\text { behaviour }\end{array}$ & $\begin{array}{l}\text { No specification for } \\
\text { novel behaviour }\end{array}$ & $\begin{array}{l}\text { CP can add novel action } \\
\text { into repetitive play }\end{array}$ & $\begin{array}{l}\text { CP can add in novel } \\
\text { actions on an object } \\
\text { indispersed with familiar } \\
\text { actions }\end{array}$ \\
\hline
\end{tabular}




\section{Features of Intensive Interaction}

Many of the procedures used in II could be seen as incorporating several elements that might be considered best practice for learners with PMLD. CPs are supposed to adapt their communication styles in ways that will gain enhanced communication from learners (Nind, Kellet, \& Hopkins, 2001). That is, CPs should communicate at the level of the learner and respond to their interests and what motivates them (Cameron \& Bell, 2001; Quill, 2000). CPs are also supposed to respond to the learner's vocal behaviour, body movements, facial expression and gestures as if these had a communicative function or purpose (Downing, 2005; Quill, 2000).

More specifically, in terms of procedures, II involves the CP getting down to the learner's level whether this be sitting, standing, or on the floor. By doing so, the intent is that the $\mathrm{CP}$ is now in a better position to respond to any communication signals or social overtures made by the learner, rather than expecting the learner to respond to $\mathrm{CP}$ initiations. In II, CPs are instructed to follow the learner's behaviours, whether they are body movements, vocalisations, facial expressions, gestures or performing an action with an object. This aspect of II appears to be similar to some of the procedures inherent in other interventions, such as incidental teaching (Cowan \& Allen, 2007), milieu and enhanced milieu teaching (Warren, et al., 2008; Yoder \& Warren, 1994), and the concept of behavior indication described by Drasgow, Halle, Ostrosky, and Harbers, (1996).

By following the learner's lead in this way, the CP is supposed to provide contingent responding and provide opportunities for the learner to initiate a social-communicative interaction. Following the learner's lead is 
also intended to support the development of communication behaviours such as eye contact, joint reference, and turn taking, which are considered to be essential pre-symbolic communication behaviours (Firth, et al., 2010). Firth et al. (2010), suggest that the interaction with a learner using II gives the learner a context in which they want to relate and use some of the skills/behaviours they might already have (p. 32).

Another aspect of II, shared with other naturalistic approaches is that the CP is supposed to respond to the learner's pre-symbolic behaviours as if they had communicative intent. A high level of CP responsivity to learner initiated pre-symbolic behaviours is also characteristic of other approaches for engaging learners with PMLD, such as Structured Over-interpretation, described by von Tetzchner (1997), and the Interpretive Pathway described in Sigafoos et al. (2006). In these approaches as in II, a high level of CP responsivity to learner initiated pre-symbolic behaviours is intended to encourage the learner's communication behaviour.

Initially the learner might look at the $\mathrm{CP}$ and then at the item in order to request that the item be given to them. Once this has been done repetitively and developed into a turn-taking game, the $\mathrm{CP}$ might pause to allow the learner to use other behaviours, such as touching the item, giving the item to the $\mathrm{CP}$ or banging on the item to make the request. Or the $\mathrm{CP}$ might use their turn to model a different requesting behaviour, such as holding out their hand towards the item or tapping on the item.

An aspect of II that is less clearly part of current best practice, and which might be seen as somewhat controversial, involves imitating aspects of a learner's behaviour. For example, if the learner was observed to be 
repetitively shake a noise-making toy, then the $\mathrm{CP}$ is supposed to do the same with a similar item or make a movement with their own body in time to the shaking (Barber, 2007a). Ingersoll (2008), suggests that contingent imitation can be used initially to enhance communication as one of the strategies for Reciprocal Imitation Training.

There is some evidence to support this aspect of II. Heinmann, Laberg, and Nordoen (2006) investigated the use of imitation in a study involving 20 children (mean age $=6.5$ years) with ASD, who were non-verbal or had no functional speech. Children were randomly assigned into two groups of 10, with one group having the imitation intervention and the other group having a contingent non-imitation intervention. The imitation intervention involved the experimenter imitating all the child's behaviours including vocalisations, movements and stereotypies (p. 300). Analysis of results showed increases in both touch and "looking at" behaviours at a significant level for the imitation intervention group. This group also showed an increase in elicited imitation which did not occur for the contingent intervention group. Field, Field, Sanders, and Nadel (2001) and Escalona, Field, Nadel, and Lundy (2002) reported similar results. It appears that the imitation condition in these studies closely corresponds to imitation used in II. Imitation used with autistic children, and as a specific area of II, has been examined in other studies (Hart, 2006; O'Neill \& Zeedyk, 2006; Zeedyk, 2006).

One proponent of II urges caution in the use of the type of imitation used in II. Barber $(2005,2007 c)$ has warned that there could be problems with using imitation if CPs do not move on from the use of imitation. One 
such problem could be that the CP simply encourages or reinforces repetitive activity (Barber, 2005). Instead, he suggested that CPs need to reflect on their practice, which would include watching video footage with others to analyse their use of imitation, and change their behaviour to keep the interaction developing (Barber, 2005, 2007a, 2007c).

Being responsive and following the learner's lead should also allow the $\mathrm{CP}$ to be sensitive to when the learner wants to have a break or finish the interaction (Nind \& Hewett, 2001, 2005). This involves the CP pausing and waiting when the learner indicates this. The CP would turn away when the learner turned away and only restart the interaction if the learner indicated this.

An interesting aspect of II is that the CP is supposed to use minimal or no language during the interactions with learners (Firth, et al., 2010; Nind \& Hewett, 2005). This aspect of II is similar to the 'minimal speech approach' described by (Potter \& Whittaker, 2001), which has been associated with more social and communicative engagement among children with autism.

Another aspect of II is that, in addition to following the learner's lead, the CP can also introduce a novel behaviour, such as an element of surprise, once the interaction is underway. This is dependent on the behaviours the learner is using, such as turn taking and joint focus being underway, and is a judgment made by the CP (Barber, 2007b; Firth, et al., 2010). For example, once the learner and $\mathrm{CP}$ are engaged in an enjoyable repetitive game, the $\mathrm{CP}$ can introduce a new element to the game, such as hiding the item that has been being passed back and forth. There are similar strategies 
described in Floor-time (Greenspan \& Wieder, 1998) and for Reciprocal imitation training (Ingersoll, 2008).

The $\mathrm{CP}$ is able to introduce behaviours that they have seen the learner use previously to the interaction. These behaviours could have been noted during an assessment phase or during previous intensive interaction sessions. These can have the effect of adding a new element into the interaction, as for novel behaviours, as above.

Unlike other approaches, II does not require that the CP define specific target behaviours or goals (Cowan \& Allen, 2007; Drasgow, et al., 1996; Ingersoll, 2008; Warren, et al., 2008; Yoder \& Warren, 1994). Instead II has been described as "taskless" with a general aim of increasing social and communicative engagement (Firth, et al., 2010; Nind \& Hewett, 2005). That is, the main aim of II is to create of a sense of mutual pleasure and fun. However, the hypothesis seems to be that by having this aim, II will help develop joint reference and turn taking behaviours (Barber, 2007a, 2007b; Firth, 2008).

Researchers in II have also looked at the relationship between II and any reduction in repetitive and negative behaviours (Elgie \& Maguire, 2001; Jones \& Williams, 1998; Nind \& Kellet, 2002a). Hogg (2002) and Goldbart have both challenged the dichotomy that arises from the theoretical stance of II proponents (Nind \& Kellet, 2002a), that learners' stereotypical behaviours need to be accepted while at the same time suggesting that II can reduce these behaviours. Goldbart (2002) has also suggested that while II may have a place when used for non-injurious behaviours, it should be looked at alongside other behavioural approaches. 
In summary, II is primarily intended as an intervention for learners with PMLD who function at the beginning stages of communication development. II procedures include working at the learner's level and with their choice of activity, responding to all behaviours of the learner, as if they have communicative intent, imitating the learner's behaviour or using behaviours that respond to the rhythm of their behaviours, pausing when the learner turns away or needs a break, using no or minimal language, introducing new behaviours into the interaction (either those behaviours the learner has previously used or responded to, or novel behaviours that appear appropriate to the situation), and building on sequences of behaviour that develop into games. While II includes elements of best practice, it also has unique aspects that suggest the need for empirical study of the effects of II on the social and communicative engagement of learners with PLMD. The next chapter reviews studies that have evaluated II. 


\section{CHAPTER 2}

\section{LITERATURE REVIEW}

This chapter reports on the methodology and results of a systematic review of the literature. There have been two previous literature reviews of II (Firth, 2006; Firth, et al., 2009). Firth (2006) looked at three adult studies using a quantitative design and three child studies using both quantitative and qualitative designs. Firth (2006) concluded that there had been only a small number of studies completed and of the need for further systematic research on II. Firth et al. (2009) examined seventeen studies in detail covering quantitative and qualitative studies and also those which looked at research on practitioners' use of II. A reference list was also provided. This current review is intended to provide an update as well as looking critically at the research methodology that has been used. The aim of this systematic review was to identify and analyse studies that reported on the use of II with child and adult participants with PMLD.

\section{Methods}

\section{Search Strategies}

Six databases were searched electronically, specifically (a) Academic Search Premier, (b) ERIC (Education Resources Information Centre), (c) ProQuest, (d) PsychINFO, (e) Scopus, and (f) MultiSearch (a search base provided by Victoria University of Wellington's library service which enabled the researcher to search across disciplines). The search terms used for this stage were: "intensive interaction" AND "special education" OR "disabilit"” AND "research". Search terms were entered as free text into the keywords 
field. The symbol * was used to ensure covering the widest possible permutations of the word 'disability'. The search was limited to English language, peer- reviewed journal articles up to and including the year 2010.

Articles returned from the database search that had reference to II were identified by examination of titles, keywords, abstracts, and a review of the full article when the nature of the study was not clear from the title, keywords, or abstract. There were 47 items identified in the first stage of the search after removing duplicate articles. The references from all these articles were then hand searched for any articles that made reference to II and a further 15 articles were found, after subtracting duplicate articles. Hewett and Barber, two researchers who have published articles in II, were contacted and provided references. These were then searched for additional studies which were not in the electronic or hand searches. There were a further seven articles identified following this personal contact. This gave a total of 69 articles for possible inclusion in the review. One of these papers could not be retrieved because no physical nor on-line version could be located by the university library. The final 68 articles were then evaluated against inclusion and exclusion criteria.

\section{Inclusion and Exclusion Criteria}

As for the first selection step, only English-language, peer-reviewed journal articles were included in this review. No year limit was adopted. All articles had to contain original research that was quantitative in design. In addition, included studies had to focus on the use of II with child or adult participants with severe to profound levels of developmental disability, and who were non-verbal or minimally verbal. This included PMLD as well as 
various permutations of the term and related syndromes. Studies that looked at isolated elements of II, and not intensive interaction as a whole were excluded, although studies which used an adapted form of II were included.

\section{Inter-rater Agreement}

An inter-rater agreement check was conducted to assess the reliability of the application of the inclusion and exclusion criteria. This involved presenting an independent rater with the 68 articles for possible inclusion and with the inclusion and exclusion criteria. The rater decided if each article met the inclusion criteria and compared this with the researcher. Inter-rater agreement for this was $97 \%$. For the two articles that were not agreed on, the researcher and independent rater met to resolve the discrepancy. Appendix 1 lists all 69 articles, with inclusion and exclusion ratings for both researcher and the inter-rater check, and provides a reason for excluded articles.

\section{Results}

Following application of the inclusion and exclusion criteria, 15 articles were identified for inclusion in the review. These were the 15 articles which used a quantitative research methodology, described as research which relies on the collection of numerical data (Johnson \& Christensen, 2008, p. 33). These studies are presented in Table 2, giving findings on participants and setting, target behaviours, procedures, main findings and appraisal of the research. The 15 studies were published between 1996 and 2009, indicating that research on II using a quantitative design, has been completed in the last 15 years. 
Table 2: II Summary of Quantitative Research Studies Focused on Adult and Child Participants

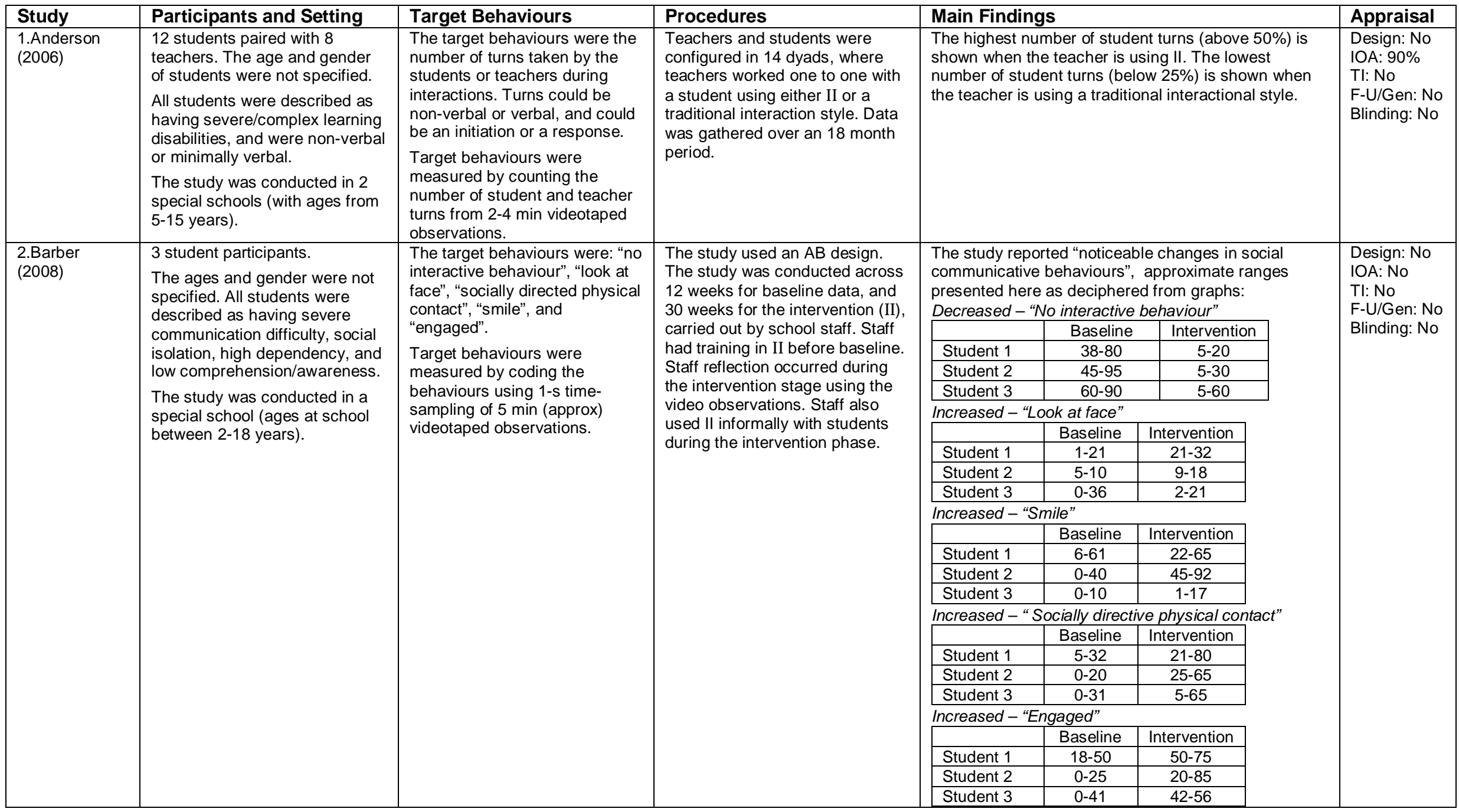




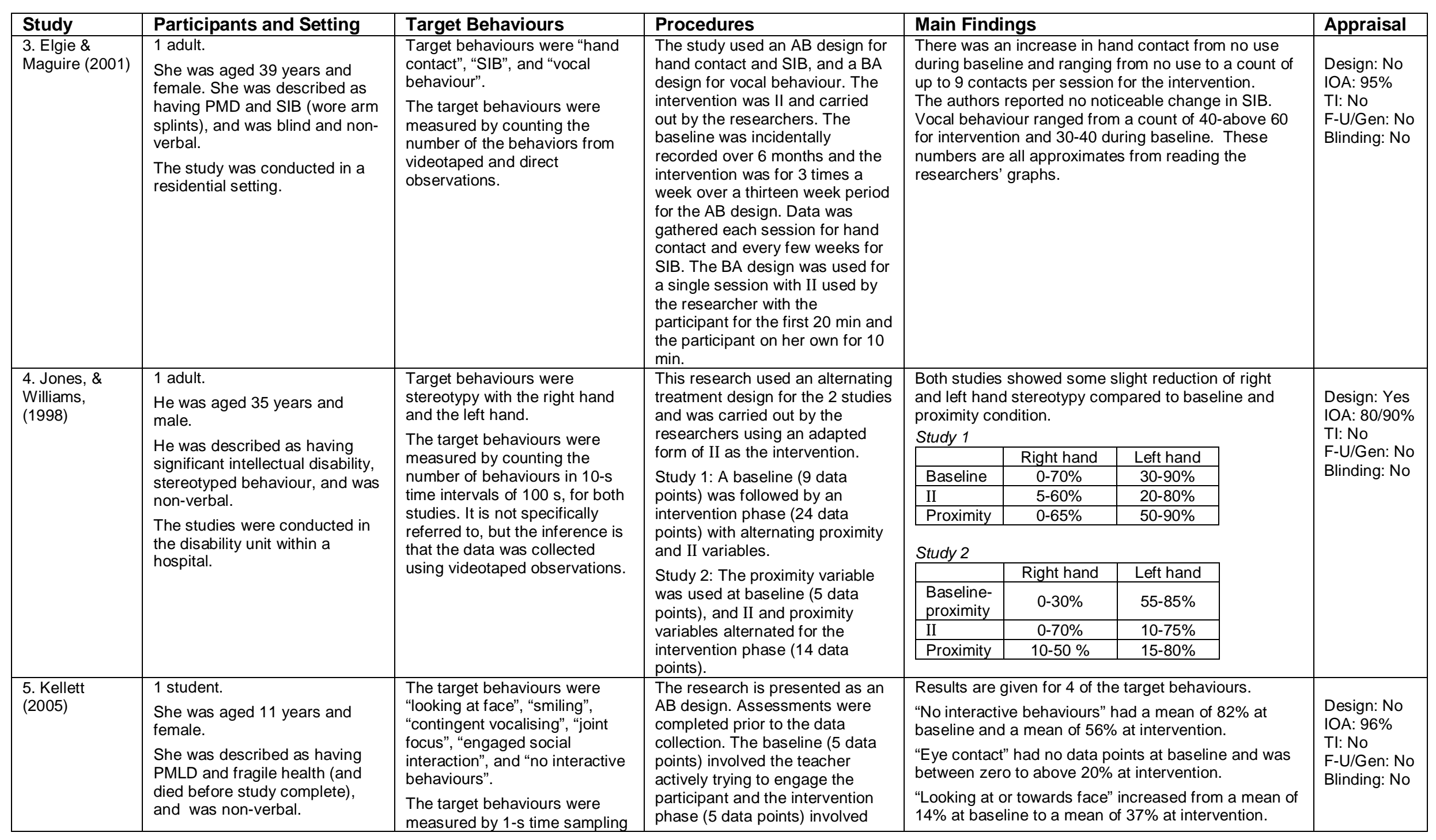




\begin{tabular}{|c|c|c|c|c|c|}
\hline Study & $\begin{array}{l}\text { Participants and Setting } \\
\text { The study was conducted in a } \\
\text { special school }\end{array}$ & $\begin{array}{l}\text { Target Behaviours } \\
\text { of weekly (where possible) } 5 \\
\text { min videotaped observations. }\end{array}$ & $\begin{array}{l}\text { Procedures } \\
\text { the teacher using II. } \\
\text { Qualitative data was also } \\
\text { gathered with staff. }\end{array}$ & $\begin{array}{l}\text { Main Findings } \\
\text { "Joint focus" increased from a mean of } 0.4 \% \text { at } \\
\text { baseline to a mean of } 28 \% \text { at intervention. }\end{array}$ & Appraisal \\
\hline $\begin{array}{l}\text { 6. Kellett } \\
(2004)\end{array}$ & $\begin{array}{l}1 \text { student. } \\
\text { He was aged } 6 \text { years and male. } \\
\text { He was described as having } \\
\text { SLD, some repetitive behaviour, } \\
\text { and was non-verbal, and } \\
\text { seldom interacted with peers. } \\
\text { The study was conducted in a } \\
\text { mainstream class }\end{array}$ & $\begin{array}{l}\text { Target behaviours were "eye } \\
\text { contact", "looking at face", } \\
\text { "smiling", "vocalisations", "social } \\
\text { physical contact", and } \\
\text { "engaged". } \\
\text { The target behaviours were } \\
\text { measured by coding behaviours } \\
\text { by } 1 \text {-s time sampling of } 5 \text { min } \\
\text { weekly (changing to fortnightly) } \\
\text { videotaped observations. }\end{array}$ & $\begin{array}{l}\text { This study was presented as an } \\
\text { AB design. Support staff carried } \\
\text { out the baseline and then } \\
\text { intervention using II for an hour } \\
\text { each day over the school year. } \\
\text { Staff were already trained in } \\
\text { using II. A change in teacher } \\
\text { during the intervention phase } \\
\text { meant the daily II sessions with } \\
\text { staff were not as consistent. In } \\
\text { the latter part of the study. }\end{array}$ & $\begin{array}{l}\text { Looking at face increased from a mean of } 5 \% \text { at } \\
\text { baseline to a mean of } 31 \% \text { at intervention. Social } \\
\text { physical contact increased from a mean of } 2.5 \% \text { at } \\
\text { baseline to a mean of } 28.2 \% \text { at intervention. } \\
\text { Eye contact was below } 5 \% \text { at baseline and reached a } \\
\text { highest point of around } 40 \% \text { at intervention (no mean } \\
\text { given). } \\
\text { Joint focus increased from a mean of } 14 \% \text { during } \\
\text { baseline to a mean of } 67 \% \text { for intervention. } \\
\text { Engagement had a mean of } 2 \% \text { at baseline to } \\
\text { intervention points from } 10 \% \text { to } 80 \% \text { with an } \\
\text { increasing trend. }\end{array}$ & $\begin{array}{l}\text { Design: No } \\
\text { IOA: } 96.1 \% \\
\text { TI: No } \\
\text { F-U/Gen: No } \\
\text { Blinding: No }\end{array}$ \\
\hline 7. Kellet (2003) & $\begin{array}{l}1 \text { student. } \\
\text { He was aged } 8 \text { years and male. } \\
\text { He was described as having } \\
\text { generalised developmental } \\
\text { delay, physical impairment, } \\
\text { epilepsy and was pre-verbal. } \\
\text { The study was conducted in a } \\
\text { special school. }\end{array}$ & $\begin{array}{l}\text { Target behaviours were "eye } \\
\text { contact", "looking at face", } \\
\text { "smiling", "vocalisations", } \\
\text { "social physical contact", "no } \\
\text { interactive behaviour", and } \\
\text { "stereotypical behaviour". } \\
\text { The target behaviours were } \\
\text { measured by coding weekly } \\
\text { (changing to fortnightly) } 5 \text { min } \\
\text { videotaped observations using } \\
\text { 1-s time sampling. }\end{array}$ & $\begin{array}{l}\text { The study is presented in } A B \\
\text { format. A staff member carried } \\
\text { out the baseline phase for } 5 \\
\text { weeks and the intervention } \\
\text { phase for } 42 \text { weeks using II. } \\
\text { Assessment was done using } \\
\text { standardized assessments. } \\
\text { Qualitative data was gathered } \\
\text { from staff. } \\
\text { Generalisation data was also } \\
\text { gathered in the classroom, for } \\
\text { stereotypical behaviour during } \\
\text { the intervention phase. }\end{array}$ & $\begin{array}{l}\text { No intervention behaviour had a mean of } 82 \% \text { at } \\
\text { baseline and a mean of } 11.6 \% \text { at intervention. } \\
\text { Looking at face had a mean of } 3.7 \% \text { at baseline with a } \\
\text { mean of } 65 \% \text { at intervention. } \\
\text { Joint focus had a mean of } 3.7 \& \text { at baseline with a } \\
\text { mean of } 65 \% \text { at intervention. } \\
\text { Means not given for eye contact and physical contact } \\
\text { but graphs show increasing trends. } \\
\text { Engagement had a mean of } 2.6 \% \text { at baseline with a } \\
46.4 \% \text { mean at intervention. } \\
\text { Generalisation data is discussed and graphs } \\
\text { presented for stereotypy. They show a reduction in } \\
\text { stereotypy from baseline (above80\%) to intervention } \\
\text { phase (below } 10 \% \text { ) and data gathered in the regular } \\
\text { classroom which shows } 100 \% \text { stereotypy at baseline } \\
\text { with a downward trend during the intervention phase. } \\
\text { Progress was also recorded using one of the } \\
\text { assessment tools. }\end{array}$ & $\begin{array}{l}\text { Design: No } \\
\text { IOA: } 94.1 \% \\
\text { TI: No } \\
\text { F-U/Gen: } \\
\text { Yes } \\
\text { Blinding: No }\end{array}$ \\
\hline $\begin{array}{l}\text { 8. Kellett } \\
(2000)\end{array}$ & $\begin{array}{l}1 \text { student. } \\
\text { He was aged } 5 \text { years and male. } \\
\text { He was described as having } \\
\text { intellectual disability, ritualistic } \\
\text { and stereotyped behaviour, and }\end{array}$ & $\begin{array}{l}\text { Target behaviours were "eye } \\
\text { contact", "looking at face", } \\
\text { "smiling", "vocalisations", } \\
\text { "social physical contact", "no } \\
\text { interactive behaviour", and }\end{array}$ & $\begin{array}{l}\text { The study is presented in } A B \\
\text { format. } \\
\text { A teacher carried out daily } \\
\text { sessions for the baseline phase } \\
\text { over } 12 \text { weeks and intervention }\end{array}$ & $\begin{array}{l}\text { Looking at face increased from a mean of } 0 \% \text { at } \\
\text { baseline to a mean of } 23 \% \text { at intervention. } \\
\text { Social physical contact had a mean of } 0 \% \text { at baseline } \\
\text { and increased figures are given for different terms. } \\
\text { Joint focus had a mean of } 19.8 \% \text { at baseline and }\end{array}$ & $\begin{array}{l}\text { Design: No } \\
\text { IOA: No } \\
\text { TI: No } \\
\text { F-U/Gen: No } \\
\text { Blinding: No }\end{array}$ \\
\hline
\end{tabular}




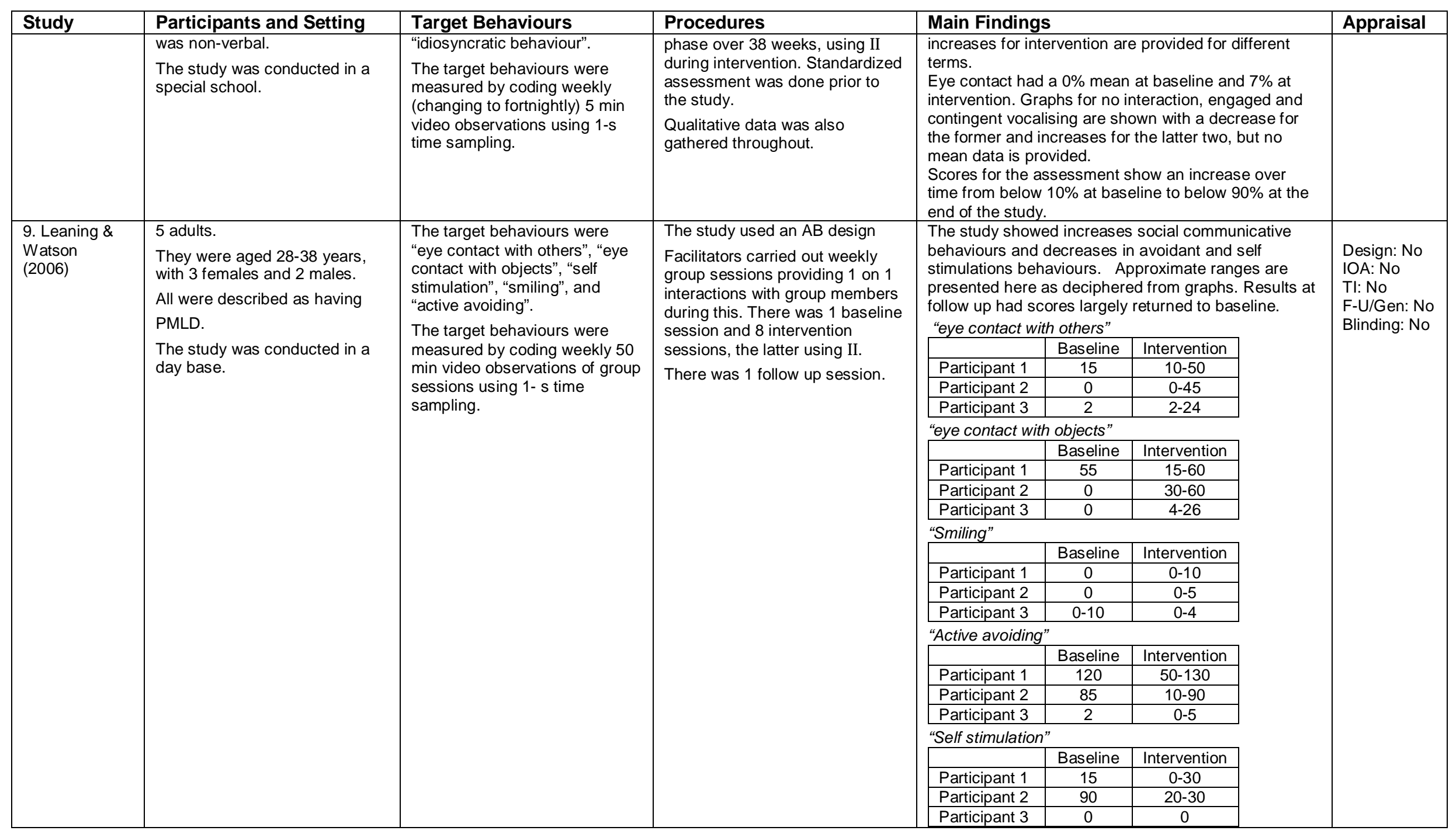




\begin{tabular}{|c|c|c|c|c|c|c|c|c|}
\hline Study & Participants and Setting & Target Behaviours & Procedures & \multicolumn{4}{|l|}{ Main Findings } & Appraisal \\
\hline \multirow[t]{9}{*}{$\begin{array}{l}\text { 10. Lovell, } \\
\text { Jones, \& } \\
\text { Ephraim } \\
\text { (1998) }\end{array}$} & \multirow{9}{*}{$\begin{array}{l}1 \text { adult. } \\
\text { He was aged } 53 \text { years and } \\
\text { male. } \\
\text { He was described as having } \\
\text { severe intellectual disability and } \\
\text { was non-verbal. } \\
\text { The study was conducted in a } \\
\text { long stay hospital, either in or } \\
\text { outside the villa. }\end{array}$} & \multirow{9}{*}{$\begin{array}{l}\text { Target behaviours were } \\
\text { "physical behaviour", "gaze", } \\
\text { "vocalising", "joint awareness", } \\
\text { "joint focus on item", "smiling", } \\
\text { and "idiosyncratic behaviour". } \\
\text { The target behaviours were } \\
\text { measured by coding } 5 \text { min } \\
\text { video observations of each } \\
\text { session using 10- s time } \\
\text { sampling. }\end{array}$} & \multirow{9}{*}{$\begin{array}{l}\text { The study used an alternating } \\
\text { treatment design. } \\
\text { The baseline ( } 10 \text { sessions) was } \\
\text { followed by the intervention with } \\
\text { alternating II ( } 9 \text { sessions) and } \\
\text { proximity conditions ( } 8 \text { sessions). } \\
\text { The data was gathered over } 3 \\
\text { days. }\end{array}$} & \multicolumn{4}{|c|}{$\begin{array}{l}\text { The results show increases in physical contact, gaze, } \\
\text { joint attention, and smiling for II compared to proximity } \\
\text { condition. The results for vocalisation and looking at } \\
\text { toy have a higher percentage for proximity than for II. } \\
\text { There was a decrease in idiosyncratic behaviours for } \\
\text { both II and proximity. }\end{array}$} & \multirow[t]{9}{*}{$\begin{array}{l}\text { Design: No } \\
\text { IOA: } 90 \% \\
\text { TI: No } \\
\text { F-U/Gen: No } \\
\text { Blinding: No }\end{array}$} \\
\hline & & & & Variables & Baseline & II & Proximity & \\
\hline & & & & $\begin{array}{l}\text { Physical } \\
\text { contact }\end{array}$ & $0 \%$ & $5-90 \%$ & $0-10 \%$ & \\
\hline & & & & $\begin{array}{l}\text { Looking at } \\
\text { someone }\end{array}$ & $0-10 \%$ & $15-75 \%$ & $0-20 \%$ & \\
\hline & & & & Vocalisation & $0-15 \%$ & $5-45 \%$ & $0-50 \%$ & \\
\hline & & & & $\begin{array}{l}\text { Joint } \\
\text { attention }\end{array}$ & $0 \%$ & $0-75 \%$ & $0-5 \%$ & \\
\hline & & & & Smiling & $0 \%$ & $0-15 \%$ & $0-5 \%$ & \\
\hline & & & & $\begin{array}{l}\text { Looking at } \\
\text { toy }\end{array}$ & $0-10 \%$ & $0-10 \%$ & $0-20 \%$ & \\
\hline & & & & $\begin{array}{l}\text { Covering } \\
\text { face }\end{array}$ & $0-50 \%$ & $0 \%$ & $0-5 \%$ & \\
\hline \multirow[t]{8}{*}{$\begin{array}{l}\text { 11. Nind } \\
\text { (1999) }\end{array}$} & \multirow{8}{*}{$\begin{array}{l}1 \text { adult. } \\
\text { He was aged } 28 \text { years and } \\
\text { male. } \\
\text { He was described as autistic, } \\
\text { non-verbal and withdrawn, with } \\
\text { repetitive behaviours. } \\
\text { The study was conducted in the } \\
\text { school (with adult students) } \\
\text { which was part of a long stay } \\
\text { hospital. }\end{array}$} & \multirow{8}{*}{$\begin{array}{l}\text { The target behaviours were the } \\
\text { total amount of time spent in } \\
\text { "self involved behaviour", } \\
\text { "interaction with familiar staff", } \\
\text { 'engagement with familiar staff", } \\
\text { "initiation with familiar staff", } \\
\text { "responses to physical } \\
\text { proximity", and "physical } \\
\text { contact". } \\
\text { The target behaviours were } \\
\text { measured by calculating the } \\
\text { percentage of time engaged in } \\
\text { the behaviours from weekly } 5 \\
\text { min videotaped observations, } \\
\text { and systematic sequential } \\
\text { observations in real time using } \\
\text { an observation scale. }\end{array}$} & \multirow{8}{*}{$\begin{array}{l}\text { The study was reported in an AB } \\
\text { design using II as the } \\
\text { intervention. } \\
\text { The baseline was done over a } 5 \\
\text { month period and the } \\
\text { intervention over } 13 \text { months, with } \\
\text { the staff member alongside the } \\
\text { participant. } \\
\text { Published assessments were } \\
\text { done and re-administered } \\
\text { throughout the study } \\
\text { Qualitative data was also } \\
\text { recorded. } \\
\text { Narrative data from } 2 \text { previous } \\
\text { case studies and qualitative data } \\
\text { from study looking at } \\
\text { practitioners' usage also } \\
\text { discussed. }\end{array}$} & \multicolumn{4}{|c|}{$\begin{array}{l}\text { Results suggest a decrease in self involved behaviour } \\
\text { and an increase in other behaviours. }\end{array}$} & \multirow{8}{*}{$\begin{array}{l}\text { Design: No } \\
\text { IOA: No } \\
\text { TI: No } \\
\text { F-U/Gen: No } \\
\text { Blinding: No }\end{array}$} \\
\hline & & & & Variables & Baseline & \multicolumn{2}{|c|}{ Intervention } & \\
\hline & & & & $\begin{array}{l}\text { time in self } \\
\text { involvement }\end{array}$ & $0-100 \%$ & \multicolumn{2}{|c|}{$0-85 \%$} & \\
\hline & & & & $\begin{array}{l}\text { Overall time } \\
\text { in interaction }\end{array}$ & $0-45 \%$ & \multicolumn{2}{|c|}{$0-80 \%$} & \\
\hline & & & & $\begin{array}{l}\text { Engagement } \\
\text { with staff }\end{array}$ & $0-25 \%$ & \multicolumn{2}{|c|}{$0-65 \%$} & \\
\hline & & & & $\begin{array}{l}\text { Initiation with } \\
\text { staff }\end{array}$ & $0 \%$ & \multicolumn{2}{|c|}{$0-40 \%$} & \\
\hline & & & & $\begin{array}{l}\text { Responses to } \\
\text { physical } \\
\text { proximity }\end{array}$ & $0-25 \%$ & \multicolumn{2}{|c|}{$0-80 \%$} & \\
\hline & & & & $\begin{array}{l}\text { Responses to } \\
\text { physical } \\
\text { contact }\end{array}$ & $0-65 \%$ & \multicolumn{2}{|c|}{$0-100 \%$} & \\
\hline
\end{tabular}




\begin{tabular}{|c|c|c|c|c|c|}
\hline Study & Participants and Setting & Target Behaviours & Procedures & Main Findings & Appraisal \\
\hline $\begin{array}{l}\text { 12. Nind } \\
\text { (1996) }\end{array}$ & $\begin{array}{l}6 \text { adults. } \\
\text { They were aged } 27-36 \text { years } \\
\text { and gender was not specified. } \\
\text { They were described as having } \\
\text { severe to profound and multiple } \\
\text { disabilities. } \\
\text { The } 6 \text { participants attended a } \\
\text { school (with adult students) at a } \\
\text { long stay hospital. }\end{array}$ & $\begin{array}{l}\text { Target behaviours were" } \\
\text { initiation of social contact", " } \\
\text { response to physical proximity } \\
\text { to familiar staff", "response to } \\
\text { physical contact of familiar } \\
\text { staff", "mainframe behaviours" } \\
\text { for when participant alone, and } \\
\text { "interactive behaviours" } \\
\text { including "looking at face", } \\
\text { "smiling", "joint focus" etc, and } \\
\text { "engagement". } \\
\text { The target behaviours were } \\
\text { measured by coding weekly } \\
\text { (and later fortnightly), } 5 \text { min } \\
\text { video observations using 5-s } \\
\text { time sampling, and systematic } \\
\text { sequential observations in real } \\
\text { time using an observation } \\
\text { scale. }\end{array}$ & $\begin{array}{l}\text { The study used a MBD across } \\
\text { subjects- interrupted time series } \\
\text { design. The baseline data was } \\
\text { gathered over a period of } 6 \\
\text { weeks to } 6 \text { months, and } \\
\text { intervention data was gathered } \\
\text { over } 12 \text { to } 18 \text { months. These } \\
\text { phases were carried out by a } \\
\text { different staff member alongside } \\
\text { and interacting with each } \\
\text { participant, with II as the } \\
\text { interaction. } \\
\text { Published assessments were } \\
\text { administered during the data } \\
\text { collection phase. Qualitative data } \\
\text { was also recorded including a } \\
\text { historical log and teacher } \\
\text { recordings. }\end{array}$ & $\begin{array}{l}\text { For social initiation, there is a zero baseline for } 5 \text { of } \\
\text { the } 6 \text { participants, and percentages between } 0 \text { and } \\
100 \% \text { for interaction. For patterns of engagement, } \\
\text { baseline showed scores between } 0 \text { and } 25 \% \text { and } 0 \text { to } \\
100 \% \text { for intervention. } \\
\text { Overall time spent in interactive behaviours shows an } \\
\text { increasing trend for } 5 \text { of the } 6 \text { participants. Baseline } \\
\text { had scores between } 0 \text { and } 25 \% \text { for all students and } \\
\text { between } 0 \text { and } 100 \% \text { during intervention. } \\
\text { Results for the other target behaviours are not shown } \\
\text { using figures but are tabled and discussed. }\end{array}$ & $\begin{array}{l}\text { Design: Yes } \\
\text { IOA: } 88 \% \\
\text { TI: No } \\
\text { F-U/Gen: No } \\
\text { Blinding: No }\end{array}$ \\
\hline $\begin{array}{l}\text { 13. Nind \& } \\
\text { Kellet (2002) }\end{array}$ & $\begin{array}{l}\text { Intervention 1: } 6 \text { adults } \\
\text { As for Nind (1996) } \\
\text { Intervention 2: } 4 \text { students. } \\
2 \text { to } 3 \text { of the participants were } \\
\text { part of Kellett }(2004,2003 \text {, } \\
\text { 2000). }\end{array}$ & $\begin{array}{l}\text { 1. Target behaviours were } 3 \text { to } \\
6 \text { stereotyped behaviours for } \\
\text { each participant, totaling } 19 \\
\text { behaviours, including "rocking", } \\
\text { 'mouthing", "paper eating" etc. } \\
\text { 2.Target behaviours were } 2 \text { to } 3 \\
\text { stereotyped behaviours for } \\
\text { each participant, totaling } 7 \\
\text { behaviours, including "finger } \\
\text { play", "hand biting", and } \\
\text { "mouthing/chewing". } \\
\text { The target behaviours were } \\
\text { measured by coding weekly } \\
\text { (and later fortnightly), } 5 \text { min } \\
\text { video observations for total } \\
\text { amount of time engaged in } \\
\text { these behaviours. }\end{array}$ & $\begin{array}{l}\text { Both studies used a quasi- } \\
\text { experimental design. Video } \\
\text { observations from the original } \\
\text { studies ( } 18 \text { and } 12 \text { months) were } \\
\text { viewed and coded for the target } \\
\text { behaviours. Alongside the one to } \\
\text { one baseline and intervention } \\
\text { stages using II, video } \\
\text { observations were also gathered } \\
\text { of the participants in their } \\
\text { everyday environments. Staff } \\
\text { members had carried out the } \\
\text { baseline and intervention phases } \\
\text { in the adult and children's } \\
\text { schools, using II as the } \\
\text { intervention. }\end{array}$ & $\begin{array}{l}\text { 1. Results are reported using baseline and } \\
\text { intervention percentages for behaviours for each of } \\
\text { the participants. A percentage is also given for the } \\
\text { total average time spent in all stereotyped behaviours } \\
\text { (or } 2+\text { behaviours). These show variable changes for } \\
\text { the different behaviours, with a decrease in } 2+/ \text { total } \\
\text { amount of time spent in stereotyped behaviours } \\
\text { shown by } 4 \text { out of } 6 \text { participants e.g. } 92 \%->62 \% \text { for } \\
\text { participant } 1,61 \%->15 \% \text { for participant } 2,33.1 \% \text {-> } \\
32 \% \text { for participant } 5 \text {, and } 67.6 \%->65.9 \% \text { for } \\
\text { participant } 6 . \text { One participant's total is not shown, and } \\
\text { one other has no change. } \\
2 \text {. Results are reported using baseline and } \\
\text { intervention percentages for behaviours for each of } \\
\text { the participants. A percentage is also given for the } \\
\text { total average time spent in stereotyped behaviours. } \\
\text { This shows } 6 \text { behaviours increased from baseline and } \\
4 \text { behaviours decreased. Total scores show that each } \\
\text { participant's total amount of time spent in stereotyped } \\
\text { behaviours decreased, e.g. } 26.9 \%->14.5 \% \text {, for } \\
\text { participant } 1,29.3 \%->12.1 \% \text { for participant } 2,17.3 \\
\%->4.2 \% \text { for participant } 3 \text {, and } 42.9 \%->16.1 \% \text { for } \\
\text { participant } 4 \text {. }\end{array}$ & $\begin{array}{l}\text { Design: No } \\
\text { IOA: No } \\
\text { TI: No } \\
\text { F-U/Gen: No } \\
\text { Blinding: No }\end{array}$ \\
\hline
\end{tabular}




\begin{tabular}{|c|c|c|c|c|c|}
\hline Study & Participants and Setting & Target Behaviours & Procedures & Main Findings & Appraisal \\
\hline $\begin{array}{l}\text { 14. Samuel et } \\
\text { al (2008) }\end{array}$ & $\begin{array}{l}4 \text { adults. } \\
\text { They were aged, } 23-56 \text { years } \\
\text { and female. } \\
\text { They were all described as } \\
\text { having PMD. } \\
\text { The study was conducted in } \\
\text { supported residential } \\
\text { bungalows in } 4 \text { different towns. }\end{array}$ & $\begin{array}{l}\text { The target behaviours were } \\
\text { "visual scanning", "looking at } \\
\text { face", "engagement", "joint } \\
\text { focus", and "initiation". } \\
\text { The target behaviours were } \\
\text { measured by coding } 5 \text { points } \\
\text { during baseline and } 12 \text { points } \\
\text { during intervention, from } \\
\text { variable lengths of videotaped } \\
\text { observations. }\end{array}$ & $\begin{array}{l}\text { MBD across participants- } \\
\text { interrupted time series. The } \\
\text { baseline was staggered } 6 \text { weeks } \\
\text { and the intervention lasted } 20 \\
\text { weeks. Training in II was } \\
\text { provided for staff before the } \\
\text { intervention. Qualitative data was } \\
\text { also gathered before, during and } \\
\text { at the end of the data gathering. } \\
\text { During baseline and intervention, } \\
\text { data was also gathered in the } \\
\text { participants' regular environment. }\end{array}$ & $\begin{array}{l}\text { Results for the baseline mean compared to the later } \\
\text { intervention mean showed: } \\
\text { Visual scanning: noticeable increases for } 4 \\
\text { participants }(>5 \%) \\
\text { Looking at face: noticeable increase for } 1(>5 \%) \text { and } \\
\text { slight increases for } 2(<5 \%) \\
\text { Engagement: noticeable increase for } 3(>5 \%) \text { and } \\
\text { slight for } 1(<5 \%) \\
\text { Joint focus: noticeable increases for } 3(>5 \%) \text { and } \\
\text { slight for } 1(<5 \%) \\
\text { Initiating soc/phys contact: noticeable increases for } 1 \\
9>5 \%) \text { and slight increases for } 2(<5 \%) \text {. Decline for } 1 \text {. }\end{array}$ & $\begin{array}{l}\text { Design: No } \\
\text { IOA: } 80 \% \\
\text { TI: No } \\
\text { F-U/Gen: No } \\
\text { Blinding: No }\end{array}$ \\
\hline $\begin{array}{l}\text { 15. Zeedyk et } \\
\text { al (2009) }\end{array}$ & $\begin{array}{l}10 \text { adults. } \\
\text { They were aged from late teens } \\
\text { to early } 60 \text { s, with } 6 \text { females and } \\
4 \text { males. } \\
\text { They were all described as } \\
\text { having a range of severe and } \\
\text { profound disorders, and were } \\
\text { non verbal. } \\
\text { The study used archival video } \\
\text { footage which had been filmed } \\
\text { in residential settings or day } \\
\text { bases for all participants bar } \\
\text { one who was filmed at home. }\end{array}$ & $\begin{array}{l}\text { The target behaviours were } \\
\text { "eye gaze to partners", "bodily } \\
\text { orientation to partner", } \\
\text { "proximity to partner", and } \\
\text { "emotional valence". } \\
\text { The target behaviours were } \\
\text { measured by coding each } \\
\text { behaviour on a } 3 \text { scale level } \\
\text { from } 3-14 \text { min videotaped } \\
\text { observations broken into four } \\
\text { segments. }\end{array}$ & $\begin{array}{l}\text { Archival video footage for the } 10 \\
\text { participants was selected. This } \\
\text { footage was of their first II } \\
\text { session. } \\
\text { Session length was determined } \\
\text { by when the participant first } \\
\text { indicated a need for a break. }\end{array}$ & $\begin{array}{l}\text { Of the target behaviours, } 9 \text { showed an increase in } \\
\text { emotional valence and one a decrease, } 9 \text { showed an } \\
\text { increase in eye gaze and one a decrease, } 6 \text { showed } \\
\text { an increase in orientation and } 8 \text { had an increase in } \\
\text { proximity and one no change. Emotion, eye gaze and } \\
\text { orientation had a p value }<0.05 \text { and proximity had a } p \\
\text { value }<0.01 \text {. }\end{array}$ & $\begin{array}{l}\text { Design: No } \\
\text { IOA: } 89 \% \\
\text { TI: No } \\
\text { F-U/Gen: No } \\
\text { Blinding: } \\
\text { Yes }\end{array}$ \\
\hline
\end{tabular}




\section{Participants and Setting}

Of the 15 studies, there were 8 that have a single participant [Studies $3,4,5,6,7,8,10$, and 11] and 7 that had from 3 to 12 participants [Studies 1, 2, 9, 12, 13, 14, and 15]. The studies comprised six with student participants [Studies 1, 2, 5, 6, 7, and 8] and eight that had adult participants [Studies 3, 4, 9, 10, 11, 12, 14, and 15]. One study considered two previous studies so had both adult and student participants [Study 13]. For student participants, where age was specified, all studies involved children between 5 and 12 years [Studies 5, 6, 7, and 8]. There is a possibility that Barber's (2008) study had children aged less than five years and/or at secondary school level, as the special school where the study was conducted had children from 2-18 years of age, and Anderson's (2006) study could also have had some secondary school students as the special schools where the study was conducted had children aged from 5 to 15 years of age. However, neither of these studies specified age of the participants. For the studies where participants' ages were specified there were none with early childhood or secondary school children. Adult studies included participants aged from their late teens to 60 years of age [Studies $3,4,9,10,11,12,14$, and 15]. There were no studies involving people in their retirement years. For those studies where gender was specified [Studies 3, 4, 5, 6, 7, 8, 9, 10, 11, 12, 14, and 15] there were 15 females and 12 males. This appears to be a relatively balanced number between the genders.

For the six studies conducted with school age children, five were conducted in special school settings [Studies 1, 2, 5, 7, and 8]. There was only one study conducted in an inclusive setting [Study 6]. Another study 
(Whittaker, 2004) had been carried out in a mainstream setting, but this was excluded from the review because the majority of the participants were verbal. For the eight studies specifying setting which had only adult participants, four were conducted in residential settings for people with disabilities [Studies 3, 4, 10, and 14]. One had nine participants in residential or day-base settings and a tenth participant who lived in the family home [Study 15]. One study was conducted in a day base programme [Study 9],

and two were conducted at the part-time school that exists for people in a long stay hospital [Studies 11 and 12]. One study [Study 13] had both child and adult participants who were in special schools, inclusive nursery class, and a school attached to a long stay hospital respectively. Thus research on II has mostly involved child and adult participants in specialised settings.

\section{Target Behaviours}

The studies focussed on social and communication behaviours and/or repetitive or negative behaviours. Social and communication behaviours included eye contact, social physical contact, joint focus, smiling, and vocalising. There are six studies that contain social and communication target behaviours only [Studies 1, 2, 5, 6, 14, and 15]. Repetitive or negative behaviours were described in the articles as self-stimulating behaviours, selfinjurious behaviours, idiosyncratic behaviours, stereotypies, and self-involved behaviours. There were two studies that cover only these behaviours [Studies 4 and 13]. There were seven studies that had both social and communication behaviours, and repetitive and negative behaviours as target behaviours [Studies $3,7,8,9,10,11$, and 12]. In all, 13 studies had target 
behaviours related to the social-communication domain and 8 studies involved repetitive and negative behaviours as target behaviours.

\section{Measurement and Data Collection}

Fourteen studies used video observation as part of the procedure for data gathering. The fifteenth study did not specify this but did refer to recordings and the implication is that these would have involved using video [Study 4]. Two studies used real time observation alongside video observation [Studies 11 and 12]. Nine studies used time sampling and coded behaviour from the video observation at between 1-s and 10-s duration [Studies 2, 4, 5, 6, 7, 8, 9, 10, and 12]. Other studies do not specify whether time sampling was done or not. Thus it appears that video observation was the main method of gathering data.

\section{Procedures}

\section{Duration of Intervention}

The duration of intervention in these studies varied. Eight studies were conducted over one school year (47/48 weeks) or for up to 18 months [Studies 1, 2, 6, 7, 8, 11, 12, and 13]. Four studies lasted between 9 and 47 weeks [Studies 3, 5, 9, and 14]. One study [Study 10] was conducted over a week and another [Study 15] was of a single intervention ranging from 3-14 min of videotaped observations for 10 different participants. One article [Study 4] reported on two studies, but did not specify the length of time of the study, and reported that nine interval points were gathered over the baseline period and 24 interval points were gathered over the intervention period for study one; and 20 interval points for baseline and intervention for study two. 
Thus 8 of the studies were conducted over a school year or longer (53\%) and 12 of the studies were conducted over nine weeks or longer (80\%).

\section{Baseline}

Not all studies described the baseline phase adequately [Studies 11, 12, 13], nor demonstrated a stable baseline [Studies 2, 9, 11]. One study [Study 3] collected baseline data incidentally. One study [Study 4] did not have someone alongside the participant for baseline, and another [Study 10] described the baseline as normal conditions but did not specify whether someone was alongside the participant.

\section{Intervention}

All studies used II as the intervention although two studies could be described as using an adapted form of II [Studies 3 and 4].

\section{Assessment and qualitative data}

Standardised assessment scales were used in six studies as part of the process [Studies 6, 7, 8, 11, 12 and 14], and not used or not stated in eight others [Studies 1, 2, 3, 4, 5, 10, 13, and 15]. One of the research studies used video observation for initial assessment of behaviours [Study 9]. Qualitative data was also gathered for 11 of the research articles [Studies 2, $5,6,7,8,9,11,12,13,14$, and 15] with 4 studies either not stating use or using only the quantitative data [Studies 1, 3, 4, and 10]. Qualitative data was often in the form of treatment diaries and logs, observations, and feedback. This feedback was mainly from staff, but one article also included a parent giving feedback [Study 6]. 


\section{Main Findings}

Of the 13 studies that had social-communicative behaviours as the target behaviour, all reported increases for some or all of these behaviours with the use of II [Studies 1, 2, 3, 5, 6, 7, 8, 9, 10, 11, 12, 14, and 15]. One of these studies [Study 15] measured the target behaviours across the four segments in a single session for each of the participants and showed increases across these segments. Some of the target behaviours were described as 'no interactive behaviours' or active avoidance, and these behaviours decreased.

For the eight articles that involved negative or repetitive behaviours as target behaviours, six reported decreases in these behaviours [Studies 3, 4, 7, 9, 10, and 13] and two studies did not report the results for these behaviours [Studies 11 and 12].

\section{Appraisal}

\section{Research Designs}

Only three studies used an experimental design that is either a multiple baseline design [Study 12] or the alternating treatment design [Studies 4 and 10]. The remaining studies were pre-experimental, that is, intervention only or $\mathrm{AB}$ designs.

\section{Inter-observer Agreement Checks}

Ten of the 15 studies included inter-observer agreement checks to assess the reliability of data collection [Studies 1, 3, 4, 5, 6, 7, 10, 12, 14, and 15]. All these studies had inter-observer agreement percentages above $80 \%$, which is an acceptable level of consistency (C. H. Kennedy, 2005). 
However, not all these studies indicated the percentage of sessions that included inter-observer agreement checks. Those that did reported checks in 10 to $33 \%$ of the sessions [Studies 1, 5, 14, and 15]. One study [Study 3] gave inter-observer agreement data for only one of the variables and this was done on $100 \%$ of the single session. Five studies provided the agreement percentage but not the amount of the data that this was calculated on [Studies 4, 6, 7, 10, and 12]. There were three studies that did not report or provide inter-observer agreement figures [Studies 8, 9, 11, and 13] and one study that reported using collaborative means to determine agreement where analysing data was difficult [Study 2].

\section{Procedural Integrity}

None of these 15 studies reported procedural integrity data.

\section{Follow-up and Generalisation}

One study included a one month follow-up for the three participants following intervention [Study 9] and one study [Study 7] assessed generalisation to regular classroom activities for stereotypy.

\section{Blinding}

Three studies used people to analyse data that were not involved in the data collection [Study 9] or were blind to the purpose of the study [Studies 14 and 15].

\section{Discussion}

This literature review has considered quantitative research conducted using II. The researcher is aware that excluding unpublished theses and research published in books may have placed limitations on accessing the 
amount of research that has been done. This review also excluded qualitative research on II and this could be useful for a future literature review. From studies analysed in this review there is a gap in research using experimental design. There appears to be a lack of research involving children either in the early childhood years or with adolescents at secondary schools. There is also a gap in research focussed on participants in an inclusive setting. Target behaviours have included both socialcommunicative behaviours and negative and repetitive behaviours. As discussed in the introduction, there has been some criticism of proponents of II for contradictory views, and the negating of behavioural approaches when these might also be useful. Research has not always adequately defined the baseline condition and has not sought to measure procedural integrity. This thesis will seek to respond to some of these limitations. It will utilise video observation for data collection and analyse the data by coding target behaviours at 10-s intervals. 


\section{Research Question}

The research question for this thesis is: Does intensive interaction influence the levels of social and communicative engagement for students with profound and multiple learning disabilities?

This could be demonstrated by increasing the levels of social and communicative engagement for a group of students. In order for this increase to be demonstrated, changes in the levels would happen once the intervention phase (II) had begun either through the emergence of new higher-level behaviours or where there was an increase in use of behaviours at a higher level. 


\section{CHAPTER 3}

\section{METHODS}

\section{Ethical Approval and Recruitment}

Ethics approval for this research was gained from the Victoria University of Wellington, Faculty of Education Ethics Committee (Reference number 17701). The first person approached was the principal of the secondary school who gave written consent for the researcher to be in touch with the head teacher at the unit and through them the other staff and students and families involved in the unit. Following a meeting with staff, staff completed their consent forms and participants were selected. The head teacher spoke to each of the three participant's families to introduce the researcher and the purpose of the research. The three families responded positively at this initial phone call and said they were happy for their children to take part. The families were encouraged to be in contact with the researcher and information letters and forms were sent out. One parent had English as a second language and said her comprehension of English was better for verbal rather than written language. She requested some extra time so that she could meet with another person to go over the written information before signing. Two parents spoke to the researcher by phone with follow up questions.

The ethics process paid particular attention to the vulnerability of the participants given that they were non-verbal and with limited communication skills. There was also the issue of the video footage images and ensuring that these were respectful. The families signed on their children's behalf. The researcher took responsibility for being responsive to the participants' moods 
over when and when not to video-tape them, and also used assessment data given by staff and staff input during filming to assist with responsiveness. For example, one of the participants began having seizures during an intervention session so that the intervention was stopped for that day and the video footage was deleted and not used for analysis.

The researcher also sought consent from the families of all other students who attended the unit. This was because it was likely that other students might appear in the background during filming. Following notification in the class newsletter, information letters and consent forms were sent out. The researcher also asked families to decide whether their teenage children were able or unable to understand the research and give written consent. If they believed they were able, then the students could sign a simplified consent form with guidance from either family or the head teacher. As with the participants, the researcher was careful to ensure that any video footage was respectful. Confidentiality agreements were also signed by the inter-observer, any other post graduate students involved, and by any information technology person if support was required. Copies of the information letters and consent forms are contained in Appendices 2-16.

\section{Participants}

Three students from the special unit attached to a state secondary school in the Wellington area, were selected by staff, out of a possible five, to be participants in this research. In order to be part of the study students had to meet the following criteria, which relied on teacher reports:

- They were non-verbal (i.e., did not have any spoken words); 
- They had no or minimal use of Alternative and Augmentative Communication (AAC) systems;

- They were difficult to engage in communication;

- They had severe to profound levels of disability; and

- They had to have a regular pattern of attendance at school.

The three participants were between 15-20 years at the beginning of the study (mean age $=18$ years). The three participants were all verified at the "very high" level of ORS funding. The participants were part of the group of students who had the majority of their programme delivered in the main classroom and were full time within the unit. Pseudonyms, Kathy, Megan and Bronwyn, have been used in this research to protect the participants' privacy.

The participants were assessed for the purpose of this study by interviewing their key staff members using the Survey Interview Form from the second edition of the Vineland Adaptive Behavior Scales (Vineland II:Sparrow, Cicchetti, \& Balla, 2005) and the Inventory of Potential Communicative Acts (IPCA:Sigafoos, et al., 2006). Table 3 presents the characteristics of the participants, the resulting stanine levels, percentile rank and disability levels from the Vineland II assessment for the participants. 
Table 3: Participant Characteristics.

\begin{tabular}{|c|c|c|c|}
\hline & Kathy & Megan & Bronwyn \\
\hline Gender & female & female & female \\
\hline Age & $19: 4$ & $19: 4$ & $15: 4$ \\
\hline $\begin{array}{l}\text { Ethnicityl } \\
\text { Language }\end{array}$ & $\begin{array}{l}\text { NZ European } \\
\text { English is first language at } \\
\text { home }\end{array}$ & $\begin{array}{l}\text { NZ Chinese } \\
\text { English is first language at } \\
\text { home }\end{array}$ & $\begin{array}{l}\text { Chinese/Malaysian } \\
\text { Chinese is first language at } \\
\text { home }\end{array}$ \\
\hline $\begin{array}{l}\text { Disabilities/ } \\
\text { Diagnosis }\end{array}$ & $\begin{array}{l}\text { Chromosome 18Q deletion } \\
\text { Epilepsy, complex partial } \\
\text { seizures } \\
\text { Under orthopaedic } \\
\text { services } \\
\text { Can't walk unaided, has } \\
\text { wheel chair } \\
\text { Under-weight } \\
\text { Sensory issues } \\
\text { Can't regulate own } \\
\text { temperature }\end{array}$ & $\begin{array}{l}\text { Dubowitz Syndrome } \\
\text { Severe Intellectual Disability } \\
\text { Features of ASD } \\
\text { Epilepsy } \\
\text { Hearing loss } \\
\text { Visual impairment } \\
\text { MCP- joint stiffness and } \\
\text { weakness } \\
\text { Sensory issues } \\
\text { Mobile }\end{array}$ & $\begin{array}{l}\text { Severe Intellectual } \\
\text { Disability } \\
\text { Features of ASD } \\
\text { Epilepsy } \\
\text { Behavioural Challenges } \\
\text { Mobile }\end{array}$ \\
\hline Health & $\begin{array}{l}\text { Special diet, fed food and } \\
\text { drink by adults } \\
\text { Skin complaint } \\
\text { Fragile health }\end{array}$ & $\begin{array}{l}\text { Special diet, fully supported } \\
\text { during meal times by staff } \\
\text { member }\end{array}$ & $\begin{array}{l}\text { Sits at table with group and } \\
\text { eats independently }\end{array}$ \\
\hline Self care & $\begin{array}{l}\text { Incontinent, wears } \\
\text { nappies, on toileting } \\
\text { schedule }\end{array}$ & Incontinent, wears nappies & $\begin{array}{l}\text { Takes self to toilet, } \\
\text { occasionally needs } \\
\text { reminders }\end{array}$ \\
\hline $\begin{array}{l}\text { Socio- } \\
\text { Communication }\end{array}$ & $\begin{array}{l}\text { Non-verbal, } \\
\text { Holds eye contact } \\
\text { Enjoys people } \\
\text { Vocalisations } \\
\text { Minimal gestures }\end{array}$ & $\begin{array}{l}\text { Non-verbal } \\
\text { Little eye contact } \\
\text { Does not seek out people } \\
\text { Vocalisations } \\
\text { Minimal gestures }\end{array}$ & $\begin{array}{l}\text { Non-verbal } \\
\text { Holds eye contact } \\
\text { Actively seeks out people } \\
\text { Vocalisations } \\
\text { Has range of gestures }\end{array}$ \\
\hline Symbolic level & $\begin{array}{l}\text { Responds to real items } \\
\text { Understands that picture } \\
\text { schedule means 'Change' }\end{array}$ & $\begin{array}{l}\text { Responds to known real } \\
\text { items }\end{array}$ & $\begin{array}{l}\text { Responds to picture } \\
\text { symbols and schedules }\end{array}$ \\
\hline AAC systems & $\begin{array}{l}\text { Pushes a "Big Mac" at her } \\
\text { turn at circle time } \\
\text { Can operate switches on } \\
\text { music toys but does not } \\
\text { use a switch to operate } \\
\text { toy/activity }\end{array}$ & $\begin{array}{l}\text { Pushes a "Big Mac" at her } \\
\text { turn at circle time } \\
\text { At meal times will pass a } \\
\text { picture to request food and } \\
\text { drink (does not discriminate) }\end{array}$ & $\begin{array}{l}\text { Pushes a "Big Mac" at her } \\
\text { turn at circle time and to } \\
\text { request items at specific } \\
\text { bingo game. }\end{array}$ \\
\hline $\begin{array}{l}\text { Independent } \\
\text { behaviour }\end{array}$ & $\begin{array}{l}\text { Sits in chair or on floor. } \\
\text { Will look at objects she is } \\
\text { holding, turning objects } \\
\text { around and will turn off and } \\
\text { on if there is an easy } \\
\text { switch. Will also scrunch } \\
\text { paper/magazines if close. } \\
\text { Will look at people as they } \\
\text { go past or stop to talk with } \\
\text { her. Enjoys music and } \\
\text { books and will watch } \\
\text { activities. Will smile at } \\
\text { people. Occasionally } \\
\text { vocalises or laughs in } \\
\text { responses to people. }\end{array}$ & $\begin{array}{l}\text { Alternates between being } \\
\text { seated and walking around. } \\
\text { Mostly holding onto item and } \\
\text { will turn this repetitively. If no } \\
\text { item will play with body part. } \\
\text { Will vocalise and smile but } \\
\text { this doesn't appear to be in } \\
\text { response to people. Enjoys } \\
\text { music and books being read } \\
\text { aloud. Moves towards items } \\
\text { when she wants them and is } \\
\text { very aware when food break } \\
\text { is about to happen }\end{array}$ & $\begin{array}{l}\text { Sits at class work space } \\
\text { and will complete some of } \\
\text { activity. Will sit with staff to } \\
\text { listen to music, look at } \\
\text { books and do some } \\
\text { activities. Gets up and } \\
\text { moves off when she has } \\
\text { had enough. } \\
\text { Most often will pick up } \\
\text { items such as books and } \\
\text { puzzle pieces and pass } \\
\text { them repetitively to staff. } \\
\text { Does not want to stop until } \\
\text { all items are passed and } \\
\text { will often restart this. } \\
\text { Protests if change of } \\
\text { activity is suggested. }\end{array}$ \\
\hline \multicolumn{4}{|c|}{ Vineland II Scores } \\
\hline \multicolumn{4}{|c|}{ Communication subdomain } \\
\hline $\begin{array}{l}\text { Percentile } \\
\text { ranking }\end{array}$ & $\leq 0.1$ & $\leq 0.1$ & $\leq 0.1$ \\
\hline Stanine & 1 & 1 & 1 \\
\hline \multicolumn{4}{|c|}{ Daily living subdomain } \\
\hline $\begin{array}{l}\text { Percentile } \\
\text { ranking }\end{array}$ & $\leq 0.1$ & $\leq 0.1$ & $\leq 0.1$ \\
\hline Stanine & 1 & 1 & 1 \\
\hline \multicolumn{4}{|c|}{ Socialization subdomain } \\
\hline Percentile & $\leq 0.1$ & $\leq 0.1$ & $\leq 0.1$ \\
\hline
\end{tabular}




\begin{tabular}{|c|c|c|c|}
\hline & Kathy & Megan & Bronwyn \\
\hline \multicolumn{4}{|l|}{ ranking } \\
\hline Stanine & 1 & 1 & 1 \\
\hline \multicolumn{4}{|l|}{ Motor skills } \\
\hline $\begin{array}{l}\text { Percentile } \\
\text { ranking }\end{array}$ & $\leq 0.1$ & $\leq 0.1$ & $\leq 0.1$ \\
\hline Stanine & 1 & 1 & 1 \\
\hline \multicolumn{4}{|c|}{ Adaptive composite score } \\
\hline $\begin{array}{l}\text { Percentile } \\
\text { ranking }\end{array}$ & $\leq 0.1$ & $\leq 0.1$ & $\leq 0.1$ \\
\hline Stanine & 1 & 1 & 1 \\
\hline Adaptive Level & Low & Low & Low \\
\hline \multicolumn{4}{|l|}{ Age equivalents } \\
\hline receptive & 1.4 & 0.9 & 1.3 \\
\hline expressive & 0.8 & 0.1 & 0.9 \\
\hline written & 1.10 & 1.10 & 1.10 \\
\hline $\begin{array}{l}\text { Interpersonal } \\
\text { relationships }\end{array}$ & 0.5 & 0.2 & 1.1 \\
\hline $\begin{array}{l}\text { Play and leisure } \\
\text { skills }\end{array}$ & 0.8 & 0.9 & 1.1 \\
\hline Coping skills & 0.10 & 1.1 & 2.3 \\
\hline
\end{tabular}

\section{Setting}

The research was conducted in the special needs unit that the participants all attended. The unit was attached to a state secondary school in the Wellington region. The unit included a total of 18 students, ranging from 13 to 21 years of age.

Staffing in the unit consisted of two full time teaching staff, including the head teacher, and six support staff. The students also received support from visiting specialists including speech-language therapist, occupational therapist, physiotherapist, special education advisor and music therapist. Each student has a staff member identified as their key staff member.

\section{Session Schedule and Content}

The participants received individual $5 \mathrm{~min}$ sessions with the researcher for sessions in both the baseline and intervention phases. The sessions occurred in the context of the daily programme delivered in the 
main class room. The sessions occurred once a day, across several days of the week, and were videotaped and later scored and coded.

\section{Measurement and Response Definitions}

The dependent variable was the level of social and communicative engagement shown by the participant during the 5 min sessions. Initially Firth's (2007) 'Framework for recognising attainment in intensive interaction' was to be used as the basis for operationally defining the different possible levels of social-communicative engagement. This framework has seven levels of engagement: (a) encounter, (b) awareness, (c) attention and response, (d) engagement, (e) participation, (f) involvement and (g) student initiated interaction. These range from the learner being present, but unaware through to the learner independently initiating an activity. However, at the training stage for coding data by the inter-observer and researcher, it proved difficult to reach agreement on these levels and so a new set of levels was developed by the researcher (names for each level have been italicised to avoid words being misread). A new category was added, withdrawal, so that a participant's withdrawal by either turning or moving away could be coded. Firth's two levels of 'encounter' and 'awareness' were made into one level coded as present. This was because it proved difficult to determine whether certain behaviours used by participants were evidence of awareness or not. The other four levels, responding, increased responding, intentional, and extension are more closely aligned to Firth's levels, but more precise behavioural descriptions of each level were developed to aid coding. The final level extension is similar to Firth's 'student initiated interaction', but also allowed for the participant responding to the researcher's new interaction. 
Finally there was the ability to code any part of the video footage as uncodable such as when the footage moved away from the participant and researcher and on to the floor or another part of the room. As with Firth (2007) this set of levels demonstrates an ascending scale of social and communicative engagement where the level present represents no engagement, and responding through to extension relates to an increase in social and communicative engagement at each level. This can be illustrated by the example of vocalising behaviour. At present this behaviour would occur but not in relation to the presence of a $\mathrm{CP}$. At responding vocalising on its own could be made in response to the CP. At increased responding it could be done in conjunction with another behaviour such as looking at the CP's face. At intentional it could occur while reaching out to take an item that the $\mathrm{CP}$ holds. At extension during a game where both people are vocalizing in a turn taking game, the $L$ could extend the game by changing the sound being vocalised or imitate the CP when they introduce a new sound. As such it is not the individual behaviour that is noted but its context. Withdrawal could be seen as a level below present or even perhaps as a communication that the $L$ wishes to take a break from or to end the interaction. Table 4 sets out the levels of social and communicative engagement.

Table 4: Categories and Definitions for the Levels of Social and Communicative Engagement

\begin{tabular}{|c|c|c|}
\hline Stage & Definition & Behaviours \\
\hline Uncodable $(\varnothing)=0$ & Footage not clear & \\
\hline $\begin{array}{l}\text { Withdrawal } \\
(\mathrm{W})=1\end{array}$ & $\begin{array}{l}\text { Student moves away or turns away from } \\
\text { interaction. This may be as a pause or to } \\
\text { end the activity }\end{array}$ & $\begin{array}{l}\text {-turns head or body away from interaction } \\
\text { while seated or standing } \\
\text {-turns from standing, gets up from seat or } \\
\text { floor and moves away }\end{array}$ \\
\hline $\begin{array}{c}\text { Present } \\
(P)=2\end{array}$ & $\begin{array}{l}\text { Student alongside interaction partner. May } \\
\text { appear unaware or at times aware of } \\
\text { interaction partner or extraneous events }\end{array}$ & $\begin{array}{l}\text {-turns head/body towards voice, noise or } \\
\text { action. No eye contact. } \\
\text {-may be engaged in self-activity. } \\
\text {-may pause, move, have facial expression } \\
\text { or body movement }\end{array}$ \\
\hline
\end{tabular}




\begin{tabular}{|c|c|c|}
\hline Stage & Definition & Behaviours \\
\hline $\begin{array}{l}\text { Responding } \\
\qquad(\mathrm{R})=3\end{array}$ & $\begin{array}{l}\text { Student alongside interaction partner. } \\
\text { Uses communication behaviour directed } \\
\text { towards partner or other event/person. } \\
\text { Small range }(1-2) \text { of behaviours and used } \\
\text { one at a time. }\end{array}$ & $\begin{array}{l}\text {-eye contact } \\
\text {-body movement } \\
\text {-facial expression } \\
\text {-vocalisation } \\
\text {-gesture } \\
\text {-may be periods of joint focus }\end{array}$ \\
\hline $\begin{array}{l}\text { Increased } \\
\text { responding } \\
(\mathrm{IR})=4\end{array}$ & $\begin{array}{l}\text { Student alongside interaction partner. } \\
\text { Increased amount of communication } \\
\text { behaviours in frequency and range. May } \\
\text { use three plus behaviours together. } \\
\text { Intent of behaviours may be ambiguous } \\
\text { e.g. initiation, protest comment, attention } \\
\text { etc... }\end{array}$ & $\begin{array}{l}\text {-eye contact } \\
\text {-body movement } \\
\text {-facial expression } \\
\text {-vocalisation } \\
\text {-gesture } \\
\text {-periods of joint focus } \\
\text { - turn taking emerging }\end{array}$ \\
\hline $\begin{array}{l}\text { Intentional } \\
(\mathrm{I})=5\end{array}$ & $\begin{array}{l}\text { Student alongside interaction partner. } \\
\text { Communication behaviour less ambiguous } \\
\text { and able to determine intent e.g. initiation, } \\
\text { protest, comment, attention etc. } \\
\text { Activity is often repetitive. }\end{array}$ & $\begin{array}{l}\text {-eye contact } \\
\text {-body movement } \\
\text {-facial expression } \\
\text {-vocalisation } \\
\text {-gesture e.g. Giving item to partner, taking } \\
\text { partners hand } \\
\text {-turn taking become more established } \\
\text {-emergence of a 'game' }\end{array}$ \\
\hline $\begin{array}{c}\text { Extension } \\
\qquad(E)=6\end{array}$ & $\begin{array}{l}\text { Student alongside interaction partner. } \\
\text { Using a range of communication } \\
\text { behaviours, the student will introduce new } \\
\text { activities or extend those being used. S/he } \\
\text { also responds to a change of activity by } \\
\text { the communication partner. }\end{array}$ & $\begin{array}{l}\text {-Communication behaviours as above } \\
\text {-turn taking well established } \\
\text {-repertoire of games } \\
\text {-can change from one game to another e.g.: } \\
\text { playing with puzzle then playing with ball, } \\
\text { throwing the ball becomes rolling the ball, } \\
\text { sitting with ball becomes standing with ball, } \\
\text { taking pieces for puzzle becomes turns } \\
\text { putting pieces in. }\end{array}$ \\
\hline
\end{tabular}

\section{Experimental Design}

The effects of the intervention on the level of social and communicative engagement were evaluated in a multiple baseline across participants design (Johnson \& Christensen, 2008; C. H. Kennedy, 2005). This method was selected for several reasons. First, the design can provide a convincing demonstration of an intervention if the dependent variable changes when, and only when, the intervention is introduced. Because the intervention is introduced to each participant at different times, the design can help to rule out threats to interval validity, such as history, practice, and exposure effects (C. H. Kennedy, 2005).

\section{Coding}


Each socio-communicative level was given a letter code (e.g. $\mathrm{W}=$ withdrawal, I = intentional). While coding the video footage, each $10 \mathrm{~s}$ video segment was coded for the above levels from the total of $5 \mathrm{~min}$. The level chosen was the level which best reflected the 10-s footage. The total score at each level was then calculated. For example, if the participant had a total of six for the withdrawal level, than that would mean the participant had been engaged in behaviour from this level for $60 \mathrm{~s}$ of the $5 \mathrm{~min}$. Initially, it was decided to have a daily mean for each participant. To do this, a numerical value was given for each level (e.g., withdrawal $=1$, intentional $=5$, as shown on Table 4). Once the number of times a level occurred was calculated, this was then multiplied by the assigned numerical value (e.g., if the participant had a total of 6 for the withdrawal level as above, then this would be multiplied by the number 1 . The score would then be 6). Once scores for all levels were calculated for a given session, they were totaled and then divided by 30 , the maximum number of ten s segments. This gave daily means for each session.

The mean scores were graphed and used to determine the order of participants starting the intervention phase. However, as discussed later in this thesis, they were not than used for presentation of data. This was done using the six different social and communication engagement levels.

\section{Procedures}

Before the data gathering began the researcher met with all staff at the special unit to describe the research and briefly outline the process. Minimal information was given about the specific intervention to be used (so as to avoid influencing staff behaviour), and the need to precisely follow the 
protocols to ensure procedural integrity was discussed. This was particularly emphasised to the staff members who were involved with any of the videotaping for the baseline and intervention phases.

The researcher spent a two-week period in the unit for familiarisation and to habituate the participants to her presence. This was to allow all students, not just the participants to get used to her presence. During this time, the researcher completed the assessments with key staff and did a number of formal observations as discussed previously. The researcher also introduced the video camera and took some initial footage of the participants that was later used for training with the inter-observer. Different students were interested in the camera and the researcher filmed students on request and showed them the footage or allowed students to do some filming. This footage was immediately deleted from the camera and was not downloaded. The three participants had varying responses to being filmed. One participant appeared completely unaware of the camera, the second appeared aware of the person filming rather than the camera itself, and the third was aware of the camera, but often ignored it. This last participant's behavior did not appear to change while being filmed and she never requested to look at or use the camera.

\section{Baseline}

Baseline data were gathered by videotaping $5 \mathrm{~min}$ of interaction between the researcher and each participant. This 5 min footage was done on a daily basis several times each week. The researcher sat alongside each participant, either at the table or on the floor, with an activity. The researcher made a verbal comment approximately every $10 \mathrm{~s}$ to the participant (e.g. 
"Let's turn the page", "You've got the flowers there"). The activity was either part of the group lesson for that period or had been chosen for the participant by their key staff member.

The key staff member for each participant videotaped the 5 min session. If this was not possible another staff member or a fellow postgraduate student did the videotaping. The 5 min video footage began when the staff member sat alongside the participant. The footage was then coded by analysing each 10-s segment (Appendix 17) of the five min footage using the levels of social-communicative engagement (Table 4) as discussed in the section on response definitions. The initial baseline phase was conducted over a two and a half week period due to participant absences over this time. Kathy had five baseline data points. Megan had four baseline points and one probe baseline point. Bronwyn had five baseline data points and two probe baseline points.

\section{Intervention}

The researcher used the II approach during the intervention phase. All other procedural aspects were the same as in baseline, including context, session schedule, and length of sessions. The following strategies and behaviours were utilised by the researcher:

- Session occurring in the natural setting for the student;

- Being alongside the participant at their level. While at baseline the researcher would sit alongside the participant, at intervention the researcher could be in whatever places the participant was at, such as sitting alongside, standing, on the floor, or moving around. However, 
in effect the researcher used this strategy at both baseline and intervention;

- Following the participant's lead. As opposed to baseline where a planned or staff chosen activity was undertaken, the researcher joined in with the current activity being done by the participant e.g. body movement, chosen toy or activity;

- Responding to participant behaviours as if they had communicative intent (contingent responding);

- Imitating the behaviours used by the participant including body movements, facial expressions, eye focus, vocalisations, and actions on self and others. It was not always appropriate to do exactly the same behaviour e.g. sucking on items, and in these instances the researcher responded to the rhythm or movement of the behaviour. This has been referred to as responding to the timbre of the behaviour (Barber, 2007c);

- Pausing and waiting when the participant did so. The researcher responded to any withdrawal by the participant as if they were asking for a break. This fits with the ideas of mirroring and contingent responding as above. The researcher also made use of pauses to see whether the participant used any further communication behaviour before they responded. This was used especially once turn taking had been established and as a means to encourage initiating;

- Responding to any communication such as joint focus, turn taking, requesting and protest, e.g., if the student pushed an item away the researcher would not reintroduce the item; 
- Using no or minimal language during the session;

- Building observed participant behaviour into the routine. The researcher noted any behaviour used by the participant during the observations and baseline and intervention phases, and then would introduce them at other times; and

- Extending the activity. The researcher would introduce a novel behaviour into the interaction. This could include behaviour previously used by the participant as above or be something new to the participant. While following the participant's lead was still the priority, this was a useful strategy to use when the researcher and participant were engaged in turn taking during a repetitive exchange.

As with the baseline phase, the researcher was videotaped during a 5 min session once each day over several days of the week alongside each participant, but this time using the intensive interaction strategies. Because the intervention was introduced in a staggered manner for each of the participants, there were differing numbers of baseline and intervention sessions.

\section{Inter-observer Agreement}

Inter-observer reliability was assessed for $30 \%$ of the baseline and intervention sessions. Initially the researcher had a training stage to ensure the independent observer had been trained on how to analyse the video footage using the response definitions. The independent observer was not blind to the purpose of the study or phase of the study because it was not possible to edit the videotapes so as to prevent the observer from knowing 
whether the child was receiving the baseline versus intervention procedures. This stage lead to the creation of the new social and communicative levels derived from Firth (2007) as discussed. During this stage it was also determined that both the researcher and independent observer would view the agreed footage at the same time to ensure that exactly the same time footage was analysed. The researcher and the independent observer would be seated in such a way as to ensure neither could view the scoring of the other. Each video segment of $5 \mathrm{~min}$ was viewed on a laptop with the researcher monitoring time and stopping the video after each $10 \mathrm{~s}$. It was agreed that if either the researcher or the independent observer wanted to view the 10-s clip again, that this would be asked for and done. It was also decided that if either the researcher or independent observer was unsure which level to code the behavior at, they were to choose the lower level to attempt to control for over estimating the participants' behavior. Training was completed through using some of the footage recorded in the researcher's initial familiarisation phase. Once there was consistent agreement of above $80 \%$ during training, the actual analysis began.

The researcher and independent observer met together one to three times each week over this period. Dates for each participant were presented in written form and the independent observer would randomly select approximately $30 \%$ of these for each participant. As discussed the researcher and independent observer viewed the selected footage together but independently, and coded it using the coding system and agreed on directions ascertained during the training stage. 
Inter-observer agreement was calculated using the formula: (Agreement/Agreements + Disagreements) x 100\% (C. H. Kennedy, 2005).

An agreement was defined as both researcher and independent observer coding the same social and communication level for the same 10-s segment (e.g., both would code responding). A disagreement was defined as the researcher and independent observer each coding a different sociocommunication level for the same 10-s segment, from each other (e.g., one would code responding and one would code present).

In total inter-observer reliability checks were carried out on $29 \%$ of the baseline data, $34 \%$ of the intervention data, and $33 \%$ of the total data. Interobserver agreement averaged $77 \%, 82 \%$, and $91 \%$ for each of the participants at baseline. Inter-observer agreement averaged 80\%, 93\%, and $80 \%$ for each of the participants at intervention. Inter-observer agreement ranged from $66 \%$ to $93 \%$ for all baselines with an average of $85 \%$. Interobserver agreement ranged from $63 \%$ to $97 \%$ for the intervention phase with an average of $80 \%$.

\section{Procedural Integrity}

A checklist of strategies was developed that incorporated the strategies the researcher intended to use as appropriate with all participants as part of II during the intervention phase. However, for procedural integrity, it was decided to limit the number of strategies for II to only those strategies the researcher intended to use at the intervention phase. Thus, using a natural setting and sitting at the learner's level were part of the baseline condition and excluded from the check on procedural integrity. It was also decided not to include strategies that may be used in II, but are not 
necessarily used with all participants in this study. Thus, strategies such as developing a game sequence and introducing novel behaviours that were conditional on participants demonstrating certain behaviours were excluded. The strategies included for the check on procedural integrity are set out in Appendix [18].

Procedural integrity was assessed for $24 \%$ of the sessions for each participant and across both phases of the study. The dates of all sessions were presented to the independent observer who randomly selected approximately $30 \%$ of each participant's total number of sessions. For this next stage, the researcher left the independent observer by herself to watch the different video sessions. This took place on two separate occasions. The independent observer then watched the selected video segments. Each segment was watched for the full five minutes. The independent observer would tick off each strategy as it was seen, using the checklist (Appendix 18). Only one tick was required regardless of the number of times the strategy was used by the researcher. If the researcher had not used the strategy by the end of the 5 min video footage, the independent observer would place a cross on the checklist.

The results showed that strategy 1 was used $25 \%$ of the time during baseline and $100 \%$ of the time during intervention. Strategy 2 was used $20 \%$ of the time during baseline and $100 \%$ of the time during intervention. The other strategies were used zero\% at baseline and 100\% at intervention.

The strategies were then examined for each participant. Both Kathy and Megan had zero \% of all six strategies used at baseline and $100 \%$ at 
intervention. Bronwyn had $24 \%$ of the strategies used at baseline and $100 \%$ of the strategies used at intervention. 


\section{CHAPTER 4}

\section{RESULTS}

Results are presented in three figures using the multiple baseline design for this research (Figures 1 to 3), and a table setting out the mean scores at baseline and intervention (Table 5).

Originally, it was intended to use a figure showing the mean scores for all of the six variables being coded. This had been used initially to determine when to move from baseline to intervention for each participant. However, this was not sensitive enough to show progress for participants and in fact tended to flatten out the results, and instead the figures each contain two of the six variables. Figure 1 shows the data for the variables withdrawal and present. Figure 2 shows the data for the variables responding and increased responding. Figure 3 shows the data for the variables intentional and extension.

Table 5, setting out the baseline and intervention mean scores is shown below. Mean scores were based on how many $10 \mathrm{~s}$ units were being used by each participant for each social and communicative level. As discussed there were thirty $10 \mathrm{~s}$ units for every $5 \mathrm{~min}$ of video footage (the length of baseline and intervention sessions). Thus a mean score of 9.80 would represent nearly $100 \mathrm{~s}$ at a level or a score of 21.00 would represent 3 $\min 30 \mathrm{~s}$, at a particular level. Thus a decrease in mean score from baseline to intervention would mean a decrease in amount of time spent in behaviours at that level. An increase in mean score from baseline to intervention would mean an increase in amount of time spent in behaviours at that level. 
Table 5: Baseline and intervention mean scores

\begin{tabular}{|l|c|c|c|c|c|c|}
\hline & Kathy & Kathy & Megan & Megan & Bronwyn & Bronwyn \\
\hline & Baseline & Intervention & Baseline & Intervention & Baseline & Intervention \\
\hline Withdrawal & 0.00 & 0.16 & 1.20 & 3.25 & 1.29 & 0.89 \\
\hline Present & 9.80 & 3.34 & 21.00 & 15.30 & 3.86 & 1.22 \\
\hline Responding & 17.60 & 11.09 & 7.40 & 7.60 & 9.71 & 2.56 \\
\hline $\begin{array}{l}\text { Increased } \\
\text { responding }\end{array}$ & 2.00 & 7.13 & 0.00 & 1.50 & 5.57 & 3.67 \\
\hline Intentional & 0.00 & 8.28 & 0.00 & 1.80 & 8.17 & 18.78 \\
\hline Extension & 0.00 & 0.00 & 0.00 & 0.00 & 0.00 & 2.89 \\
\hline
\end{tabular}

\section{Kathy}

During the baseline phase, Kathy was predominantly using behaviours in the present and the responding variables, as shown across Figures 1 and 2. She demonstrated a small amount of increased responding behaviours, and no behaviours for withdrawal, intentional or extension, (Figures 1, 2, and 3). During the intervention phase, there was a small increase in withdrawal behaviours (Figure 1). There was also a decrease in present and responding behaviours (Figures 1 and 2), her two main behavioural variables for the baseline. There was some increase for increased responding (Figure 2) and an increase from a nil baseline for intentional behaviours (Figure 3). There was no increase and no behaviour rated at the extension level during intervention.

The changes in mean scores illustrate this. The withdrawal behaviours went from a mean of 0 at baseline to 0.16 at intervention. The present behaviours went from a mean of 9.80 at baseline to a mean of 3.34 at intervention. The responding behaviours went from a mean of 17.60 at baseline to a mean of 11.09 at intervention. The increased responding 
behaviours went from a mean of 2.00 at baseline to a mean of 7.13 at intervention. The intentional behaviours went from a mean of 0 at baseline to 8.28 at intervention. There was no change from a mean of 0 at baseline to intervention for extension behaviours.

\section{Megan}

During the baseline phase Megan used behaviours mainly from the present and responding levels with some from the withdrawal level. She used no behaviours from the increased responding, intentional, and extension variables. During the intervention, she initially increased the use of withdrawal behaviours, and this was variable following that. She also began to use behaviours from the increased responding and intentional levels as opposed to no behaviours at these levels during baseline. There was a decrease in the number of present behaviours and little change for responding behaviours. There was no change from zero for behaviours for the extension level.

These results are also shown with the changes in means for baseline and intervention: withdrawal increased from a mean of 1.20 for baseline to a mean of 3.25 for intervention; increased responding increased from a mean of zero to 1.50 at intervention; intentional increased from a mean of zero at baseline to a mean of 1.80 at intervention; present decreased from a mean of 21.00 at baseline to a mean of 15.30 at intervention. The mean for responding only had a slight increase at intervention. The mean for extension remained at zero for both baseline and intervention.

\section{Bronwyn}


Bronwyn used behaviours in all levels except for extension during baseline. She predominantly made use of responding, increased responding, and intentional behaviours. During the intervention she decreased behaviours in withdrawal, present, responding, and increased responding. She increased behaviours for the intentional level and went from no extension behaviours at baseline to using some behaviour at intervention.

This was shown in the mean scores for baseline and intervention. The mean for withdrawal at baseline was 1.29 and reduced to 0.89 at intervention. The mean for present at baseline was 3.86 and reduced to 1.22 at intervention. The mean for responding was 9.71 at baseline and reduced to 2.56 at intervention. The mean for increased responding was 5.57 at baseline and 3.67 at intervention. The mean score for intentional behaviour increased from a mean of 8.71 at baseline to a mean of 18.78 at intervention. The mean for extension behaviours was zero at baseline and increased to 2.29 at intervention. 

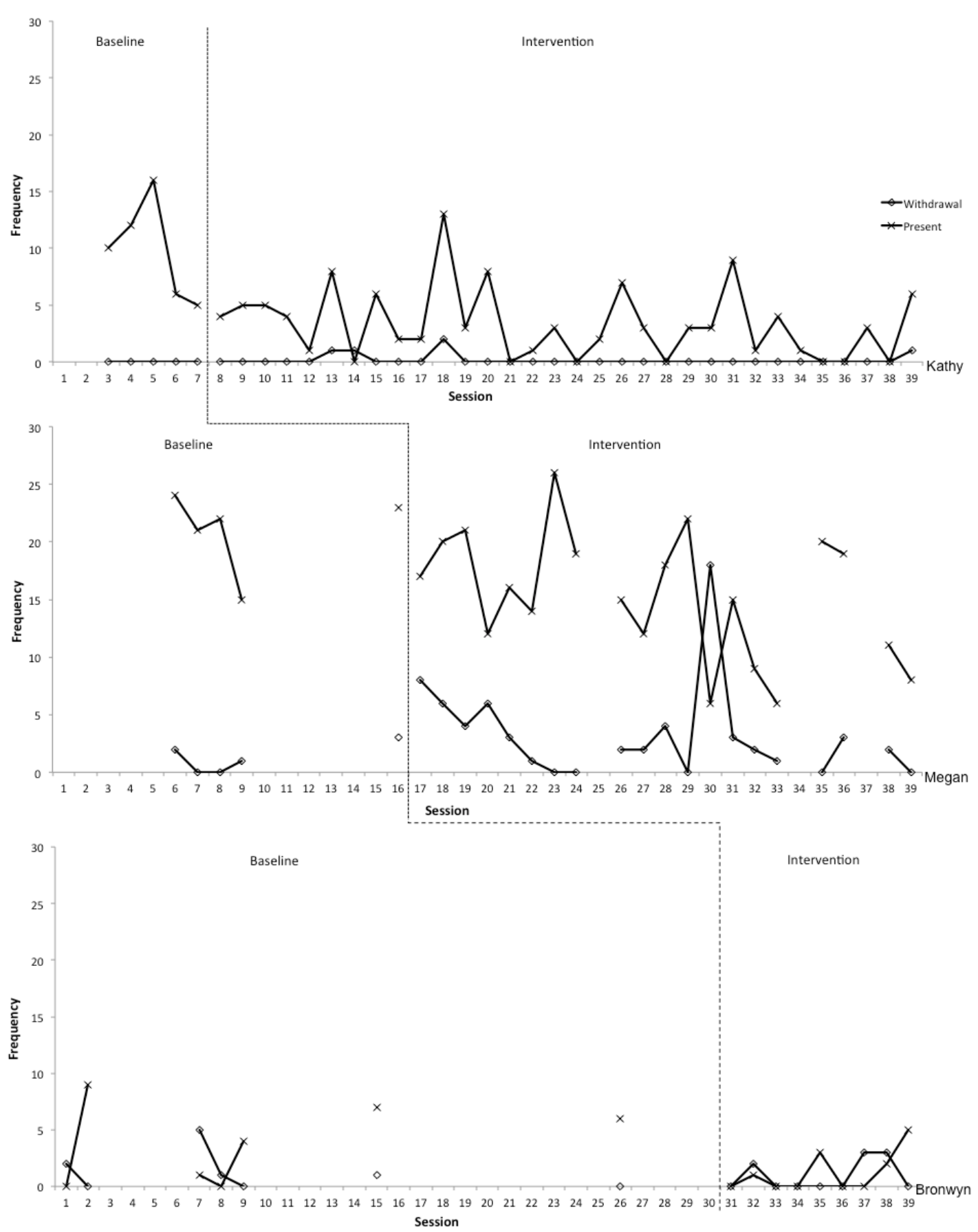

Figure 1: Frequency (ten second segments for five minutes) of target behaviours (withdrawal and present) for Kathy, Megan, and Bronwyn 


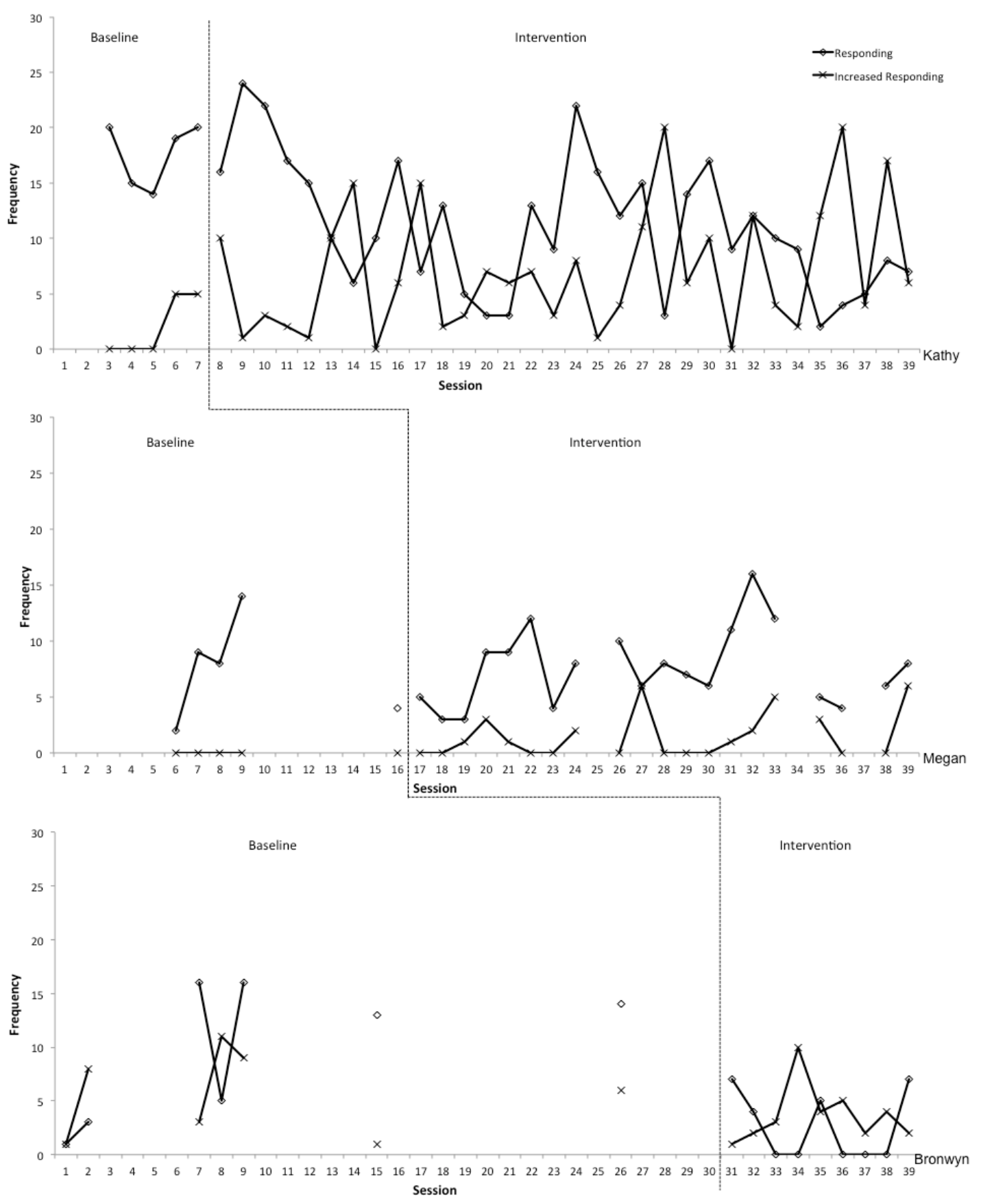

Figure 2: Frequency (ten second segments for five minutes) of target behaviours (responding and increased responding) for Kathy, Megan, and Bronwyn 


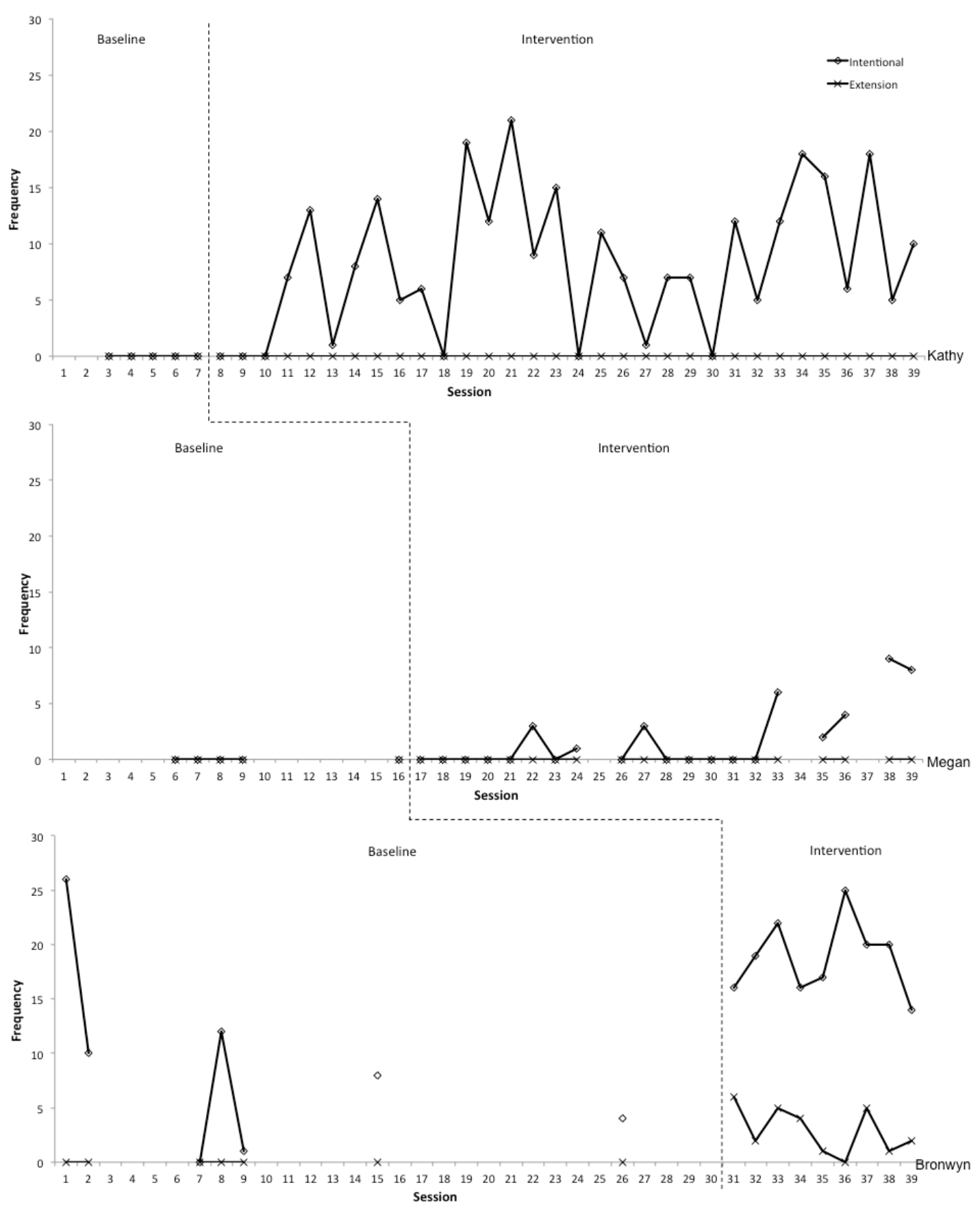

Figure 3: Frequency (ten second segments for five minutes) of target behaviours (intentional and extension) for Kathy, Megan, and Bronwyn 


\section{Summary}

Each of the three participants had increases in behaviours in the top three levels, with increasing use of increased responding for Kathy and Megan, and increasing use of intentional levels for Bronwyn. Each participant also developed new behaviours at a higher level, with Kathy and Megan's use of intentional behaviours, and Bronwyn's use of extension behaviours. 


\section{CHAPTER 5}

\section{DISCUSSION}

The results showed increases in the students' levels of social and communicative engagement with the introduction of II, in comparison to the levels that were observed in a previous baseline phase. These results suggest that II was effective in increasing the students' levels of social and communicative engagement. In addition, each participant began to use new levels of behaviours during II that had not been demonstrated prior to the introduction of II. For participants Kathy and Megan, this was the use of intentional behaviours, for Megan alone this was use of increased responding, and for Bronwyn this was the use of extension behaviours. Thus two participants each began to use a new target behaviour, and one participant began to use two new target behaviours, none of which had been demonstrated at baseline.

As well as these positive findings, there was evidence of increased use of behaviours at the upper levels of the scale as demonstrated by the increasing means for the levels when compared to baseline (Table 5). Kathy as well as developing use of intentional behaviour increased the amount of increased responding she used. Bronwyn, as well as developing use of extension behaviour, also increased the amount of intentional behaviour she used. This provides some empirical evidence that II was associated with increased levels of social and communicative engagement of the participants in this study. This fits with the prediction that participants would demonstrate increased use of the higher levels of social and communicative engagement. 
Related to these increases, there was evidence from intervention of a change in use of withdrawal for each of the participants. Kathy had a slight increase at intervention compared to baseline, while Megan's mean increased two points. And Bronwyn had a mean decrease in withdrawal from baseline to intervention. Given that withdrawal might be seen as a lower level of social and communicative engagement, the decreases in withdrawal from baseline to intervention for one of the three participants can be seen as a positive finding. On the other hand, withdrawal behaviours could be seen as the participant's way to signal a need for a break or a desire to stop the activity (p. 41). One could posit that if engagement was normally difficult for a participant, then when they began to be more engaged they would also need to be able to have breaks from the intensity of interacting with another person. Thus an increase in withdrawal behaviours for Kathy does not necessarily suggest a negative intervention effect. Along these lines, Megan often got up and moved around before coming back to sit with the researcher. This was coded as withdrawal, but could be a natural part of her routine. A couple of times she took the researcher's hand to come with her or waited for the researcher to come as well.

It is important to note that there was an inverse relation between some of the target behaviours related to the six levels on the rating scale. That is, when certain target behaviours increased, this meant that other target behaviours would have to show a decrease. When Kathy, for example, began to use intentional behaviours and increased her use of increased responding, her use of behaviours indicative of present and responding showed a collateral decrease as shown in Figures 1-3 and Table 5. Similarly, 
when Megan began to use increased responding and intentional behaviours, there was a corresponding decrease in present and responding behaviour as shown in Figures 1-3 and Table 5. Bronwyn also showed this effect in that when she had an increase in intentional behaviour and began to use extension behaviours, there was a decrease for withdrawal, present, responding and increased responding behaviours as shown in Figures 1-3 and Table 5.

The changes in levels of engagement that were associated with the use of II, also appeared to bear some relation to the participants' levels of adaptive behaviour functioning as measured by the Vineland II (Sparrow, et al., 2005). For example, Megan had the lowest age equivalents in the communication and social skills subdomains and she also had the most modest developments in increased responding and intentional behaviours. In contrast, Bronwyn had the highest age equivalent scores on the Vineland II for the communication and social skills subdomains and she also had the largest increase in increased responding and began to use the highest level extension behaviours during II. While existing strengths in communication and social skills could explain Bronwyn's seemingly greater response to II, it is important to note that she was already using comparatively more intentional communication during baseline.

This research did not seek to look at the negative and repetitive behaviours of participants, but change in these behaviours for Bronwyn is noted here for discussion. Bronwyn was described during assessment as having a frequent behaviour of repetitive giving of items to staff members such as books or puzzle pieces. If a staff member tried to stop her giving 
them the items, she would find another person to give the items to. If a staff member tried to stop the behaviour and redirect her to a class task, Bronwyn would resist this, often lying down on the floor. This repetitive giving also occurred with the researcher during baseline and intervention phases. During the baseline phase the researcher would accept all the items. In the intervention phase, the researcher would also offer Bronwyn an item as an imitation of what Bronwyn was doing. This appeared to lead to Bronwyn participating in a joint activity where items were shared and used in different ways, rather than moving to another person or protesting at the change. Staff commented on this, as they had not seen this occur before.

It is important to look at why II might have influenced the social and communicative behaviours of the three participants. Was it just because they were getting an increased level of attention? This is less likely to be the case given that the researcher was already giving them attention during the baseline phase. The emergence of new behaviours and increases in other behaviours came after II had been introduced suggesting that it was the intervention rather than attention that led to the changes. II is an intervention made up of a number of strategies, and it appears at this stage as if it was the total of these strategies which influenced the social and communicative behaviours of the participants.

\section{Conclusion}

Overall, the results suggest that II may be an effective mode of intervention that can increase the level of social and communicative engagement of some students with PLMD. This conclusion is in line with existing research which has also suggested that II can be used to increase 
the social and communication engagement of individuals with severe/multiple disabilities (Barber, 2008; Elgie \& Maguire, 2001; Kellet, 2000, 2003, 2004, 2005; Leaning \& Watson, 2006; Lovell, Jones, \& Ephrain, 1998; Nind, 1996, 1999; Samuel, Nind, Volans, \& Scriven, 2008; Zeedyk, Caldwell, \& Davies, 2009).

Most of the above research looked at specific social and communicative behaviours rather than a scale of increasing levels of behaviour therefore direct comparison is somewhat harder. However some behaviours can translate to some of the levels for this research. Barber (2007) and Kellett $(2000 ; 2003)$ both used 'no interactive behaviour' as a variable and this would correspond to present where is no discernible interactive behaviour. All three studies showed decreases in 'no interactive behaviour'. The three participants in this study also showed a decrease in present levels of behaviour and this is shown most strongly in the differences in means for each participant where the amount of time spent at this level has decreased between baseline and intervention phases.

Several studies (Kellett, 2000; 2003; 2004; 2005; Lovell, et al., 1998) have 'joint attention' or 'joint focus' as a variable, with all studies showing increases in these. This study had these emerging at the responding level and being established at increased responding. These behaviours are also assumed at the levels for intentional and extension. For each of the participants there are changes at three or four of these levels but these are harder to translate, as 'joint attention/focus' is only one of the behaviours occurring within these levels. 
Perhaps a comparison is more likely with 'initiation' and the intentional level. Two studies (Nind, 1996; 1999) had 'initiation' as one of the variables. In the first study, this increased for five of the six participants and in the latter it increased for the single participant. For this current study, two of the participants developed behaviours at the intentional level, which did include initiations, and the third participant increased the intentional behaviours following introduction of the intervention.

The strongest evidence for the influence II had on social and communicative levels of engagement is the emergence of behaviours that were not demonstrated at baseline. Kathy had a stable zero baseline for the intentional and usage developed following introduction of the intervention II. Megan had stable zero baselines for both increased responding and intentional and began to develop behaviours at these levels following introduction of II. Bronwyn had a stable zero baseline for the extension level and began to use behaviours at this level following introduction of II. Once again it is noted that these three levels where behaviours emerged are the top three levels of social and communicative engagement in the scale (Table 4). Means for baseline and intervention phases show either increases or decreases for all levels except the highest level extension for Kathy and Megan. The smallest change was for Kathy at the withdrawal level and Megan at the responding level. These changes across nearly all levels and for all three participants also suggests II did influence the social and communicative levels of engagement. 


\section{Limitations}

This conclusion should be interpreted with caution, however, due to several limitations. First, the study involved only three participants and thus may have limited generality to other students. Second, the study did not measure the effect of II on negative and repetitive behaviours. This is a limitation as negative and repetitive behaviours have already been the focus of research into the effects of II. However, along with Nind and Kellett (2002a), changes in adaptive behaviour were not part of the original research but were noted during the research. Thus the researcher will be able to re-examine the data from this thesis in a further study. This was not done as the researcher was answering the research question on II's influence on social and communicative levels of engagement and thus baseline data was not gathered about negative and repetitive behaviours.

The study was also conducted over a short period of time, with the longest period of intervention being eight weeks for Kathy. This differs from the majority of research on II which has been conducted over 40 weeks to 18 months (p.30). This is explained in part because of practicalities and the intensity of the research which was carried out several times per week with 37 data points collected for Kathy, 25 data points collected for Megan and 16 data points for Bronwyn.

This research does not have a follow up phase so that how the participants' responded to II after a period of not using it was not examined. This was largely due to the time constraints of a master's thesis and because participant ill health and absences meant that the baseline and intervention phases were run over a longer period than were initially intended. There is 
no data presented here for generalisation and so the research does not examine whether increasing levels of social and communicative engagement were also occurring in other situations. Some data was recorded for this over the course of the study and has the potential to be analysed at a later date.

This research did not use staff members at the unit to carry out the baseline and intervention phases with the participants. This is a limitation because it would be the staff of a special unit who would be most likely to be carrying out II within students' programmes. However for this study, having the researcher carry out the baseline and intervention phases allowed for more control over procedural integrity. The research did involve the key staff members for each participant in completing the assessments, and in doing the videotaping of each session. Informal feedback was sought from the staff members but this was not done formally because it was discussed as appropriate for a master's thesis to use only one method for data gathering.

This study used a graduated scale of social-communicative levels of engagement rather than specific behaviours. This was because the participants in the study already used a number of specific behaviours such as eye contact for Kathy, moving away for Megan, and giving behaviour for Bronwyn. It was felt that a graduated scale would capture better the idea of increased engagement. However, use of a scale does not provide results that are as readily accessible as specific behaviours increasing or decreasing and this is a limitation. In future both a scale and specific behaviours could both be used as target behaviours.

As discussed there were also some differences between the three participants as shown by the age equivalents for the Vineland II (Sparrow, et 
al., 2005) and for adaptive communication skills with different levels of sociability and use and responding to alternate and augmentative communication forms (Table 3). This research would have been stronger if all participants had had similar levels of social and communication skills.

The sessions were conducted in the regular environment for the participants' programme. It is possible that the participants could have had different results if the research had been conducted in a withdrawal space at the unit. This would have controlled for distractions within the classroom. However, the intervention was intended to be used in the regular environment. This also meant the special unit did not have to contend with juggling staff numbers present for the group. While the staff member was focused on videotaping the sessions, they were still able to respond to any adverse situations that might arise during this time.

\section{Applications}

In spite of these limitations, the results from this current study suggest that II could be a useful addition to approaches used by staff for students with PMLD. This could include staff working directly with students in a day to day setting, as well as staff who provide advice and guidance to school staff on ways to enhance social and communication skills for students. Although the baseline and intervention phases were carried out by the researcher, staff informally reported being interested in using the intervention with the students. Two of the three participants had features of ASD which includes this group of students as potential recipients of this approach. Because this research was conducted in a special unit attached to a regular school, it supports the usage of II within a specialised setting. 
The research was conducted in the students' regular learning environment within the unit rather than in a withdrawal space which supports the use of II being done with students alongside different programmes and approaches for other students. Given the nature of the special classroom, and the needs of other staff and students, the use of II alongside what else was happening did not appear to detract in any way from other staff and students delivering and accessing other programmes. This suggests that staff would be able to carry out II as part of any student's program within their everyday environment as opposed to a programme that requires a quiet withdrawal space.

II uses no special equipment or technology, the only items used by the practitioner being items similar to those that students favour. This makes II a relatively cost free intervention. The cost of the intervention is in the oneon-one time required. However, for students with PMLD, their programme is often delivered in large chunks of one-on-one time and therefore it differs little from the way other parts of the programme are delivered.

In order for staff members to carry out II, they would need to be trained to use the intervention. Thus a cost that would be associated with the intervention would be staff training. Training would need to cover how to use II, plus include looking at a means to record progress for the students, and also encourage staff use of reflection to develop ongoing competency (Barber, 2005, 2007a, 2007b).

This research supports the idea that II could be a useful strategy when dealing with students' negative and repetitive behaviours, but does not provide any evidence towards this. As found in this research, changes in 
negative and repetitive activities might be a by-product of using II. However, the arguments put forward by Hogg (2002) and Goldbart (2002) as discussed in Chapter 1 would need to be addressed when considering future research.

\section{Future Research Directions}

While II appeared to be effective for increasing social and communicative engagement of the three participants, it is unclear if other intervention approaches would have been equally or more effective. It would thus be useful to compare II to the other naturalistic and behavioural approaches reviewed in Chapter 1. One study, (Howlin, Gordon, Pasco, Wade, \& Charman, 2006) looked at the use of PECS with autistic children, and found that while the use of requesting specific objects increased, there was no increase in other communicative behaviours. Looking at the use of II compared to interventions introducing symbolic systems would also be useful. Research could attempt to identify what specific behaviours II might influence particularly in light of the inverse relationship that appeared to be operating between the different levels (Table 4) for this study. Research could also be conducted using II in combination with other procedures or where II preceded or followed other procedures.

Another area for future research would be to examine the effects of II on repetitive and negative behaviours. Current research looking at the effectiveness of II on changing repetitive and negative behaviours has produced mixed and inconclusive results (Elgie \& Maguire, 2001; Jones \& Williams, 1998; Lovell, et al., 1998; Nind \& Kellet, 2002a). This would be done using experimental design. It would be useful also to contrast the use 
of II with other interventions for these behaviours. Research could distinguish between those behaviours that caused any harm and those that did not.

Research on II would be useful conducted in early childhood, with those children under five years old. In the field of ASD, the importance of early intervention has been stressed (Ministries of Health and Education, 2008) and it would be useful to measure the effects of early intervention involving II on young children. This research looked specifically at the influence of II on students' social and communicative behaviours, who had PMLD. Research that looked at its effectiveness with different populations of this group such as ASD and Rhett syndrome would be appropriate. It could also be useful to identify whether II was appropriate with students with different levels of ability.

II is made up of several different components or strategies. An area to examine would be to identify which of the strategies are most successful in influencing students' behaviour. Some research, as discussed in Chapter 1, has already been conducted focusing on imitation as a component of II or of imitation as an intervention approach (Field, et al., 2001; Hart, 2006; Heinmann, et al., 2006; O'Neill \& Zeedyk, 2006; Zeedyk, 2006). It could be that not all components of II are necessary and research could identify these.

Future research could also focus on use of II in the inclusive setting. As discussed, only one study in the literature review looked at a student in an inclusive setting (Kellet, 2004). Research on II has been carried out by researchers and staff in educational and adult settings (Table 2). Research 
has also looked at practitioners' experiences of using II (Culham, 2004; Firth, Elford, Leeming, \& Crabbe, 2008; Nind, 2000). Future research could compare the effects of II when carried out by trained staff and support staff. Only one study was located which looked at II being carried out by peers in an educational setting (Whittaker, 2004) and this was with children who had ASD and were mostly verbal. This research showed variable progress for the participants with ASD, but did show that the peers undertaking the intervention viewed their involvement positively. One study did discuss a parent using II at home because of special circumstances (Kellet, 2005). Given that II is an intervention that might be used by families (Moor, 2008) it would be important to research the effectiveness of II when carried out by families and on families' experiences in using the approach. 


\section{REFERENCES}

Anderson, C. (2006). Early communication strategies: Using video analysis to support teachers working with preverbal pupils. British Journal of Special Education, 33(3), 114-120.

Arthur-Kelly, M., Bochner, S., Center, Y., \& Mok, M. (2007). Socio-communicative perspectives on research and evidence-based practise in the education of students with profound and multiple disabilities. Journal of Developmental and Physical Disabilities, 19, 161-176.

Arthur-Kelly, M., Foreman, P., Bennet, D., \& Pascoe, S. (2008). Interaction, inclusion and students with profound and multiple disabilities: Towards an agenda for research and practice. Journal of Child Reseach in Special Education Needs, 8(3), 161-166.

Bailey, J. S. (1981). Wanted: A rational search for the limiting conditions in the retarded. Analysis and intervention in developmental disabilities, 1, 45-52.

Barber, M. (2005). Intensive interaction: Some practical considerations.

Barber, M. (2007a). Creating cultures of intensive interaction in australian schools. Agosci in focus, 1-7

Barber, M. (2007b). Imitation, interaction and dialogue using intensive interaction: Tea party rules. Support for Learning, 22(3), 124-130.

Barber, M. (2007c). Intensive interaction; Staying in the grey.

Barber, M. (2008). Using intensive interaction to add to the palette of interactive possibilities in teacher-pupil communication. European Journal of Special Needs Education, 23(4), 393-402.

Batshaw, M. L., Pellegrino, L., \& Roizen, N. J., (Eds) (2007). Children with disabilities (6th ed.). Baltimore: Paul H Brookes Publishing Co.

Byers, R. (1999). Experience and achievement: Initiatives in curriculum development for pupils with severe and profound and multiple learning difficulties. British Journal of Special Education, 26(4), 184-188.

Caldwell, P. (1997). Getting in touch with people with severe learning disabilities. British Journal of Nursing, 6(13), 751-756.

Caldwell, P. (2006). Speaking the other's language: Imitation as a gateway to relationship. Infant and Child Development, 15, 275-282.

Cameron, L., \& Bell, D. (2001). Enhanced interaction training. Working with people who have a Learning Disability, 18(3), 8-15.

Carr, E. G., Levin, L., McConnachie, G., Carlson, J. I., Kemp, D. C., \& Smith, C. E. (1994). Communication-based intervention for problem behavior: A user's guide for producing positive change. Baltimore: Paul H Brookes Publishing.

Central Regional Special Schools Administration Cluster (2005). Curriculum exemplars for teachers of students with special needs. Pathways within level 1: written language. Palmerston North: Central Regional Special Schools Administration Cluster.

Central Regional Special Schools Administration Cluster (2008). Curriculum exemplars for teachers of students with diverse learning needs. Pathways within level 1: number and algebra. Palmerston North: Central Regional Special Schools Administration Cluster. 
Cohen, S. (1998). Targeting Autism: What we know, don't know and can do to help young children with autism and related developmental disorders. Berkeley: University of California Press.

Cornish, K., \& Bramble, D. (2002). Cri du chat syndrome: genotype-phenotype correlations and recommendations for clinical management. Developmental Medicine and Neurology, 44(7), 494-497.

Cowan, R. J., \& Allen, K. D. (2007). Using naturalistic procedures to enhance learning in individuals with autism: A focus on generalized teaching within the school setting. Psychology in Schools, 44(7), 701- 715.

Crabbe, M., \& Firth, G. (2007). The Intensive Interaction research project....... and beyond. Royal College Speech Language Therapy Bulletin, August, 12-13.

Culham, A. (2004). Getting in touch with our feminine side? men's difficulties and concerns with doing intensive interaction. British Journal of Special Education, 31(2), 81-88.

Davies, F. (2008). Phoebe Caldwell with Jane Horwood: From isolation to intimacy: Making friends without words. Journal of Intellectual Disability Research, 52(3), 269.

Downing, J. E. (2004). Educating children with multiple disabilities. In F. P. Orelove, D. Sobsey \& R. K. Silberman (Eds.). Baltimore: Paul H Brookes Publishing Co.

Downing, J. E. (2005). Teaching communication skills to students with severe disabilities. Baltimore: Paul Brookes.

Drasgow, E., Halle, J., Ostrosky, M. M., \& Harbers, H. M. (1996). Using behavioral indication and functional communication training to establish an initial sign repertoire with a young child with severe disabilities. Topics in Early Childhood Special Education, 16(4), 500-512.

Duncan, D., Matson, J. L., Bamburg, J. W., Cherry, K. E., \& Buckley, T. (1999). The relationship of self-injurious behaviour and aggression to social skills in persons with severe and profound learning disability. Research in Developmental Disabilities, 20(6), 441-448.

Durand, V. M. (1999). Functional communication training using assistive devices: Recruiting natural communities of reinforcement. Journal of Applied Behavior Analysis, 32(3), 247-267.

Elgie, S., \& Maguire, N. (2001). Intensive interaction with a woman with multiple and profound disabilities: A case study. Tizard learning Disability Review, 6(3), 18-24.

Ephrain, G. (1989). Idiosyncratic behaviour and how to encourage it. Talking Sense, Summer, 14-15.

Escalona, A., Field, T., Nadel, J., \& Lundy, B. (2002). Brief report: Imitation effects on children with autism. Journal of Autism and Developmental Disorders, 32(2), 141-144.

Field, T., Field, T., Sanders, C., \& Nadel, J. (2001). Children with autism display more social behaviours after repeated imitation sessions. Autism, 5(3), 317-323.

Firth, G. (2006). Intensive interaction: A research review. Mental Health and Learning Disabilities Research and Practice, 3(1), 53-63.

Firth, G. (2007 ). A Framework for Recognising Attainment in Intensive Interaction (pp. 1-4). Leeds: Leeds Partnership NHS Trust. 
Firth, G. (2008). A dual aspect process model of intensive interaction. British Journal of Learning Difficulties, 37, 43-49.

Firth, G., Berry, R., \& Irvine, C. (2010). Understanding intensive interaction. London: Jessica Kingsley Publishers.

Firth, G., Elford, H., Leeming, C., \& Crabbe, M. (2008). Intensive interaction as a novel approach in social care: Care staff's views on the practice change process. Journal of Applied Research in Intellectual Disabilities, 21, 58-69.

Firth, G., Sampson, A., Leeming, C., Clark, N., Egerton, K., Tangri, K., et al. (2009). Intensive Interaction: The published research summaries document.

Forster, S., \& Iacono, T. (2008). Disability support workers' experience of interaction with a person with profound intellectual disability. Journal of Intellectual and Developmental Disability, 33(2), 137-147.

Gardner, A., \& Rikberg -Smyly, S. (1997). How do we stop doing and start listening: responding to the emotional needs of people with learning disabilities. British Journal of Learning Difficulties, 25, 26-30.

Glasby, A.-M. (2007). Phoebe Caldwell with Jane Horwood: From isolation to intimacy: Making friends without words

. Learning Disability Practice, 10(11), 25.

Goldbart, J. (2002). Commnetary on: Melanie Nind and Mary Kellet (2002). 'Responding to individuals with severe learning difficulties and stereotyped behaviour: Challenges for an inclusive era'. European Journal of Special Needs Education, 17(3), 283-287.

Granlund, M., \& Olsson, C. (1999). Efficacy of communication intervention for presymbolic communicators. AAC Augmentative and Alternative Communication, 15, 25-37.

Green, M. G., \& Luce, S. (1996). Behavioral Intervention for Young Children with Autism. Austin, TX: Pro-Ed.

Greenspan, S., \& Wieder, S. (1998). The Child with Special Needs: Encouraging Intellectual and Emotional Growth. Cambridge, Mass.: Addison-Wesley.

Grove, N. (1994). Nind and Hewett: Access to communication: Developing the basics of communication with people with severe learning difficulties through intensive interaction. European Journal of Special Needs Education, 9(3), 308-309.

Halle, J., Brady, N. C., \& Drasgow, E. (2004). Enhancing socially adaptve communicative repairs of beginning communicators with disabilities. American Journal of Speech-Language Pathology, 13(1), 43-54.

Harding, C., \& Berry, R. (2009). Intensive interaction as a psychological therapy. The Psychologist, 22(9), 758-759.

Hart, P. (2006). Using imitation with congenitally deaf blind adults: Establishing meaningful communication partnerships. Infant and Child Development, 15(3), 263-274.

Heinmann, M., Laberg, K. E., \& Nordoen, B. (2006). Imitative interaction increases social interest and elicited imitation in non-verbal children with autism. Infant and Child Development, 15(3), 297-309.

Hewett, D. (2007). Do touch: Physical contact and people who have severe, profound and multiple difficulties. Support for Learning, 22(3), 116-123.

Hewett, D., \& Nind, M. (2003). Severe learning difficulties: Intensive Interaction. Five to Eleven, 2(10), 30-33. 
Hogg, J. (2002). Commentary on: Nind and Kellet (2002). European Journal of Special Needs Education, 17(3), 293-297.

Howlin, P., Gordon, R. K., Pasco, G., Wade, A., \& Charman, T. (2006). The effectiveness of the Picture Exchabge Communication System (PECS) training for teachers of children with autism: a group randomised controlled study. Journal of Child Psychology and Psychiatry, 48(5), 473481.

Ingersoll, B. (2008). The social role of imitation in autism. Infants \& Young Children, 21(2), 107-119.

Jeffries, L. (2009). Introducing intensive interaction. The Psychologist, 22(9), 756-758.

Johnson, B., \& Christensen, L. (2008). Education Research: Quantitative, Qualitative, and Mixed Approaches (3rd ed.). Los Angeles, London, New Delhi, Singapore: Sage Publications.

Jones, R. S. P., \& Williams, H. (1998). Reducing stereotyped behaviour: An experiemental analysis of intensive interaction. International Journal of Practical Approaches to Disability, 22(2/3), 21-25.

Kellet, M. (2000). Sam's story: Evaluating intensive interaction in terms of its effect on the social and communicative ability of a young child with severe learning difficulties Support for Learning, 15(4), 165-171.

Kellet, M. (2003). Jacob's journey: Developing sociability and communication in a young boy with severe and complex learning difficulties using the intensive interaction teaching approach. Journal of Research in Special Education Needs, 3(1), 1-8.

Kellet, M. (2004). Intensive interaction in the inclusive classroom: Using interactive pedagogy to connect with students who are hardest to reach. Westminster Studies in Education, 27(2), 175-188.

Kellet, M. (2005). Catherine's legacy: social communication development for individuals with profound learning difficulties and fragile life expectancies. British Journal of Special Education, 32(3), 116-121.

Kellet, M., \& Nind, M. (2001). Ethics in quasi-experomental research on people with severe learning disabilities: Dilemmas and compromises. British Journal of Learning Difficulties, 29(2), 51-55.

Kennedy, A. (2001). Intensive interaction. Learning Disability Practice, 4, 14-17.

Kennedy, C. H. (2005). Single case designs for educational research. Boston: Allyn and Bacon.

Kimhi, Y. (2010). M. Suzanne Zeedyk (ed.): Promoting social interaction for individuals with communicative impairments: Making contact. Journal of Autism and Developmental Disorders, 40(3), 394-395.

Kishida, Y., \& Kemp, C. (2006). A measure of engagement for children with intellectual disabilities in early childhood settings: A preliminary scale. Journal of Intellectual and Developmental Disability, 31(2), 101-114.

Leaning, B., \& Watson, T. (2006). From the inside looking out-an intensive interaction group for people with profound and multiple learning disabilities. British Journal of Learning Difficulties, 34(2), 103-109.

Learning Disability Practice (2006). The use of intensive interaction and postural care in care provision. Learning Disability Practice, 9(7), 32.

Learning Disability Practice (2008). Evaluating intensive interaction. Learning Disability Practice, 11(9), 25. 
Lovell, D. M., Jones, R. S. P., \& Ephrain, G. (1998). The effect of intensive interaction on the sociability of a man with severe intellectual disabilities. International Journal of Practical Approaches to Disability, 22(2/3), 3-9.

Lynch, S. A., \& Adams, P. (2008). Developing standards-based individualised education program objectives for students with significant needs. Teaching Exceptional Children, 40(3), 36-39.

Matson, J. L., Cooper, C., Malone, C. J., \& Moskow, S. L. (2008). The relationship of self-injurious behaviour and other maladaptive behaviours among individuals with severe and profound intellectual disability. Research in Developmental Disabilities, 29, 141-148.

Meyer, L. H., \& Evans, I. M. (2006). Literature review on intervention with challenging behaviour in children and youth with developmental disabilities. Wellington: Victoria University of Wellington.

Ministries of Health and Education (2008). NZ autistic spectrum disorder guidelines. Wellington: Ministry of Health.

Ministry of Education (1999). Individual education programme (IEP) guidelines.

Ministry of Education (2007). Years and curriculum levels, from nzcurriculum.tki.org.nz/Curriculum-documents

Ministry of Education (2010). National data base : ORRS. Wellington.

Ministry of Education (2011). Ongoing and reviewable resourcing schemme orrs Retrieved 16.5.11, from www.minedu.govt.nz/NZEducationPolicies/SpecialEducation/For msAndGuidelines/ORSGuidelines/The Ongoing Resourcing Scheme.asp $\underline{\mathrm{x}}$

Moor, J. (2008). Playing, laughing and learning with children on the autistic spectrum (2nd ed.). London: Jessica Kingsley.

Nind, M. (1996). Efficacy of intensive interaction: Developing sociability and communication in people with severe and complex learning difficulties using an approach based on caregiver-infant interaction. European Journal of Special Needs Education, 11(1), 48-66.

Nind, M. (1999). Intensive interaction and autism: A useful approach? British Journal of Special Education, 26(2), 96-102.

Nind, M. (2000). Teachers' understanding of intensive interaction approaches in special education. International Journal of Disability, Development and Education, 47(2), 183-199.

Nind, M. (2002). Early childhood education and special needs education: Some neglected common ground. Westminster Studies in Education, 25(1), 7790.

Nind, M. (2003). Enhancing the communication learning environment of an early years unit through action research. Educational Action Research, 11(3), 347-363.

Nind, M. (2005). Phoebe Caldwell with Pene Stevens: Creative conversations with people with profound learning disabilities. British Journal of Learning Difficulties, 33(4), 205-207.

Nind, M. (2006). Conducting systematic reveiw in education: A reflexive narrative. London Review of Education, 4(2), 183-195.

Nind, M. (2007). Supporting lifelong learning for people with profound and multiple learning difficulties. Support for Learning, 22(3), 111-115. 
Nind, M., \& Cochrane, S. (2002). Inclusive curricula? Pupils on the margins of special schools. International Journal of Inclusive Education, 6(2), 185198.

Nind, M., \& Hewett, D. (1988). Interaction as curriculum. British Journal of Special Education, 15(2), 55-57.

Nind, M., \& Hewett, D. (2001). A practical guide to intensive interaction. Worcestershire: BILD publications.

Nind, M., \& Hewett, D. (2005). Access to communication: developing the basics of communication with people with severe learning difficulties through intensive interaction (2nd ed.). London: David Fulton Publishers Ltd.

Nind, M., \& Kellet, M. (2002a). Responding to individuals with severe learning difficulties and stereotyped behaviour: Challenges for an inclusive era. European Journal of Special Needs Education, 17(3), 265-282.

Nind, M., \& Kellet, M. (2002b). Response by Melanie Nind and Mary Kellet. European Journal of Special Needs Education, 17(3), 299-300.

Nind, M., Kellet, M., \& Hopkins, V. (2001). Teachers' talk styles: Communicating with learners with severe and complex learning difficulties. Child Language Teaching and Therapy, 17(2), 143-159.

Nind, M., \& Powell, S. (2000). Intensive interaction and autism: Some theoretical concerns. Children and Society, 14, 98-109.

Nind, M., \& Thomas, G. (2005). Reinstating the value of teachers' tacit knowledge for the benefit of learners: Using 'intensive interaction'. Journal of Research in Special Education Needs, 5(3), 97-100.

O'Neill, M. B., \& Zeedyk, M. S. (2006). Spontaneous imitation in the social interactions of young people with developmental delay and their adult carers. Infant and Child Development, 15(3), 283-295.

Odom, S. L., Boyd, B. A., Hall, L. J., \& Hume, K. (2010). Evaluation of comprehensive treatment models for individuals with autism spectrum disorder. Journal of Autism and Developmental Disorders, 40, 425-436.

Osterling, J., Dawson, G., \& McPartland, J. (2001) Handbook of clinical child psychology (3rd ed., pp. 432-452). New York: John Wiley \& Sons.

Parr, S. (1997). Melanie Nind and Dave Hewett: Access to communication. Developing the basics of communication with people with severe learning difficulties through intensive interaction. Disability and Society, 2(1), 151-153.

Petry, K., \& Maes, B. (2006). Identifying expressions of pleasure and displeasure by persons with profound and multiple disabilities. Journal of Intellectual and Developmental Disability, 31(1), 28-38.

Poppes, P., van der Putten, A. J. J., \& Vlaskamp, C. (2010). Frequency and severity of challenging behavior in people with profound and multiple disabilities. Research in Developmental Disabilities, 31, 1269-1275.

Porter, J., Ouvry, C., Morgan, M., \& Downs, C. (2001). Interpreting the communication of people with profound and multiple learning difficulties. British Journal of Learning Disabilities, 29, 12-16.

Potter, C., \& Whittaker, C. (2001). Enabling communication in children with autism. London: Jessica Kingsley.

Profound and multiple learning disabilities network $(2009,12 / 09)$. Who has profound and multiple learning disabilities?, from www.pmldnetwork.org.uk 
Quill, K. A. (2000). Do-watch-listen-say: Social and communication intervention for children with autism. Baltimore: Paul Brookes.

Richard, G. J. (2000). The source for treatment methodologies in Autism. East Moline II: Lingui Systems.

Samuel, J. (2001a). Intensive interaction. Clinical Psychology Forum, 148, 22-25.

Samuel, J. (2001b). Intensive interaction in context. Tizard learning Disability Review, 6(3), 25-30.

Samuel, J., Nind, M., Volans, A., \& Scriven, I. (2008). An evaluation of intensive interaction in community living settings for adults with profound intellectual disabilities Journal of Intellectual Disabilities, 12, 111-126.

Schopler, E. (2001). Treatment for Autism: From Science to Pseudo-Science or Anti-Science. In E. Schopler, N. Yirmiya, C. Shulman \& L. Marcus (Eds.), The Research Basis for Autism Intervention. New York: Kluwer Academic/Plenum Publishers

Sellers, T., \& Higbee, T. S. (2010). Julia Moor: Playing, laughing and learning with children on the autism spectrum: A practical resource of play ideas for parents and carers (second edition)

.Journal of Autism and Developmental Disorders, 40(4), 520-521.

Sheehy, K., \& Nind, M. (2005). Emotional well-being for all: Mental health and people with profound and multiple learning disabilities. British Journal of Learning Difficulties, 33(1), 34-38.

Sigafoos, J. (2000). Communication development and aberrant behaviour in children with developmental disabilities. Education and Training in Developmental Disabilities, 35(2), 168-176.

Sigafoos, J., Arthur-Kelly, M., \& Butterfield, N. (2006). Enhancing everyday communication for children with disabilities. Baltimore: Brookes.

Smith, T., Klevstrand, M., \& Lovaas, O. I. (1995). Behavioral treatment of Rett's disorder: Ineffectiveness in three cases. American Journal of Mental Retardation, 100(3), 317-322.

Sparrow, S. S., Cicchetti, D. V., \& Balla, D. A. (2005). Vineland II: Vineland adaptive behavior scales: Survey interveiw form manual (2nd ed.). Minneapolis, MN: Pearson Assessments.

Tadema, A. C., \& Vlascamp, C. (2009). The time and effort in taking care for children with profound intellectual and multiple disabilities: A study on care and local support. British Journal of Learning Difficulties, 38, 41-48.

Thurman, S., Jones, J., \& Tarleton, B. (2005). Without words-meaningful information for people with high individual communication needs. British Journal of Learning Difficulties, 33(2), 83-89.

Towbin, K. E., Mauk, J. E., \& Batshaw, M. L. (2002 ). Pervasive developmental disorders. In M. L. Batshaw (Ed.), Children with disabilities: A medical primer (3rd ed., pp. 365-387). Sydney: MacLennan and Petty.

Von Tetzchner (1997). Communication skills among females with rett syndrome. European Child and Adolescent Psychiatry, 6, 33-37.

Vorhaus, J. (2006). Respecting profoundly disabled learners. Journal of Philosophy of Education, 40(3), 314-328.

Wagner, S. (1999). Inclusive programming for elementary students with autism. Arlington, Texas: Future Horizons.

Walter, C. (2008). Intensive intearction with autistic children. Relational Child and Youth Care practice, 21(2), 60-70. 
Ware, J. (2004). Ascertaining the views of people with profound and multiple learning disabilities. British Journal of Learning Difficulties, 32, 175-179.

Warren, S. F., Fey, M. E., Finestack, L. H., Brady, N. C., Bredin-Oja, S. L., \& Fleming, K. K. (2008). A randomized trial of longitudinal effects of low-intensity responsivity education/prelinguistic miieu teaching. Journal of Speech, Language and Hearing Research, 51(2), 451-470.

Watson, J., \& Fisher, A. (1997). Evaluating the effectiveness of intensive interaction teaching with pupils with profound and complex learning difficulties. British Journal of Special Education, 24(2), 80-87.

Watson, J., \& Knight, C. (1991). An evaluation of intensive interactive teaching with pupils with very severe learning difficulties. Child Language Teaching and Therapy, 7(3), 310-325.

Whittaker, C. (2004). Fostering communication and shared play between mainstream peers and children with autism: Approaches, outcomes and experiences. British Journal of Special Education, 31(4), 215-222.

Woodyatt, G., Marinac, J., Darnell, R., Sigafoos, J., \& Halle, J. (2010). Behaviour state analysis in rett syndrome: Continuous data reliability measurement. International Journal of Disability, Development and Education, 51(4), 383-400.

Yoder, P. J., \& Warren, S. F. (1994). Facilitating prelinguistic communication in young children with developmental delay II: Systematic replication and extension. Journal of Speech and Hearing Research, 37(4), 841-860.

Zeedyk, M. S. (2006). From intersubjectivity to subjectivity: The transformative roles of emotional intimacy and imitation. Infant and Child Development, 15(3), 321-344.

Zeedyk, M. S., Caldwell, P., \& Davies, C. E. (2009). How rapidly does intensive interaction promote social engagement for adults with profound learning disabilities? European Journal of Special Needs Education, 24(2), 119-137.

Zeedyk, M. S., Davies, C. E., Parry, S., \& Caldwell, P. (2009). Fostering social engagement in romanian children with communicative impairments: The experiences of newly trained practioners of intensive interaction. British Journal of Learning Difficulties, 37(3), 186-196. 


\section{APPENDIX 1}

INTER-RATER AGREEMENT- SYSTEMATIC LITERATURE REVIEW MARCH 2011

\begin{tabular}{|c|c|c|c|c|c|}
\hline No. & $\begin{array}{l}\text { Study- electronic } \\
\text { search \& database }\end{array}$ & Researcher & IOA & Outcome & $\begin{array}{l}\text { Reason for } \\
\text { Excl }\end{array}$ \\
\hline 1 & $\begin{array}{l}\text { (Jeffries, 2009) } \\
\text { Scopus }\end{array}$ & Excl & Excl & Excl & Commentary \\
\hline 2 & $\begin{array}{l}\text { (Firth, et al., 2008) } \\
\text { Scopus }\end{array}$ & Excl & Excl & Excl & Qualitative \\
\hline 3 & $\begin{array}{l}\text { (Kellet, 2005) } \\
\text { Scopus }\end{array}$ & Incl & Incl & Incl & \\
\hline 4 & $\begin{array}{l}\text { (Hewett, 2007) } \\
\text { Psychlnfo }\end{array}$ & Excl & Excl & Excl & Discussion \\
\hline 5 & $\begin{array}{l}\text { (Kellet \& Nind, } \\
\text { 2001)PsychInfo }\end{array}$ & Excl & Excl & $\mathrm{ExCl}$ & Discussion \\
\hline 6 & $\begin{array}{l}\text { (Culham, 2004) } \\
\text { ERIC }\end{array}$ & Excl & Excl & Excl & Qualitative \\
\hline 7 & $\begin{array}{l}\text { (Sellers \& Higbee, } \\
\text { 2010)ProQuest }\end{array}$ & Excl & Excl & Excl & Book review \\
\hline 8 & $\begin{array}{l}\text { (Kimhi, 2010) } \\
\text { ProQuest }\end{array}$ & Excl & Excl & Excl & Book review \\
\hline 9 & $\begin{array}{l}\text { (Firth, 2008) } \\
\text { ASP }\end{array}$ & Excl & Excl & Excl & Discussion \\
\hline 10 & $\begin{array}{l}\text { (Barber, 2008) } \\
\text { ASP }\end{array}$ & Incl & Incl & Incl & \\
\hline 11 & $\begin{array}{l}\text { (Learning Disability } \\
\text { Practice, 2008) ASP }\end{array}$ & Excl & Excl & Excl & Book review \\
\hline 12 & $\begin{array}{l}\text { (Walter, 2008) } \\
\text { ASP }\end{array}$ & Excl & Excl & Excl & Qualitative \\
\hline 13 & $\begin{array}{l}\text { (Forster \& lacono, } \\
\text { 2008) ASP }\end{array}$ & Excl & Excl & Excl & $\begin{array}{l}\text { Qualitative } \\
\text { Discussion } \\
\end{array}$ \\
\hline 14 & $\begin{array}{l}\text { (Davies, 2008) } \\
\text { ASP }\end{array}$ & Excl & Excl & Excl & Book review \\
\hline 15 & $\begin{array}{l}\text { (Glasby, 2007) } \\
\text { ASP }\end{array}$ & Excl & Excl & Excl & Book review \\
\hline 16 & $\begin{array}{l}\text { (Nind, 2007) } \\
\text { ASP }\end{array}$ & Excl & Excl & Excl & Discussion \\
\hline 17 & $\begin{array}{l}\text { (Anderson, 2006) } \\
\text { ASP }\end{array}$ & Incl & Incl & Incl & \\
\hline 18 & $\begin{array}{l}\text { (Learning Disability } \\
\text { Practice, 2006)ASP }\end{array}$ & Excl & Excl & Excl & $\begin{array}{l}\text { Conference } \\
\text { notification }\end{array}$ \\
\hline 19 & $\begin{array}{l}\text { (Vorhaus, 2006) } \\
\text { ASP }\end{array}$ & Excl & Excl & Excl & Discussion \\
\hline 20 & $\begin{array}{l}\text { (Nind, 2006) } \\
\text { ASP }\end{array}$ & Excl & Excl & Excl & $\begin{array}{l}\text { Discussion } \\
\text { re Lit review }\end{array}$ \\
\hline 21 & $\begin{array}{l}\text { (Leaning \& Watson, } \\
2006 \text { ) } \\
\text { ASP }\end{array}$ & Incl & Incl & Incl & \\
\hline
\end{tabular}




\begin{tabular}{|c|c|c|c|c|c|}
\hline 22 & $\begin{array}{l}\text { (Hart, 2006) } \\
\text { ASP }\end{array}$ & Excl & Excl & Excl & $\begin{array}{l}\text { Imitation } \\
\text { only }\end{array}$ \\
\hline 23 & $\begin{array}{l}\text { (Caldwell, 2006) } \\
\text { ASP }\end{array}$ & Excl & Excl & Excl & Qualitative \\
\hline 24 & $\begin{array}{l}\text { (O'Neill \& Zeedyk, } \\
\text { 2006) ASP }\end{array}$ & Excl & Excl & Excl & $\begin{array}{l}\text { Imitation } \\
\text { only }\end{array}$ \\
\hline No. & $\begin{array}{l}\text { Study- electronic } \\
\text { search \& database }\end{array}$ & Researcher & IOA & Outcome & $\begin{array}{l}\text { Reason for } \\
\text { Excl }\end{array}$ \\
\hline 25 & $\begin{array}{l}\text { (Zeedyk, 2006) } \\
\text { ASP }\end{array}$ & Excl & Excl & Excl & Discussion \\
\hline 26 & $\begin{array}{l}\text { (Nind, 2005) } \\
\text { ASP }\end{array}$ & Excl & Excl & Excl & Book review \\
\hline 27 & $\begin{array}{l}\text { (Thurman, et al., } \\
\text { 2005) ASP }\end{array}$ & Excl & Excl & Excl & Discussion \\
\hline 28 & $\begin{array}{l}\text { (Sheehy \& Nind, } \\
\text { 2005) ASP }\end{array}$ & Excl & Excl & Excl & Discussion \\
\hline 29 & $\begin{array}{l}\text { (Whittaker, 2004) } \\
\text { ASP }\end{array}$ & Excl & Incl & Excl & $\begin{array}{l}\text { Participants } \\
\text { verbal }\end{array}$ \\
\hline 30 & $\begin{array}{l}\text { (Kellet, 2004) } \\
\text { ASP }\end{array}$ & Incl & Incl & Incl & \\
\hline 31 & $\begin{array}{l}\text { (Nind \& Kellet, } \\
\text { 2002a) ASP }\end{array}$ & Incl & Incl & Incl & \\
\hline 32 & $\begin{array}{l}\text { (Goldbart, 2002) } \\
\text { ASP }\end{array}$ & Excl & Excl & Excl & Commentary \\
\hline 33 & $\begin{array}{l}\text { (Hogg, 2002) } \\
\text { ASP }\end{array}$ & Excl & Excl & Excl & Commentary \\
\hline 34 & $\begin{array}{l}\text { (Nind \& Kellet, } \\
\text { 2002b) ASP }\end{array}$ & Excl & Excl & Excl & Commentary \\
\hline 35 & $\begin{array}{l}\text { (Nind \& Cochrane, } \\
\text { 2002) ASP }\end{array}$ & Excl & Excl & Excl & Qualitative \\
\hline 36 & $\begin{array}{l}\text { (Kellet, 2000) } \\
\text { ASP }\end{array}$ & Incl & Incl & Incl & \\
\hline 37 & $\begin{array}{l}\text { (Zeedyk, Davies, } \\
\text { Parry, \& Caldwell, } \\
\text { 2009) } \\
\text { Multisearch (MS) }\end{array}$ & Excl & Excl & Excl & $\begin{array}{l}\text { Participants } \\
\text { not PMLD }\end{array}$ \\
\hline 38 & $\begin{array}{l}\text { (Harding \& Berry, } \\
\text { 2009) MS }\end{array}$ & Excl & Excl & Excl & Commentary \\
\hline 39 & $\begin{array}{l}\text { (Zeedyk, Caldwell, } \\
\text { et al., 2009) } \\
\text { MS }\end{array}$ & Incl & Incl & Incl & \\
\hline 40 & $\begin{array}{l}\text { (Arthur-Kelly, et al., } \\
\text { 2008) MS }\end{array}$ & Excl & Excl & Excl & Discussion \\
\hline 41 & $\begin{array}{l}\text { (Samuel, et al., } \\
\text { 2008) MS }\end{array}$ & Incl & Incl & Incl & \\
\hline 42 & $\begin{array}{l}\text { (Nind \& Thomas, } \\
\text { 2005) MS }\end{array}$ & Excl & Excl & Excl & Discussion \\
\hline 43 & $\begin{array}{l}\text { (Nind, et al., 2001) } \\
\text { MS }\end{array}$ & Excl & Excl & Excl & Qualitative \\
\hline 44 & $\begin{array}{l}\text { (Nind, 1999) } \\
\text { MS }\end{array}$ & Incl & Incl & Incl & \\
\hline 45 & $\begin{array}{l}\text { (Watson \& Fisher, } \\
\text { 1997) MS }\end{array}$ & Excl & Excl & Excl & Qualitative \\
\hline
\end{tabular}




\begin{tabular}{|c|c|c|c|c|c|}
\hline 46 & $\begin{array}{l}\text { (Parr, 1997) } \\
\text { MS }\end{array}$ & Excl & Excl & Excl & Book review \\
\hline 47 & $\begin{array}{l}\text { (Grove, 1994) } \\
\text { MS }\end{array}$ & Excl & Excl & Excl & Book review \\
\hline No. & Study-hand search & Researcher & IOA & Outcome & $\begin{array}{l}\text { Reason for } \\
\text { Excl }\end{array}$ \\
\hline 1 & $\begin{array}{l}\text { (Elgie \& Maguire, } \\
\text { 2001) }\end{array}$ & Incl & Incl & Incl & \\
\hline 2 & (Lovell, et al., 1998) & Incl & Incl & Incl & \\
\hline 3 & (Nind, 1996) & Incl & Incl & Incl & \\
\hline 4 & $\begin{array}{l}\text { (Watson \& Knight, } \\
\text { 1991) }\end{array}$ & Excl & Excl & Excl & Qualitative \\
\hline 5 & (Kellet, 2004) & Incl & Incl & Incl & \\
\hline 6 & (Nind, 2000) & Excl & Excl & Excl & Qualitative \\
\hline 7 & (Samuel, 2001a) & Excl & Excl & Excl & Discussion \\
\hline 8 & $\begin{array}{l}\text { (Nind \& Hewett, } \\
\text { 1988) }\end{array}$ & Excl & Excl & Excl & Discussion \\
\hline 9 & (Barber, 2007b) & Excl & Excl & Excl & Discussion \\
\hline 10 & $\begin{array}{l}\text { (Cameron \& Bell, } \\
\text { 2001) }\end{array}$ & Excl & Excl & Excl & Qualitative \\
\hline 11 & $\begin{array}{l}\text { (Jones \& Williams, } \\
\text { 1998) }\end{array}$ & Incl & Excl & Incl & \\
\hline 12 & (A. Kennedy, 2001) & & & & Not received \\
\hline 13 & (Nind, 2002) & Excl & Excl & Excl & $\begin{array}{l}\text { Discussion } \\
\text { Re ECE }\end{array}$ \\
\hline 14 & (Ephrain, 1989) & Excl & Excl & Excl & Discussion \\
\hline 15 & (Firth, 2006) & Excl & Excl & Excl & Lit review \\
\hline No. & Study-other search & Researcher & IOA & Outcome & $\begin{array}{l}\text { Reason for } \\
\text { Excl }\end{array}$ \\
\hline 1 & $\begin{array}{l}\text { (Gardner \& Rikberg } \\
\text {-Smyly, 1997) }\end{array}$ & Excl & Excl & Excl & Discussion \\
\hline 2 & $\begin{array}{l}\text { (Hewett \& Nind, } \\
\text { 2003) }\end{array}$ & Excl & Excl & Excl & Discussion \\
\hline 3 & $\begin{array}{l}\text { (Nind \& Powell, } \\
2000 \text { ) }\end{array}$ & Excl & Excl & Excl & Discussion \\
\hline 4 & (Nind, 2003) & Excl & Excl & Excl & Qualitative \\
\hline 5 & (Samuel, 2001b) & Excl & $\mathrm{ExCl}$ & Excl & Discussion \\
\hline 6 & (Caldwell, 1997) & Excl & Excl & Excl & Discussion \\
\hline 7 & $\begin{array}{l}\text { (Crabbe \& Firth, } \\
\text { 2007) }\end{array}$ & Excl & Excl & Excl & Discussion \\
\hline
\end{tabular}


APPENDICES 2-16

INFORMATION LETTERS \& CONSENT FORMS 
The Principal

WELLINGTON

Date

Dear

\section{MEd Project: The Effects of Intensive Interaction on the Engagement of Children with Profound and Multiple Learning Disabilities.}

I am writing with regard to my Masters of Education thesis research project, The Effects of Intensive Interaction on the Engagement of Children with Profound and Multiple Learning Disabilities.

I am looking at how a developmental, person-centred intervention "Intensive Interaction" will work with children with profound and multiple learning disabilities (PMLD). Intensive Interaction is a promising intervention for improving social-communication skills with children with PMLD, but does not have a strong research basis. The research has been assessed and approved by Victoria University Faculty of Education Ethics Committee.

I am seeking your consent to approach staff, students and families within the special unit for their involvement in the project. This research is likely to be carried out over one school term in the special needs unit.

\section{Summary of Research Process}

Phase 1 - Consents and meetings

Once I have your consent I will approach the head teacher and staff at the unit for their consent. I will also be requesting that they identify student participants for my research. I need three students, but I will ask them to identify five possible students to provide flexibility in case some families do not wish to participate. I will be available to discuss this further. The students will need to be

- non-verbal or minimally verbal,

- at a pre-intentional level of communication or with minimal intentional communication, and

- hard to engage; 
When the appropriate participant students have been identified, separate permission from their families are needed. I will provide the head teacher with all letters and consent forms for the families. At a minimum the information for the families will involve an information letter and consent form to be signed. If families wish it, before they give consent, I will talk with them by phone, face to face, or in a meeting.

Because I am video-taping in the general classroom setting to gather my data, I will also seek general permission from all families of students in case some of those students are in the background of any footage. I will ask families to let me know if their daughters are able to give their own written consent alongside parental consent. This will be at the discretion of families and I will not proceed if this is not indicated and consent given.

A specially marked box will be placed within the office in the special unit for all returned consent forms.

I will provide separate information letters and seek consent from staff for their involvement either as key staff members with specific tasks or for general staff involvement including being in the background of any video footage. I will organise a meeting with the head teacher for all staff to discuss these issues, including ground rules and consent.

Phase 2 - Orientation and initial assessment

I will need to spend an initial period getting to know the routines and set up in the unit and also to carry out assessment of the participants using the Vineland II Adaptive Behaviour Scales (Sparrow, Cicchetti \& Balla, 2005) and the Inventory of Potential Communicative Acts (Sigafoos, Arthur-Kelly \& Butterfield, 2006). The assessment would involve me sitting alongside a staff member and completing the assessments about the students. This would take about an hour in total for each student.

Phase 3 - Baseline and intervention phases

Gathering data for the baseline phase will involve five minutes of video footage taken each day for each student for a one to two week period with me alongside the participants and interacting with them. The filming is intended to be done by a staff member. If staff are not available, I will use another person such as a visiting professional, or a post-graduate student.

Following this, gathering data for the Intervention phase will continue for the rest of the term, involving five minutes of video footage taken each school day with me sitting alongside the participants using Intensive Interaction. All participants will begin the baseline phase at the same time but the intervention phases will be staggered sequentially for each participant which is part of the Multiple Baseline design I am using to control for other explanations for the results .

During these phases I will also be conducting some separate videotaping called "probes", simply to check the generalisation of social communication behaviours outside of the baseline and intervention phases and to check my 
own consistency (treatment fidelity) in applying the intervention. These will involve five minutes taping for each and will occur on five or six occasions across the same period as the phases.

During this time I will be analysing the video footage to ascertain each participant's level of engagement. This footage will also be reviewed for $30 \%$ of the time by a colleague to ensure there is inter-observer reliability. The generalisation probes and treatment fidelity probes will also be reviewed.

I will feed back to key staff for each participant once a week and also send a note home in the home school diaries about progress for the participant students.

\section{Use of Video Camera}

There are specific issues that need to be considered when working with children and the use of the video camera. I will be conscious at all times of any child's discomfort in being filmed on any occasion and will pay attention to non-verbal cues. This will be supported by the information gathered from the assessments completed with staff for participant students and from ground rules developed as is discussed below.

Images of Children: I will aim to treat all children with respect in the video portrayal of them at the school. This will include not videoing any child when they are extremely upset. Video footage will be regularly reviewed and any inappropriate footage will be edited out.

As part of the initial consent and meetings phase I will negotiate a set of ground rules to ensure that both students and staff feel safe and comfortable with the video recording process. I will also ask families to provide input into this process. The ground rules will also include ensuring students for whom permission is not given, are not filmed, or if this does happen, then ensuring the footage will be edited out. The ground rules will cover confidentiality within the unit.

The video footage will contain the raw data for the study and will be used by me for data gathering and analysis. It will not be used for any other purpose. Copies will not be able to be passed on to the staff to use for other purposes in the unit (such as use in parent evenings/workshops, with ERO, team analysis of other aspects of practice) as this would breach the ethical approval.

Where a person other than a staff member does the videotaping, that person will have signed a confidentiality agreement.

\section{Confidentiality}

The identity of the school and participating students and staff will remain confidential in the written thesis and any papers that are prepared for presentation and/or publication. Pseudonyms will be used for the staff and school, and students identified by letters only (e.g., Child A, Child B). 
The participants and staff have the right to withdraw from the project up until the completion of the data gathering phase. If an individual staff member or student wishes to withdraw from the project, then they will be able to do so without further discussion.

Please note that you are under no obligation to give consent. Your decision about whether or not you want to participate will not affect your present or future relationship with Victoria University of Wellington (VUW) or for the school. If you decide to participate, you have the right to withdraw your consent at any time and discontinue your school's participation. Your decision to discontinue participation will not affect your present or future relationship with Victoria University of Wellington or for the school.

\section{Ethics}

The ethical application has been approved by the VUW Faculty of Education Human Ethics Committee (Reference Number 17701). If at any time you have any questions or concerns about any child's treatment as a research participant in this study, contact Dr. Allison Kirkman, Chair of the Victoria University of Wellington Human Ethics Committee (telephone: +64 4 463 5676; E-mail: allison.kirkman@vuw.ac.nz).

\section{Data Storage and Deletion}

All paper-based and video data will be stored in a locked filing cabinet in a locked office at the VUW. The electronic data will be kept in a passwordprotected file. As required by copyright, the data will be stored for 5 years after publication and then deleted/wiped/shredded after the 5-year storage period.

\section{Reporting/Dissemination}

The results of this study will be submitted for publication in research and or professional journals and may be presented at conferences. Any such reports will be given to the teacher and you can obtain a copy from me. I will also give the teacher a weekly update on each participant child's progress and provide this information weekly through the home school notebook system. However, if at any time staff or families would like more detailed feedback, I will provide this either in person, or via the telephone, letter, or email.

\section{My role as researcher}

I have been involved with special education in the region now for a number of years, including working previously as a contract speech-language therapist in the special unit at Wellington East. Because this project would involve me working with students, families and staff in a different professional capacity, during the initial visit it will be important to discuss how the students, staff and I will work together as researcher and research participants. I am also letting families know about this previous involvement in my letters to them. My supervisor, Professor Jeff Sigafoos, is also 
available to discuss any issues that the school or prospective participants may have about the research project, either prior to agreeing to participate or during the actual case study period. His contact details are below.

\section{Conclusion}

Thank you for considering my request to approach your school special needs unit for possible involvement in the project. If you have further questions about the project I am very happy to discuss these with you. My contact details are below:

I would appreciate it if you could complete the attached form, indicating whether I have approval to approach participants in the special needs unit in your school. A stamped addressed envelope is included for the return of the form.

Yours sincerely

Heather Drysdale (MEd student)

Phone: (04) 9729641

Email: hdrysdale@paradise.net.nz

School of Educational Psychology and Pedagogy

Faculty of Education

Victoria University of Wellington

PO Box 17-310, Karori

Wellington, NZ

Supervisor

Jeff Sigafoos, Ph.D.

Professor, School of Educational Psychology and Pedagogy

Faculty of Education

Victoria University of Wellington

PO Box 17-310, Karori

Wellington, NZ

Phone: +64 44639772

Email: Jeff.Sigafoos@vuw.ac.nz

Inter-rater Observer

Lynn Peace (retired educational psychologist)

Phone: 0210465869

Email:Iynnpalexd@yahoo.co.nz 


\section{MEd Project: The Effects of Intensive Interaction on the Engagement of Children with Profound and Multiple Learning Disabilities.}

\section{Approval to approach staff and families involved in the special needs} unit

I have been given and have understood an explanation of this research project. I have had an opportunity to ask questions and have them answered to my satisfaction.

I give Heather Drysdale permission to approach staff, students' families, and students where appropriate within the special needs unit at our school in order to invite them to express their interest in participating in this project.

I do not give Heather Drysdale permission to approach staff, students' families and students where appropriate within the special needs unit at our school in order to invite them to express their interest in participating in this project.

Signed:

Principal

Wellington East Girls' College

Austin Street

WELLINGTON

Date: 
The Head Teacher

Special Needs Unit

WELLINGTON

Date

Dear

\section{MEd Project: The Effects of Intensive Interaction on the Engagement of Children with Profound and Multiple Learning Disabilities.}

I am writing in regard to my Masters of Education thesis research project, The Effects of Intensive Interaction on the Engagement of Children with Profound and Multiple Learning Disabilities.

I am looking at how a developmental, person-centred intervention "Intensive Interaction" will work with children with profound and multiple learning disabilities (PMLD). Intensive Interaction is a promising intervention for improving social-communication skills with children with PMLD, but does not have a strong research basis. The research has been assessed and approved by Victoria University Faculty of Education Ethics Committee.

I have received permission from the school principal to approach you and your staff, for their involvement in the project, which is likely to require involvement with the unit for about one school term. I now invite you to participate and give consent for the following:

1. Your consent to allow me to conduct research within the special unit and your own involvement;

2. You and your staff identifying student participants for my research. I need three students, but I will ask you to identify five possible students to provide flexibility in case some families do not wish to participate. I will be available to discuss this further. The students will need to be

- non-verbal or minimally verbal,

- at a pre-intentional level of communication or with minimal intentional communication, and

- hard to engage; 
3. Overseeing the distribution of letters to families and allowing the consent forms to be collected in a specially marked box within the special unit office. This is for both participant student families and for families of all other students who may possibly be in the background of the video footage;

4. Working with me to provide further information to parents if requested. This could be at a special meeting for involved parents at the school;

5. Supporting the consent process for students in the unit who are able to sign a consent form if this is approved by individual families;

6. Supporting and being part of a staff meeting where I will talk with staff about the project, my role and staff roles, and ground rules for videotaping. I am also happy to do this before staff give consent in order to answer any questions about the research;

7. Consent for any images of you to be in the background of the video footage; and

8. Allowing release time for staff directly involved in the project. These staff members will be the key staff involved with each student and this could be up to three staff. They would be involved in the initial socialcommunication assessment (approximately 1 hour per student), the video-taping of daily sessions, and received feedback from me regarding progress each week.

\section{Summary of Research Process}

Phase 1 - Consents and meetings

When the appropriate participant students have been identified, separate permission from their families are needed. I will provide you with all letters and consent forms for the families. At a minimum the information for the families will involve an information letter and consent form to be signed. If families wish it, at any stage in this process, I will talk with them by phone, face to face, or in a meeting as for 4 above.

Because I am video-taping in the general classroom setting to gather my data, I will also seek general permission from all families of students in case some of those students are in the background of any footage. I will ask families to let me know if their daughters are able to give their own written consent alongside parental consent. This will be at the discretion of families and I will not proceed if this is not indicated and consent given. I will also provide you with all these letters and consent forms.

I will provide separate information letters and seek consent from staff for their involvement either as key staff members with specific tasks or for general staff involvement including being in the background of any video footage. I will organise a meeting with you for all staff to discuss these issues, including ground rules and consent. 
Phase 2 - Orientation and initial assessment

I will need to spend an initial period getting to know the routines and set up in the unit and also to carry out assessment of the participants using the Vineland II Adaptive Behaviour Scales (Sparrow, Cicchetti \& Balla, 2005) and the Inventory of Potential Communicative Acts (Sigafoos, Arthur-Kelly \& Butterfield, 2006). The assessment would involve me sitting alongside a staff member and completing the assessments about the students. This would take about an hour in total for each student.

Phase 3 - Baseline and intervention phases

Gathering data for the baseline phase will involve five minutes of video footage taken each day for each student for a one to two week period with me alongside the participants and interacting with them. The filming is intended to be done by a staff member. If staff are not available, I will use another person such as a visiting professional, or a post-graduate student.

Following this, gathering data for the Intervention phase will continue for the rest of the term, involving five minutes of video footage taken each school day with me sitting alongside the participants using Intensive Interaction. All participants will begin the baseline phase at the same time but the intervention phases will be staggered sequentially for each participant which is part of the Multiple Baseline design I am using to control for other explanations for the results.

During these phases I will also be conducting some separate videotaping called "probes", simply to check the generalisation of social communication behaviours outside of the baseline and intervention phases and to check my own consistency (treatment fidelity) in applying the intervention. These will involve five minutes taping and will occur on five or six occasions across the same period as the phases.

During this time I will be analysing the video footage to ascertain each participant's level of engagement. This footage will also be reviewed for $30 \%$ of the time by a colleague to ensure there is inter-observer reliability. The generalisation probes and treatment fidelity probes will also be reviewed.

I will feed back to key staff for each participant once a week and also send a note home in the home school diaries about progress for the participant students.

\section{Use of Video Camera}

There are specific issues that need to be considered when working with children and the use of the video camera. I will be conscious at all times of any child's discomfort in being filmed on any occasion and will pay attention to non-verbal cues. This will be supported by the information gathered from the assessments completed with staff and from ground rules developed as is discussed below.

Images of Children: I will aim to treat all children with respect in the video portrayal of them at the school. This will include not videoing any child when 
they are extremely upset. Video footage will be regularly reviewed by me and any inappropriate footage will be edited out.

As part of the initial consent and meetings phase I will negotiate a set of ground rules to ensure that both students and staff feel safe and comfortable with the video recording process. I will also ask families to provide input into this process. The ground rules will also include ensuring students for whom permission is not given, are not filmed, or if this does happen, then ensuring the footage will be edited out. The ground rules will cover confidentiality within the unit.

The video footage will contain the raw data for the study and will be used by me for data gathering and analysis. It will not be used for any other purpose. Copies will not be able to be passed on to the staff to use for other purposes in the unit (such as use in parent evenings/workshops, with ERO, team analysis of other aspects of practice) as this would breach the ethical approval.

Where the videotaping is done by a person other than a staff member, that person will have signed a confidentiality agreement.

\section{Confidentiality}

The identity of the school and participating students and staff will remain confidential in the written thesis and any papers that are prepared for presentation and/or publication. Pseudonyms will be used for the staff and school, and students identified by letters only (e.g., Child A, Child B).

The participants and staff have the right to withdraw from the project up until the completion of the data gathering phase. If an individual staff member or student wishes to withdraw from the project, then they will be able to do so without further discussion.

Please note that you are under no obligation to give consent. Your decision about whether or not you want to participate will not affect your present or future relationship with Victoria University of Wellington (VUW) or for your school. If you decide to participate, you have the right to withdraw your consent at any time and discontinue your school's participation. Your decision to discontinue participation will not affect your present or future relationship with Victoria University of Wellington or for your school.

\section{Ethics}

The ethical application has been approved by the VUW Faculty of Education Human Ethics Committee (Reference Number 17701). If at any time you have any questions or concerns about your treatment or your child's treatment as a research participant in this study, contact Dr. Allison Kirkman, Chair of the Victoria University of Wellington Human Ethics Committee (telephone: +64 4463 5676; E-mail: allison.kirkman@vuw.ac.nz). 


\section{Data Storage and Deletion}

All paper-based and video data will be stored in a locked filing cabinet in a locked office at the VUW. The electronic data will be kept in a passwordprotected file. As required by copyright, the data will be stored for 5 years after publication and then deleted/wiped/shredded after the 5-year storage period.

\section{Reporting/Dissemination}

The results of this study will be submitted for publication in research and or professional journals and may be presented at a conference. Any such reports will be given to you as head teacher and others can obtain a copy from me. I will also give the teacher a weekly update on each child's progress and provide this information weekly through the home school notebook system. However, if at any time you would like more detailed feedback, I would be more than happy to provide this either in person, or via the telephone, letter, or email.

\section{My role as researcher}

I have been involved with special education in the region now for a number of years, including working previously as a contract speech-language therapist in the special unit at Wellington East. Because this project would involve me working with students, families and staff in a different professional capacity, during the initial visit it will be important to discuss how the students, staff and I will work together as researcher and research participants. My supervisor, Professor Jeff Sigafoos, is also available to discuss any issues that the school or prospective participants may have about the research project, either prior to agreeing to participate or during the actual case study period. His contact details are below.

\section{Conclusion}

Thank you for considering possible involvement in the project. If you have further questions about the project I am very happy to discuss these with you. My contact details are below:

I would appreciate it if you could complete the attached form, indicating whether you agree or not to participate in the research project. A stamped addressed envelope is included for the return of the form.

Yours sincerely 
Heather Drysdale (MEd student)

Phone: (04) 9729641

Email: hdrysdale@paradise.net.nz

School of Educational Psychology and Pedagogy

Faculty of Education

Victoria University of Wellington

PO Box 17-310, Karori

Wellington, NZ

Supervisor

Professor Jeff Sigafoos

School of Educational Psychology and Pedagogy

Faculty of Education

Victoria University of Wellington

PO Box 17-310, Karori

Wellington, NZ

Phone: +64 44639772

Email: Jeff. Sigafoos@vuw.ac.nz

Inter-rater observer

Lynn Peace (retired educational psychologist)

Phone: 0210465869

Email: Iynnpalexd@yahoo.co.nz 


\section{CONSENT FORM FOR HEAD TEACHER \\ Project Title: The Effects of Intensive Interaction on the Engagement of Children with Profound and Multiple Learning Disabilities.}

This research has been assessed and approved by Victoria University of Wellington Faculty of Education Ethics Committee (Reference No. 17701).

Please tick the boxes to indicate your agreement with the statements and to provide informed consent for participation in this project.

I have been given and have understood an explanation of this research project. I have had an opportunity to ask questions and have them answered to my satisfaction.

I understand that I may withdraw myself (or any information I have provided) from this project (before data collection is complete) without having to give reasons or without penalty of any sort.

$\square$

I understand that the data collected will be kept confidential to the researcher and her supervisor, and colleague who will be doing the inter-rater reliability. Any IT technicians who provide technical assistance with the editing of video tapes gathered for this project will be asked to sign confidentiality agreements. Any other person such as a professional working in the unit or a post-graduate student who is part of video-taping will also be asked to sign a confidentiality agreement.

As head teacher, I understand that I will be supporting the research in a number of ways, including disseminating letters and consent forms, providing a collection point for consent forms, identifying potential participants, being part of meetings with staff and families, supporting students to complete a consent form if requested, and providing release time for any staff who are key workers for the participants.

I understand that the published results will not use my name or the name of the school, or include descriptions that in any way identify me or the school.

I understand that I may be videotaped in the background during the data collection.

understand that the video recordings will be electronically wiped within five years of the publication of the data.

I understand that the data will not be used for any other purpose than outlined or released to others without written consent.

I agree to take part in this research.

I do not agree to take part in this research.

Signed:

Date: 
Name of Staff Member (please print clearly)

Name

of

School:

I would like to be sent a copy of any reports arising from this study. If you tick this box, we will give a copy of any reports arising from this study to you. I include my contact details where they can be sent

Name

Address

Please return this Consent Form

In the specially marked box within the unit office. Thank you. 
TEACHER INFORMATION LETTER

\section{Project Title: The Effects of Intensive Interaction on the Engagement of Children with Profound and Multiple Learning Disabilities.}

Date

Dear teaching staff, Kia ora

I am writing with regard to my Masters of Education thesis research project, The Effects of Intensive Interaction on the Engagement of Children with Profound and Multiple Learning Disabilities.

I am looking at how a developmental, person-centred intervention "Intensive Interaction" will work with children with profound and multiple learning disabilities (PMLD). Intensive Interaction is a promising intervention for improving social-communication skills with children with PMLD, but does not have a strong research basis. The research has been assessed and approved by Victoria University Faculty of Education Ethics Committee.

I have received permission from the school principal to approach you for your involvement in the project, which is likely to require involvement with the unit for about one school term. I now invite you to participate and give consent for the following:

All staff

9. Your general consent to participate in the research

10. Your input alongside the head teacher identifying student participants for my research. I need three students, but I will ask you to identify five possible students to provide flexibility in case some families do not wish to participate. I will be available to discuss this further. The students will need to be

- non-verbal or minimally verbal,

- at a pre-intentional level of communication or with minimal intentional communication, and

- hard to engage;

11. Being part of a staff meeting where I will talk with you about the project, my role and staff roles, and ground rules for video-taping. I am also happy to do this before you give consent in order to answer any questions about the research; and 
12. Consent for any images of you to be in the background of the video footage.

Specific staff

Each of the three participating students will have a key staff member identified who will have specific involvement. This involves

1. Being part of an assessment for each student as outlined in phase 2 of the process. This involves sitting with me to go over two assessment for around one hour of time;

2. Being available to video-tape my working with each student which will be about five minutes daily for each student over the term as outlined in Phase 3; and

3. Being available to receive feedback on a weekly basis about each students progress during Phase 3.

\section{Summary of Research Process}

Phase 1 - Consents and meetings

When the appropriate participant students have been identified, separate permission from their families are needed. I will provide the head teacher with all letters and consent forms for the families. At a minimum the information for the families will involve an information letter and consent form to be signed. If families wish it, at any stage in this process, I will talk with them by phone, face to face, or in a meeting as.

Because I am video-taping in the general classroom setting to gather my data, I will also seek general permission from all families of students in case some of those students are in the background of any footage. Where appropriate, I will seek consent from the students themselves if they are able to read and understand. I will also provide the head teacher with all these letters and consent forms.

I will provide separate information letters and seek consent from staff for their involvement either as key staff members with specific tasks or for general staff involvement including being in the background of any video footage. I will organise a meeting with the head teacher for all staff to discuss these issues, including ground rules and consent.

Phase 2 - Orientation and initial assessment

I will need to spend an initial period getting to know the routines and set up in the unit and also to carry out assessment of the participants using the Vineland II Adaptive Behaviour Scales (Sparrow, Cicchetti \& Balla, 2005) and the Inventory of Potential Communicative Acts (Sigafoos, Arthur-Kelly \& Butterfield, 2006). The assessment would involve me sitting alongside a staff member and completing the assessments about the students. This would take about an hour in total for each student. 
Phase 3 - Baseline and intervention phases

Gathering data for the baseline phase will involve five minutes of video footage taken each day for each student for a one to two week period with me alongside the participants and interacting with them. The filming is intended to be done by a staff member. If staff are not available, I will use another person such as a visiting professional, or a post-graduate student.

Following this, gathering data for the Intervention phase will continue for the rest of the term, involving five minutes of video footage taken each school day with me sitting alongside the participants using Intensive Interaction. All participants will begin the baseline phase at the same time but the intervention phases will be staggered sequentially for each participant which is part of the Multiple Baseline design I am using to control for rival explanations for the results.

During these phases I will also be conducting some separate videotaping called "probes", simply to check the generalisation of social communication behaviours outside of the baseline and intervention phases and to check my own consistency (treatment fidelity) in applying the intervention. These will involve five minutes taping and will occur on five or six occasions across the same period as the phases.

During this time I will be analysing the video footage to ascertain each participant's level of engagement. This footage will also be reviewed for $30 \%$ of the time by a colleague to ensure there is inter-observer reliability. The generalisation probes and treatment fidelity probes will also be reviewed.

I will feed back to key staff for each participant once a week and also send a note home in the home school diaries about progress for the participants.

\section{Use of Video Camera}

There are specific issues that need to be considered when working with children and the use of the video camera. I will be conscious at all times of any child's discomfort in being filmed on any occasion and will pay attention to non-verbal cues. This will be supported by the information gathered from the assessments completed with staff and from ground rules developed as is discussed below.

Images of Children: I will aim to treat all children with respect in the video portrayal of them at the school. This will include not videoing any child when they are extremely upset. Video footage will be regularly reviewed and any inappropriate footage will be edited out.

As part of the initial consent and meetings phase I will negotiate a set of ground rules to ensure that both students and staff feel safe and comfortable with the video recording process. I will also ask families of participants to provide input into this process. The ground rules will also include ensuring students for whom permission is not given, are not filmed, or if this does 
happen, then ensuring the footage will be edited out. The ground rules will cover confidentiality within the unit.

The video footage will contain the raw data for the study and will be used by me for data gathering and analysis. It will not be used for any other purpose. Copies will not be able to be passed on to the staff to use for other purposes in the unit (such as use in parent evenings/workshops, with ERO, team analysis of other aspects of practice) as this would breach the ethical approval.

Where a person other than a staff member does the videotaping, that person will have signed a confidentiality agreement.

\section{Confidentiality}

The identity of the school and participating students and staff will remain confidential in the written thesis and any papers that are prepared for presentation and/or publication. Pseudonyms will be used for the staff and school, and students identified by letters only (e.g., Child A, Child B).

The participants and staff have the right to withdraw from the project up until the completion of the data gathering phase. If an individual staff member or student wishes to withdraw from the project, then they will be able to do so without further discussion.

Please note that you are under no obligation to give consent. Your decision about whether or not you want to participate will not affect your present or future relationship with Victoria University of Wellington (VUW) or for your school. If you decide to participate, you have the right to withdraw your consent at any time and discontinue your participation. Your decision to discontinue participation will not affect your present or future relationship with Victoria University of Wellington or with your school.

\section{Ethics}

The ethical application has been approved by the VUW Faculty of Education Human Ethics Committee (Reference Number 17701). If at any time you have any questions or concerns about your treatment or any child's treatment as a research participant in this study, contact Dr. Allison Kirkman, Chair of the Victoria University of Wellington Human Ethics Committee (telephone: +64 4463 5676; E-mail: allison.kirkman@vuw.ac.nz).

\section{Data Storage and Deletion}

All paper-based and video data will be stored in a locked filing cabinet in a locked office at the VUW. The electronic data will be kept in a passwordprotected file. As required by copyright, the data will be stored for 5 years after publication and then deleted/wiped/shredded after the 5-year storage period.

\section{Reporting/Dissemination}


The results of this study will be submitted for publication in research and or professional journals and may be presented at conferences. Any such reports will be given to the head teacher and you can obtain a copy from me. I will also give the key staff members a weekly update on each child's progress and provide this information weekly through the home school notebook system. However, if at any time you would like more detailed feedback, I would be more than happy to provide this either in person, or via the telephone, letter, or email.

\section{My role as researcher}

I have been involved with special education in the region now for a number of years, including working previously as a contract speech-language therapist in the special unit at Wellington East. Because this project would involve me working with students, families and staff in a different professional capacity, during the initial visit it will be important to discuss how the students, staff and I will work together as researcher and research participants. My supervisor, Professor Jeff Sigafoos, is also available to discuss any issues that the school or prospective participants may have about the research project, either prior to agreeing to participate or during the actual case study period. His contact details are below.

\section{Conclusion}

Thank you for considering possible involvement in the project. If you have further questions about the project I am very happy to discuss these with you. My contact details are below:

I would appreciate it if you could complete the attached form, indicating whether you agree or not to participate in the research project. A specially marked box will be placed in the office of the special unit and forms should be paced there.

Sincerely,

Heather Drysdale, MEd. Student

School of Educational Psychology and Pedagogy

Faculty of Education

Victoria University of Wellington

PO Box 17-310, Karori

Wellington, NZ

Phone: 0210344966

Email: hdrysdale@paradise.net.nz

Supervisor

Jeff Sigafoos. PhD

Professor, School of Educational Psychology and Pedagogy 
Faculty of Education

Victoria University of Wellington

PO Box 17-310, Karori

Wellington, NZ

Phone: +64 44639772

Email: Jeff.Sigafoos@vuw.ac.nz

Inter-rater observer

Lynn peace (retired educational psychologist)

Phone: 0210465869

Email: Iynnpalexd@yahoo.co.nz 


\section{CONSENT FORM FOR TEACHING STAFF \\ Project Title: The Effects of Intensive Interaction on the Engagement of Children with Profound and Multiple Learning Disabilities.}

This research has been assessed and approved by Victoria University of Wellington Faculty of Education Ethics Committee (Reference No. 17701).

Please tick the boxes to indicate your agreement with the statements and to provide informed consent for participation in this project.

I have been given and have understood an explanation of this research project. I have had an opportunity to ask questions and have them answered to my satisfaction.

I understand that I may withdraw myself (or any information I have provided) from this project (before data collection is complete) without having to give reasons or without penalty of any sort.

I understand that the data collected will be kept confidential to the researcher and her supervisor, and colleague who will be doing the inter-rater reliability. Any IT technicians who provide technical assistance with the editing of video tapes gathered for this project will be asked to sign confidentiality agreements. Any other person such as a professional working in the unit or a post-graduate student who is part of video-taping will also be asked to sign a confidentiality agreement.

$\square$

If I am a key staff member for one or more of the students, I understand that I will take part in the initial assessment for participants, may do videotaping of the intervention and baseline phases, and will receive weekly feedback about progress.

I understand that the published results will not use my name or the name of the school, or include descriptions that in any way identify me or the school.

I understand that I may be videotaped in the background during the data collection.

understand that the video recordings will be electronically wiped within five years of the publication of the data.

I understand that the data will not be used for any other purpose other than stated or released to others without written consent.

I agree to take part in this research.

I do not agree to take part in this research.

Signed:

Date:

Name of Staff Member (please print clearly) 
I would like to be sent a copy of any reports arising from this study. If you tick this box, we will give a copy of any reports arising from this study to you. I include my contact details where they can be sent

Name

Address

Please return this Consent Form

In the specially marked box within the unit office. Thank you. 


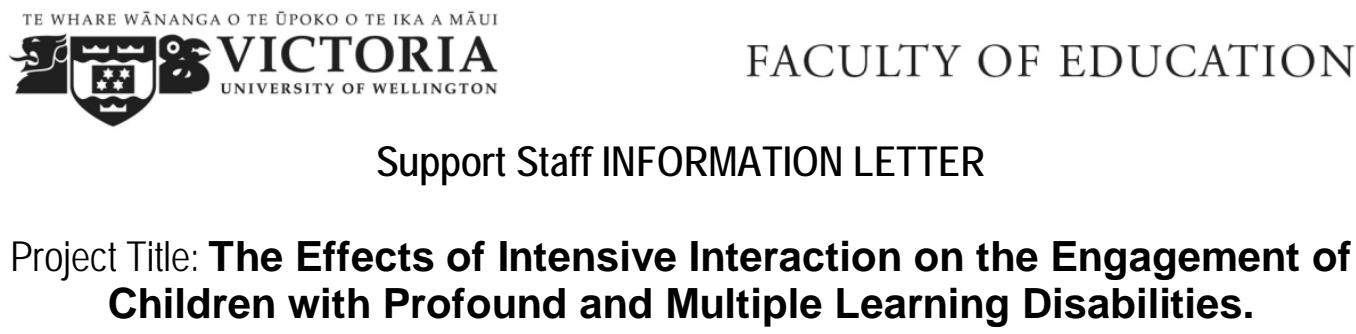

Date

Dear support staff, Kia ora

I am writing with regard to my Masters of Education thesis research project, The Effects of Intensive Interaction on the Engagement of Children with Profound and Multiple Learning Disabilities.

I am looking at how a developmental, person-centred intervention "Intensive Interaction" will work with children with profound and multiple learning disabilities (PMLD). Intensive Interaction is a promising intervention for improving social-communication skills with children with PMLD, but does not have a strong research basis. The research has been assessed and approved by Victoria University Faculty of Education Ethics Committee.

I have received permission from the school principal to approach you for your involvement in the project, which is likely to require involvement with the unit for about one school term. I now invite you to participate and give consent for the following:

All staff

13. Your general consent to participate in the research

14. Your input alongside the head teacher identifying student participants for my research. I need three students, but I will ask you to identify five possible students to provide flexibility in case some families do not wish to participate. I will be available to discuss this further. The students will need to be

- non-verbal or minimally verbal,

- at a pre-intentional level of communication or with minimal intentional communication, and

- hard to engage;

15. Being part of a staff meeting where I will talk with you about the project, my role and staff roles, and ground rules for video-taping. I am also happy to do this before you give consent in order to answer any questions about the research; and 
16. Consent for any images of you to be in the background of the video footage.

Specific staff

Each of the three participating students will have a key staff member identified who will have specific involvement. This involves

4. Being part of an assessment for each student as outlined in phase 2 of the process. This involves sitting with me to go over two assessment for around one hour of time;

5. Being available to video-tape my working with each student which will be about five minutes daily for each student over the term as outlined in Phase 3; and

6. Being available to receive feedback on a weekly basis about each students progress during Phase 3.

\section{Summary of Research Process}

Phase 1 - Consents and meetings

When the appropriate participant students have been identified, separate permission from their families are needed. I will provide the head teacher with all letters and consent forms for the families. At a minimum the information for the families will involve an information letter and consent form to be signed. If families wish it, at any stage in this process, I will talk with them by phone, face to face, or in a meeting.

Because I am video-taping in the general classroom setting to gather my data, I will also seek general permission from all families of students in case some of those students are in the background of any footage. Where appropriate, I will seek consent from the students themselves if they are able to read and understand. I will also provide the head teacher with all these letters and consent forms.

I will provide separate information letters and seek consent from staff for their involvement either as key staff members with specific tasks or for general staff involvement including being in the background of any video footage. I will organise a meeting with the head teacher for all staff to discuss these issues, including ground rules and consent.

Phase 2 - Orientation and initial assessment

I will need to spend an initial period getting to know the routines and set up in the unit and also to carry out assessment of the participants using the Vineland II Adaptive Behaviour Scales (Sparrow, Cicchetti \& Balla, 2005) and the Inventory of Potential Communicative Acts (Sigafoos, Arthur-Kelly \& Butterfield, 2006). The assessment would involve me sitting alongside a staff member and completing the assessments about the students. This would take about an hour in total for each student. 
Phase 3 - Baseline and intervention phases

Gathering data for the baseline phase will involve five minutes of video footage taken each day for each student for a one to two week period with me alongside the participants and interacting with them. The filming is intended to be done by a staff member. If staff are not available, I will use another person such as a visiting professional, or a post-graduate student.

Following this, gathering data for the Intervention phase will continue for the rest of the term, involving five minutes of video footage taken each school day with me sitting alongside the participants using Intensive Interaction. All participants will begin the baseline phase at the same time but the intervention phases will be staggered sequentially for each participant which is part of the Multiple Baseline design I am using to control for rival explanations for the results.

During these phases I will also be conducting some separate videotaping called "probes", simply to check the generalisation of social communication behaviours outside of the baseline and intervention phases and to check my own consistency (treatment fidelity) in applying the intervention. These will involve five minutes taping and will occur on five or six occasions across the same period as the phases.

During this time I will be analysing the video footage to ascertain each participant's level of engagement. This footage will also be reviewed for $30 \%$ of the time by a colleague to ensure there is inter-observer reliability. The generalisation probes and treatment fidelity probes will also be reviewed.

I will feed back to key staff for each participant once a week and also send a note home in the home school diaries about progress for the participants.

\section{Use of Video Camera}

There are specific issues that need to be considered when working with children and the use of the video camera. I will be conscious at all times of any child's discomfort in being filmed on any occasion and will pay attention to non-verbal cues. This will be supported by the information gathered from the assessments completed with staff and from ground rules developed as is discussed below.

Images of Children: I will aim to treat all children with respect in the video portrayal of them at the school. This will include not videoing any child when they are extremely upset. Video footage will be regularly reviewed and any inappropriate footage will be edited out.

As part of the initial consent and meetings phase I will negotiate a set of ground rules to ensure that both students and staff feel safe and comfortable with the video recording process. I will also ask families of participants to provide input into this process. The ground rules will also include ensuring students for whom permission is not given, are not filmed, or if this does happen, then ensuring the footage will be edited out. The ground rules will cover confidentiality within the unit. 
The video footage will contain the raw data for the study and will be used by me for data gathering and analysis. It will not be used for any other purpose. Copies will not be able to be passed on to the staff to use for other purposes in the unit (such as use in parent evenings/workshops, with ERO, team analysis of other aspects of practice) as this would breach the ethical approval.

Where a person other than a staff member does the videotaping, that person will have signed a confidentiality agreement.

\section{Confidentiality}

The identity of the school and participating students and staff will remain confidential in the written thesis and any papers that are prepared for presentation and/or publication. Pseudonyms will be used for the staff and school, and students identified by letters only (e.g., Child A, Child B).

The participants and staff have the right to withdraw from the project up until the completion of the data gathering phase. If an individual staff member or student wishes to withdraw from the project, then they will be able to do so without further discussion.

Please note that you are under no obligation to give consent. Your decision about whether or not you want to participate will not affect your present or future relationship with Victoria University of Wellington (VUW) or for your school. If you decide to participate, you have the right to withdraw your consent at any time and discontinue your school's participation. Your decision to discontinue participation will not affect your present or future relationship with Victoria University of Wellington or for your school.

\section{Ethics}

The ethical application has been approved by the VUW Faculty of Education Human Ethics Committee (Reference Number. 17701). If at any time you have any questions or concerns about your treatment or any child's treatment as a research participant in this study, contact Dr. Allison Kirkman, Chair of the Victoria University of Wellington Human Ethics Committee (telephone: +64 4463 5676; E-mail: allison.kirkman@vuw.ac.nz).

\section{Data Storage and Deletion}

All paper-based and video data will be stored in a locked filing cabinet in a locked office at the VUW. The electronic data will be kept in a passwordprotected file. As required by copyright, the data will be stored for 5 years after publication and then deleted/wiped/shredded after the 5-year storage period.

\section{Reporting/Dissemination}


The results of this study will be submitted for publication in research and or professional journals and may be presented at conferences. Any such reports will be given to the head teacher and you can obtain a copy from me. I will also give the key staff members a weekly update on each child's progress and provide this information weekly through the home school notebook system. However, if at any time you would like more detailed feedback, I would be more than happy to provide this either in person, or via the telephone, letter, or email.

\section{My role as researcher}

I have been involved with special education in the region now for a number of years, including working previously as a contract speech-language therapist in the special unit at Wellington East. Because this project would involve me working with students, families and staff in a different professional capacity, during the initial visit it will be important to discuss how the students, staff and I will work together as researcher and research participants. My supervisor, Professor Jeff Sigafoos, is also available to discuss any issues that the school or prospective participants may have about the research project, either prior to agreeing to participate or during the actual case study period. His contact details are below.

\section{Conclusion}

Thank you for considering possible involvement in the project. If you have further questions about the project I am very happy to discuss these with you. My contact details are below:

I would appreciate it if you could complete the attached form, indicating whether you agree or not to participate in the research project. A specially marked box will be placed in the office of the special unit and forms should be paced there.

Sincerely,

Heather Drysdale, MEd. Student

School of Educational Psychology and Pedagogy

Faculty of Education

Victoria University of Wellington

PO Box 17-310, Karori

Wellington, NZ

Phone: 0210344966

Email: hdrysdale@paradise.net.nz

Supervisor 
Jeff Sigafoos. PhD

Professor, School of Educational Psychology and Pedagogy

Faculty of Education

Victoria University of Wellington

PO Box 17-310, Karori

Wellington, NZ

Phone: +64 44639772

Email: Jeff.Sigafoos@vuw.ac.nz

Inter-rater observer

Lynn peace (retired educational psychologist)

Phone: 0210465869

Email: lynnpalexd@yahoo.co.nz 


\section{CONSENT FORM FOR SUPPORT STAFF \\ Project Title: The Effects of Intensive Interaction on the Engagement of Children with Profound and Multiple Learning Disabilities.}

This research has been assessed and approved by Victoria University of Wellington Faculty of Education Ethics Committee (Reference No. 17701).

Please tick the boxes to indicate your agreement with the statements and to provide informed consent for participation in this project.

I have been given and have understood an explanation of this research project. I have had an opportunity to ask questions and have them answered to my satisfaction.

I understand that I may withdraw myself (or any information I have provided) from this project (before data collection is complete) without having to give reasons or without penalty of any sort.

I understand that the data collected will be kept confidential to the researcher and her supervisor, and colleague who will be doing the inter-rater reliability. Any IT technicians who provide technical assistance with the editing of video tapes gathered for this project will be asked to sign confidentiality agreements. Any other person such as a professional working in the unit or a post-graduate student who is part of video-taping will also be asked to sign a confidentiality agreement.

$\square$

If I am a key staff member for one or more of the students, I understand that I will take part in the initial assessment for participants, may do videotaping of the intervention and baseline phases, and will receive weekly feedback about progress.

I understand that the published results will not use my name or the name of the school, or include descriptions that in any way identify me or the school.

I understand that I may be videotaped in the background during the data collection.

understand that the video recordings will be electronically wiped within five years of the publication of the data.

I understand that the data will not be used for any other purpose other than that stated or released to others without written consent.

I agree to take part in this research.

I do not agree to take part in this research.

Signed:

Date:

Name of Staff Member (please print clearly) 
I would like to be sent a copy of any reports arising from this study. If you tick this box, we will give a copy of any reports arising from this study to you. I include my contact details where they can be sent

Name

Address

Please return this Consent Form

In the specially marked box within the unit office. Thank you. 


\section{PARENTIGUARDIAN INFORMATION LETTER - PARTICIPANTS}

\section{MEd Project Title: The Effects of Intensive Interaction on the Engagement of Children with Profound and Multiple Learning Disabilities.}

Date

Dear Parent/Guardian, Kia ora

I am to invite you to allow your daughter to participate in my Masters of Education thesis research study, The Effects of Intensive Interaction on the Engagement of Children with Profound and Multiple Learning Disabilities.

I am looking at how a developmental, person-centred intervention "Intensive Interaction" will work with children with profound and multiple learning disabilities (PMLD). Intensive Interaction is a promising intervention for improving social-communication skills with children with PMLD, but does not have a strong research basis. The research has been assessed and approved by Victoria University Faculty of Education Ethics Committee.

I have received permission from the school principal to approach you for your and your daughter's involvement in the project, which is likely to require involvement with the students, staff and unit for about one school term. The staff at the special unit have recommended your daughter as one of three suitable participants required for my research.

I now seek your formal agreement for the following:

1. Your general consent to allow your daughter to be one of three participants in the research

2. Your consent to allow the videotaping of your daughter for data gathering and analysis during the research. Please read further for particular considerations around the use of video.

3. Your input into the ground rules I will be developing for videotaping in the unit. I will be getting certain information from my initial assessments and from staff input but would welcome your ideas given your special knowledge of your daughter. This can be through a phone call, face to face or by writing out information including using the home-school notebook.

4. Your consent for me to provide weekly feedback to the key staff member for your daughter. I will also be including weekly feedback in the home-school notebook. 


\section{Summary of Research Process}

Phase 1 - Consents and meetings

During this phase as well as seeking consent from you, I will also be seeking general consent from all families with daughters at the unit because of the likelihood that their daughters could be in the background of the video footage. I will also be seeking consent from all staff, including key staff, one of whom will be the key staff member identified for your daughter. I will be working particularly with the head teacher to ensure the smooth running of this phase. She will be sending home the information letters and consent forms. A specially marked box will be placed in the unit office for the return of all consent forms.

If you would like to speak to me or meet me face to face before you sign the consent or at any stage during the research, please contact me. A meeting can be arranged with all participant children if this is desired.

\section{Phase 2 - Orientation and initial assessment}

I will need to spend an initial period getting to know the routines and set up in the unit and also to carry out assessment of the participants using the Vineland II Adaptive Behaviour Scales (Sparrow, Cicchetti \& Balla, 2005) and the Inventory of Potential Communicative Acts (Sigafoos, Arthur-Kelly \& Butterfield, 2006). The assessment would involve me sitting alongside a staff member and completing the assessments about the students. This would take about an hour in total for each student.

Phase 3 - Baseline and intervention phases

Gathering data for the baseline phase will involve five minutes of video footage taken each day for each student for a one to two week period with me alongside the participants and interacting with them. The filming is intended to be done by a staff member. If staff are not available, I will use another person such as a visiting professional, or a post-graduate student.

Following this, gathering data for the Intervention phase will continue for the rest of the term, involving five minutes of video footage taken each school day with me sitting alongside the participants using Intensive Interaction.

All participants will begin the baseline phase at the same time but the intervention phases will be staggered sequentially for each participant which is part of the Multiple Baseline design I am using to control for rival explanations for the results.

During these phases I will also be conducting some separate videotaping called "probes", simply to check the generalisation of social communication behaviours outside of the baseline and intervention phases and to check my own consistency (treatment fidelity) in applying the intervention. These will involve five minutes taping and will occur on five or six occasions across the same period as the phases.

During this time I will be analysing the video footage to ascertain each participant's level of engagement. This footage will also be reviewed for $30 \%$ 
of the time by a colleague to ensure there is inter-observer reliability. The generalisation probes and treatment fidelity probes will also be reviewed.

I will feed back to key staff for each participant once a week and also send a note home in the home school diaries about progress for the participant students.

\section{Use of Video Camera}

There are specific issues that need to be considered when working with children and the use of the video camera. I will be conscious at all times of any child's discomfort in being filmed on any occasion and will pay attention to non-verbal cues. This will be supported by the information gathered from the assessments completed with staff and from ground rules developed as is discussed below.

Images of Children: I will aim to treat all children with respect in the video portrayal of them at the school. This will include not videoing any child when they are extremely upset. Video footage will be regularly reviewed and any inappropriate footage will be edited out.

As part of the initial consent and meetings phase I will negotiate a set of ground rules to ensure that both students and staff feel safe and comfortable with the video recording process. I will also ask families to provide input into this process. The ground rules will also include ensuring students for whom permission is not given, are not filmed, or if this does happen, then ensuring the footage will be edited out. The ground rules will cover confidentiality within the unit.

The video footage will contain the raw data for the study and will be used by me for data gathering and analysis. It will not be used for any other purpose. Copies will not be able to be passed on to the staff to use for other purposes in the unit (such as use in parent evenings/workshops, with ERO, team analysis of other aspects of practice) as this would breach the ethical approval.

Where a person other than a staff member does the videotaping, that person will have signed a confidentiality agreement.

\section{Confidentiality}

The identity of the school and participating students and staff will remain confidential in the written thesis and any papers that are prepared for presentation and/or publication. Pseudonyms will be used for the staff and school, and students identified by letters only (e.g., Child A, Child B).

The participants and staff have the right to withdraw from the project up until the completion of the data gathering phase. If an individual staff member or student wishes to withdraw from the project, then they will be able to do so without further discussion. 
Please note that you are under no obligation to give consent. Your decision about whether or not you want to participate will not affect your or your child's school's present or future relationship with Victoria University of Wellington (VUW). If you decide to participate, you have the right to withdraw your consent at any time and discontinue your child's participation. Your decision to discontinue participation will not affect your present or future relationship with Victoria University of Wellington or for your school.

\section{Ethics}

The ethical application has been approved by the VUW Faculty of Education Human Ethics Committee (Reference Number. 17701). If at any time you have any questions or concerns about your treatment or any child's treatment as a research participant in this study, contact Dr. Allison Kirkman, Chair of the Victoria University of Wellington Human Ethics Committee (telephone: +64 4463 5676; E-mail: allison.kirkman@vuw.ac.nz).

\section{Data Storage and Deletion}

All paper-based and video data will be stored in a locked filing cabinet in a locked office at the VUW. The electronic data will be kept in a passwordprotected file. As required by copyright, the data will be stored for 5 years after publication and then deleted/wiped/shredded after the 5-year storage period.

\section{Reporting/Dissemination}

The results of this study will be submitted for publication in research and or professional journals and may be presented at conferences. Any such reports will be given to the head teacher and you can obtain a copy from me. I will also give the key staff members a weekly update on each child's progress and provide this information weekly through the home school notebook system. However, if at any time you would like more detailed feedback, I would be more than happy to provide this either in person, or via the telephone, letter, or email.

\section{My role as researcher}

I have been involved with special education in the region now for a number of years, including working previously as a contract speech-language therapist in the special unit at Wellington East. Because this project would involve me working with students, families and staff in a different professional capacity, during the initial visit it will be important to discuss how the students, staff and I will work together as researcher and research participants. My supervisor, Professor Jeff Sigafoos, is also available to discuss any issues that the school or prospective participants may have about the research project, either prior to agreeing to participate or during the actual case study period. His contact details are below.

\section{Conclusion}


Thank you for considering you and your daughter's possible involvement in the project. If you have further questions about the project I am very happy to discuss these with you. My contact details are below:

I would appreciate it if you could complete the attached form, indicating whether you agree or not to participate in the research project. A specially marked box will be placed in the office of the special unit and forms should be paced there.

Sincerely,

Heather Drysdale - MEd. Student

Phone: 0210344966

Email: hdrysdale@paradise.net.nz

School of Educational Psychology and Pedagogy

Faculty of Education

Victoria University of Wellington

PO Box 17-310, Karori

Wellington, NZ

Supervisor

Jeff Sigafoos, Ph.D.

Professor, School of Educational Psychology and Pedagogy

Faculty of Education

Victoria University of Wellington

PO Box 17-310, Karori

Wellington, NZ

Phone: +64 44639772

Email: Jeff.Sigafoos@vuw.ac.nz

Inter-rater observer

Lynn Peace (retired educational psychologist)

Phone: 0210465689

Email:Iynnpalexd@yahoo.co.nz 


\section{CONSENT FORM FOR PARENTS/GUARDIANS (Participants)}

\section{Project Title: The Effects of Intensive Interaction on the Engagement of Children with Profound and Multiple Learning Disabilities.}

This research has been assessed and approved by Victoria University of Wellington Faculty of Education Ethics Committee (Reference No. 17701).

\section{Please tick the boxes to indicate your agreement with the statements and to provide informed consent for participation in this project.}

I have been given and have understood an explanation of this research project. I have had an opportunity to ask questions and have them answered to my satisfaction.

I understand that my child will be one of three participants in the research and that this will involve assessment as well as data collection and analysis using video footage.

I understand that I may withdraw permission for my child to be included in the research and video-recordings (before data collection is complete) without having to give reasons or without penalty of any sort.

understand that the data collected will be kept confidential to the researcher, her supervisor, and colleague who will be doing the inter-rater reliability. Any IT technicians who provide technical assistance with the editing of video tapes gathered for this project will be asked to sign a confidentiality agreement. Any other person such as a professional working in the unit or a post-graduate student who is part of video-taping will also be asked to sign a confidentiality agreement.

I understand that the published results will not use my name, my child's name or the name of the school, or include descriptions that in any way identify my child, the school or myself.

I understand that the video recording will be electronically wiped within five years of the publication of the research.

I understand that I will receive weekly feedback through the home school notebook on my child's progress and that I can request additional feedback at any time.

I understand that weekly fee back will be given to my child's key staff member.

I agree that (print name please), who is under my guardianship, may participate and be video-recorded as part of this research.

I do not agree that (print name please), who is under my guardianship, may participate and be video-recorded as part of this research. 
Name of Parent/Guardian print clearly)

Name of Child: _ Name of School:

I would like to be sent a copy of any reports arising from this study. If you tick this box, I will give a copy of any reports arising from this study to you. Please include contact details where they can be sent

Name

Address

Please return this Consent Form to your child's teacher 


\section{PARENTIGUARDIAN INFORMATION LETTER - CLASSMATES}

\section{Project Title: The Effects of Intensive Interaction on the Engagement of Children with Profound and Multiple Learning Disabilities.}

Date

\section{Dear Parent/Guardian, Kia ora}

I am writing with regard to my Masters of Education thesis research study, The Effects of Intensive Interaction on the Engagement of Children with Profound and Multiple Learning Disabilities.

I am looking at how a developmental, person-centred intervention "Intensive Interaction" will work with children with profound and multiple learning disabilities (PMLD). Intensive Interaction is a promising intervention for improving social-communication skills with children with PMLD, but does not have a strong research basis. The research has been assessed and approved by Victoria University Faculty of Education Ethics Committee.

My research involves three participant students (already identified) from the special unit and I will be videotaping during the different phases of the research over one school term within the unit.

While your daughter is not one of the participant students, I am requesting your consent

1. To be able to continue videotaping if your daughter is in the background of the footage.

2. If you feel your daughter can also give written consent alongside your parental consent for this, I have a simplified consent form that can be used. I have included a copy for you to read. This could be done with you at home or completed at school with the cooperation of the head teacher. This is at your discretion.

The school principal has already given me permission to approach, families, students and staff involved with the special unit.

If you do not give consent for this, I will initially try and ensure your daughter is not filmed in the background and if this does happen then footage of her will be edited out

\section{Summary of Research Process}

Phase 1 - Consents and meetings 
During this phase I am seeking consent from the families of the three participant students, all families, students where applicable and all staff. I will be working particularly with the head teacher to ensure the smooth running of this phase. She will be sending home the information letters and consent forms. A specially marked box will be placed in the unit office for the return of all consent forms.

Please contact me, If you would like to speak to me or meet me face to face before you sign the consent or at any stage.

Phase 2 - Orientation and initial assessment

I will need to spend an initial period getting to know the routines and set up in the unit and also to carry out assessment of the participants using the Vineland II Adaptive Behaviour Scales (Sparrow, Cicchetti \& Balla, 2005) and the Inventory of Potential Communicative Acts (Sigafoos, Arthur-Kelly \& Butterfield, 2006). The assessment would involve me sitting alongside a staff member and completing the assessments about the students. This would take about an hour in total for each student.

Phase 3 - Baseline and intervention phases

Gathering data for the baseline phase will involve five minutes of video footage taken each day for each of the three participants for a one to two week period with me alongside the participants and interacting with them. The filming is intended to be done by a staff member. If staff are not available, I will use another person such as a visiting professional, or a postgraduate student.

Following this, gathering data for the Intervention phase will continue for the rest of the term, involving five minutes of video footage taken each school day with me sitting alongside the participants using Intensive Interaction. All participants will begin the baseline phase at the same time but the intervention phases will be staggered sequentially for each participant which is part of the Multiple Baseline design I am using to control for other explanations for the results.

During these phases I will also be conducting some separate videotaping called "probes", simply to check the generalisation of social communication behaviours outside of the baseline and intervention phases and to check my own consistency (treatment fidelity) in applying the intervention. These will involve five minutes taping and will occur on five or six occasions across the same period as the phases.

During this time I will be analysing the video footage to ascertain each participant's level of engagement. This footage will also be reviewed for $30 \%$ of the time by a colleague to ensure there is inter-observer reliability. The generalisation probes and treatment fidelity probes will also be reviewed.

I will feed back to key staff for each participant once a week and also send a note home in the home school diaries about progress for the participant students. 


\section{Use of Video Camera}

There are specific issues that need to be considered when working with children and the use of the video camera. I will be conscious at all times of any child's discomfort in being filmed on any occasion and will pay attention to non-verbal cues. This will be supported by the information gathered from the assessments completed with staff and from ground rules developed as is discussed below.

Images of Children: I will aim to treat all children with respect in the video portrayal of them at the school. This will include not videoing any child when they are extremely upset. Video footage will be regularly reviewed and any inappropriate footage will be edited out.

As part of the initial consent and meetings phase I will negotiate a set of ground rules to ensure that both students and staff feel safe and comfortable with the video recording process. I will also ask families of participant students to provide input into this process. The ground rules will also include ensuring students for whom permission is not given, are not filmed, or if this does happen, then ensuring the footage will be edited out. The ground rules will cover confidentiality within the unit.

The video footage will contain the raw data for the study and will be used by me for data gathering and analysis. It will not be used for any other purpose. Copies will not be able to be passed on to the staff to use for other purposes in the unit (such as use in parent evenings/workshops, with ERO, team analysis of other aspects of practice) as this would breach the ethical approval.

Where a person other than a staff member does the videotaping, that person will have signed a confidentiality agreement.

\section{Confidentiality}

The identity of the school and participating students and staff will remain confidential in the written thesis and any papers that are prepared for presentation and/or publication. Pseudonyms will be used for the staff and school, and students identified by letters only (e.g., Child A, Child B).

The participants and staff have the right to withdraw from the project up until the completion of the data gathering phase. If an individual staff member or student wishes to withdraw from the project, then they will be able to do so without further discussion.

Please note that you are under no obligation to give consent. Your decision about whether or not you want to participate will not affect your or your child's school's present or future relationship with Victoria University of Wellington (VUW). If you decide your daughter can be videotaped, you have the right to withdraw your consent at any time and discontinue your child's participation. Your decision to discontinue participation will not affect your 
present or future relationship with Victoria University of Wellington or for your school.

\section{Ethics}

The ethical application has been approved by the VUW Faculty of Education Human Ethics Committee (Reference Number. 17701). If at any time you have any questions or concerns about your treatment or any child's treatment as a research participant in this study, contact Dr. Allison Kirkman, Chair of the Victoria University of Wellington Human Ethics Committee (telephone: +64 4463 5676; E-mail: allison.kirkman@vuw.ac.nz).

\section{Data Storage and Deletion}

All paper-based and video data will be stored in a locked filing cabinet in a locked office at the VUW. The electronic data will be kept in a passwordprotected file. As required by copyright, the data will be stored for 5 years after publication and then deleted/wiped/shredded after the 5-year storage period.

\section{Reporting/Dissemination}

The results of this study will be submitted for publication in research and or professional journals and may be presented at conferences. Any such reports will be given to the head teacher and you can obtain a copy from me. I will also give the key staff members a weekly update on each child's progress and provide this information weekly through the home school notebook system. However, if at any time you would like more detailed feedback, I would be more than happy to provide this either in person, or via the telephone, letter, or email.

\section{My role as researcher}

I have been involved with special education in the region now for a number of years, including working previously as a contract speech-language therapist in the special unit at Wellington East. Because this project would involve me working with students, families and staff in a different professional capacity, during the initial visit it will be important to discuss how the students, staff and I will work together as researcher and research participants. My supervisor, Professor Jeff Sigafoos, is also available to discuss any issues that the school or prospective participants may have about the research project, either prior to agreeing to participate or during the actual case study period. His contact details are below.

\section{Conclusion}

Thank you for considering your daughter's possible involvement in the project. If you have further questions about the project I am very happy to discuss these with you. My contact details are below:

I would appreciate it if you could complete the attached form, indicating whether you agree or not to participate in the research project. A specially 
marked box will be placed in the office of the special unit and forms should be paced there.

Sincerely,

Heather Drysdale - MEd. Student

School of Educational Psychology and Pedagogy

Faculty of Education

Victoria University of Wellington

PO Box 17-310, Karori

Wellington, NZ

Phone: 0210344966

Email: hdrysdale@paradise.net.nz

Supervisor

Professor Jeff Sigafoos

School of Educational Psychology and Pedagogy

Faculty of Education

Victoria University of Wellington

PO Box 17-310, Karori

Wellington, $\mathrm{NZ}$

Phone: +64 44639772

Email: Jeff. Sigafoos@vuw.ac.nz

Inter-rater observer

Lynn Peace (retired educational psychologist)

Phone: 0210465689

Email:lynnpalexd@yahoo.co.nz 


\section{CONSENT FORM FOR PARENTS/GUARDIANS (Classmates)} Project Title: The Effects of Intensive Interaction on the Engagement of Children with

Profound and Multiple Learning Disabilities.Enhancing peer interactions in early childhood. This research has been assessed and approved by Victoria University Faculty of Education Ethics Committee (Reference No. 17701).

\section{Please tick the boxes to indicate your agreement with the statements and to provide informed consent for participation in this project.}

I have been given and have understood an explanation of this research project. I have had an opportunity to ask questions and have them answered to my satisfaction.

I understand that while my daughter is not one of the three participants, she may be filmed in the background of any video footage. I may withdraw permission for my child to be included in video-recordings (before data collection is complete) without having to give reasons or without penalty of any sort.

understand that the data collected will be kept confidential to the researcher, her supervisor, and colleague who will be doing the inter-rater reliability. Any IT technicians who provide technical assistance with the editing of video tapes gathered for this project will be asked to sign a confidentiality agreement. Any other person such as a professional working in the unit or a post-graduate student who is part of video-taping will also be asked to sign a confidentiality agreement.

I understand that the published results will not use my name, my child's name or the name of the school, or include descriptions that in any way identify my child, the school or myself.

I understand that the video recording will be electronically wiped within five years of the publication of the research.

I agree that (print name please), who is under my guardianship, may be video-recorded as part of this research.

I do not agree that (print name please), who is under my guardianship, may be video-recorded as part of this research.

I agree that my daughter can complete her own consent form for her involvement. She may be in the background of any video footage recorded.

I do not agree that my daughter can complete her own consent form for her involvement. She may be in the background of any video footage recorded.

I agree my daughter will complete her own consent form under our guidance.

I agree my daughter will complete her own consent form under guidance from the head teacher. 
Signed:

Date:

Name of Parent/Guardian print clearly)

Name of Child: _ Name of School:

I would like to be sent a copy of any reports arising from this study. If you tick this box, I will give a copy of any reports arising from this study to you. Please include contact details where they can be sent

Name

Address

Please return this Consent Form to your child's teacher 


\section{CONSENT FORM FOR STUDENTS \\ Project Title: The Effects of Intensive Interaction on the Engagement of Children with Profound and Multiple Learning Disabilities.}

This research has been assessed and approved by Victoria University of Wellington Faculty of Education Ethics Committee (Reference No. 17701).

Please tick the boxes to indicate your agreement with the statements and to provide informed consent for participation in this project.

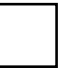

My parent/guardian or a staff member has talked about the research project with me.

I understand that I may be video-taped in the background as part of the research involving other students in my class.

I agree to take part in this research.

I do not agree to take part in this research.

Signed:

Date:

Name of Student (please print clearly)

Name

of

School:

I would like to be sent a copy of any reports arising from this study. If you tick this box, we will give a copy of any reports arising from this study to you.

Please return this Consent Form

in the specially marked box in the unit office. Thank you. 
IT TECHNICIAN CONFIDENTIALITY AGREEMENT

I, will be providing technical support for problem solving or editing of video footage collected from the research project The Effects of Intensive Interaction on the Engagement of Children with Profound and Multiple Learning Disabilities.

No names of participants or identification of their school will be provided to me. Furthermore, all the information that is provided will be deemed confidential and I will ensure that it is not released to any third party.

Signature of the technician

Date 


\section{INTER-OBSERVER CONFIDENTIALITY AGREEMENT}

I, will be observing $30 \%$ of video footage collected for the baseline and intervention phases from the research project The Effects of Intensive Interaction on the Engagement of Children with Profound and Multiple Learning Disabilities. I understand that I will also be observing $30 \%$ of the video footage collected for the generalization and treatment fidelity probes.

All the information that is provided will be deemed confidential and I will ensure that it is not released to any third party.

Signature of the Inter-observer

Date 


\section{VIDEO CONFIDENTIALITY AGREEMENT}

I, that I may take part in the videotaping for the research project The Effects of Intensive Interaction on the Engagement of Children with Profound and Multiple Learning Disabilities.

All the information that is provided will be deemed confidential and I will ensure that it is not released to any third party.

Signature of any additional person used for video-taping

Position (vesting professional or postgraduate student)

Date 
APPENDIX 17

BASELINE/INTERVENTION CODING FORM

Name

Baseline/Intervention Phase (cross out one)

\begin{tabular}{|c|c|c|c|c|c|c|c|c|c|c|}
\hline Days & Day 1 & Day 2 & Day 3 & Day 4 & Day 5 & Day 6 & Day 7 & Day 8 & Day 9 & $\begin{array}{l}\text { Day } \\
10\end{array}$ \\
\hline \multicolumn{11}{|l|}{ Date } \\
\hline & & & & & & & & & & \\
\hline \multicolumn{11}{|l|}{ Time } \\
\hline \multicolumn{11}{|l|}{$\begin{array}{l}10 \\
\text { sec }\end{array}$} \\
\hline \multicolumn{11}{|l|}{$\begin{array}{l}20 \\
\text { sec }\end{array}$} \\
\hline \multicolumn{11}{|l|}{$\begin{array}{l}30 \\
\text { sec }\end{array}$} \\
\hline \multicolumn{11}{|l|}{$\begin{array}{l}40 \\
\text { sec }\end{array}$} \\
\hline \multicolumn{11}{|l|}{$\begin{array}{l}50 \\
\mathrm{sec}\end{array}$} \\
\hline \multicolumn{11}{|l|}{$\begin{array}{l}60 \\
\text { sec }\end{array}$} \\
\hline & & & & & & & & & & \\
\hline & & & & & & & & & & \\
\hline \multicolumn{11}{|l|}{$\begin{array}{l}10 \\
\mathrm{sec}\end{array}$} \\
\hline \multicolumn{11}{|l|}{$\begin{array}{l}20 \\
\text { sec }\end{array}$} \\
\hline \multicolumn{11}{|l|}{$\begin{array}{l}30 \\
\text { sec }\end{array}$} \\
\hline \multicolumn{11}{|l|}{$\begin{array}{l}40 \\
\text { sec }\end{array}$} \\
\hline \multicolumn{11}{|l|}{$\begin{array}{l}50 \\
\mathrm{sec}\end{array}$} \\
\hline \multicolumn{11}{|l|}{$\begin{array}{l}60 \\
\text { sec }\end{array}$} \\
\hline & & & & & & & & & & \\
\hline $\begin{array}{l}10 \\
\text { sec }\end{array}$ & & & & & & & & & & \\
\hline $\begin{array}{l}20 \\
\text { sec }\end{array}$ & & & & & & & & & & \\
\hline $\begin{array}{l}30 \\
\text { sec }\end{array}$ & & & & & & & & & & \\
\hline $\begin{array}{l}40 \\
\text { sec }\end{array}$ & & & & & & & & & & \\
\hline $\begin{array}{l}50 \\
\text { sec }\end{array}$ & & & & & & & & & & \\
\hline $\begin{array}{l}60 \\
\text { sec }\end{array}$ & & & & & & & & & & \\
\hline
\end{tabular}




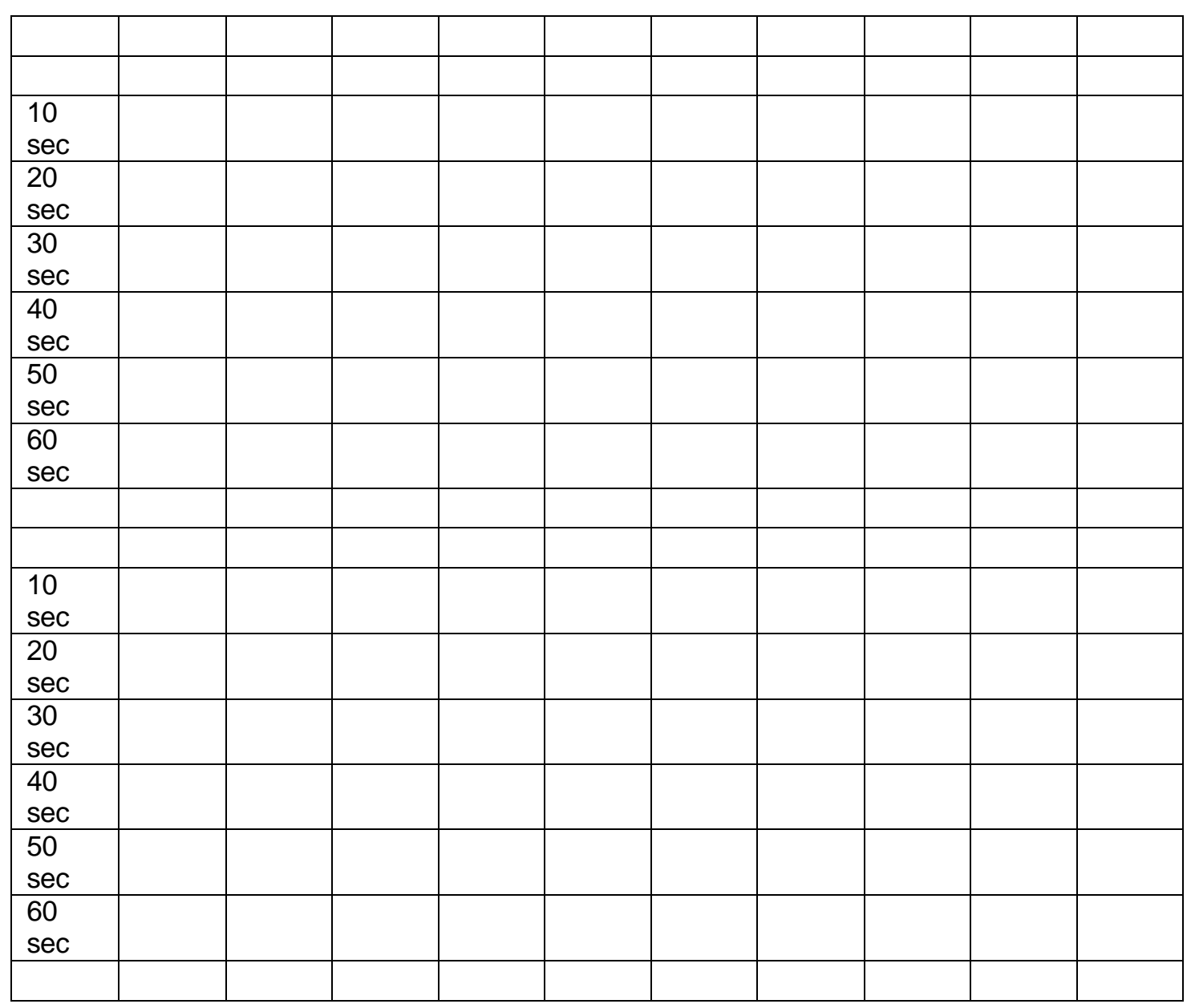


APPENDIX 18

PROCEDURAL INTEGRITY RATING FORM

(key $L=$ learner, $C P=$ communication partner)

\begin{tabular}{|l|l|l|l|l|l|l|}
\hline Strategies & date & date & date & date & date & date \\
\hline $\begin{array}{l}\text { 1.CP following L's } \\
\text { choice of activity or } \\
\text { own behaviour }\end{array}$ & & & & & & \\
\hline $\begin{array}{l}\text { 2.Contingent } \\
\text { Responding- } \\
\text { CP responds to all } \\
\text { L's behaviour as if } \\
\text { has communication } \\
\text { intent including next } \\
\text { 4categories }\end{array}$ & & & & & & \\
\hline $\begin{array}{l}\text { 3.Imitation-CP of L's } \\
\text { behaviour (vocal, } \\
\text { gestural, facial or } \\
\text { body movements } \\
\text { OR responds to the } \\
\text { rhythm of their } \\
\text { behaviour }\end{array}$ & & & & & & \\
\hline $\begin{array}{l}\text { 4.Pausing- CP } \\
\text { following L's } \\
\text { behaviour indicating } \\
\text { a break in activity }\end{array}$ & & & & & & \\
\hline $\begin{array}{l}\text { 5.Communication } \\
\text { Intent- CP } \\
\text {-responds to joint } \\
\text { focus, turn taking, } \\
\text { request } \\
\text { \& protest behaviour } \\
\text { etc... }\end{array}$ & & & & & & \\
\hline $\begin{array}{l}\text { 6.CP use no or } \\
\text { minimal language }\end{array}$ & & & & & & \\
\hline
\end{tabular}

